\title{
CONCRETO DE ALTA RESISTÊNCIA: COMPOSIÇÃO, PROPRIEDADES E DIMENSIONAMENTO
}

\author{
INÊS SANTANA DA SILVA
}

Dissertação apresentada à Escola de Engenharia de São Carlos, da Universidade de São Paulo, como parte dos requisitos para obtenção do Título de Mestre em Engenharia de Estruturas.

ORIENTADOR: Prof. Dr. Libânio Miranda Pinheiro

São Carlos 1995 


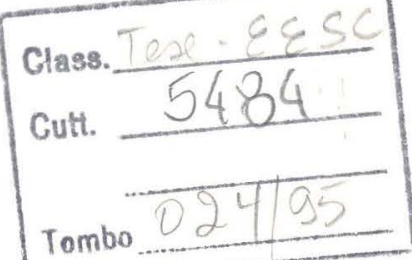

Silva, Inês Santana da

Concreto de alta resistência: composição, propriedades e dimensionamento / Inês Santana da Silva.-- São Carlos, 1995.

$128 \mathrm{p}$.

Dissertação (Mestrado) -- Escola de Engenharia de São Ca los - Universidade de São Paulo, 1995.

Jrientador: Prof. Dr. Libânio Miranda Pinheiro

1. Concreto de alta resistência. I. Título. 
A meu pai, minha mãe e Carlos 


\section{AGRADECIMENTOS}

Ao Professor Libânio Miranda Pinheiro, pela eficiente orientação durante a execução deste trabalho.

Especialmente, a Carlos Roberto Rezende e a Mônica Cristina C. da Guarda, pela amizade, apoio e incentivo.

Aos Professores Antônio Carlos Mascarenhas (in memoriam) e Hernani Sobral, por terem aberto o caminho do mestrado.

À Maria Nadir Minatel, pela dedicação na função de bibliotecária e a Francisco Carlos de Brito, pela excelente qualidade dos desenhos.

Ao CNPq, pela bolsa de estudos

Aos meus familiares, que tanto me incentivaram.

A todos que direta ou indiretamente contribuíram na realização deste trabalho. 


\section{SUMÁRIO}

LISTA DE FIGURAS $\ldots \ldots \ldots \ldots \ldots \ldots \ldots \ldots$ i

LISTA DE TABELAS $\ldots \ldots \ldots \ldots \ldots \ldots \ldots \ldots \ldots \ldots$ iii

LISTA DE SIGLAS $\ldots \ldots \ldots \ldots \ldots \ldots \ldots \ldots \ldots \ldots$

LISTA DE SÍMBOLOS $\ldots \ldots \ldots \ldots \ldots \ldots \ldots \ldots$ vi

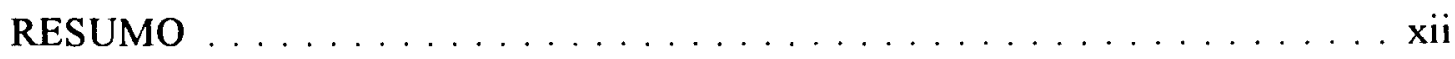

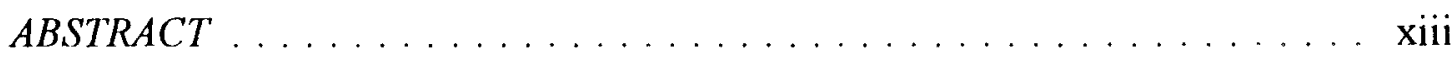

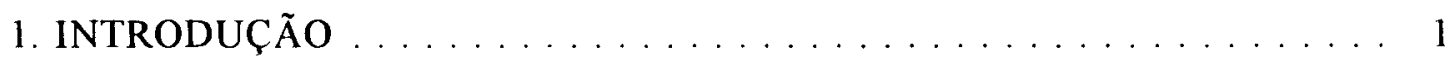

1.1 EVOLUÇÃO DO CONCRETO DE ALTA RESISTÊNCIA . . . . . . 1

1.2 OBJETIVOS $\ldots \ldots \ldots \ldots \ldots \ldots \ldots \ldots \ldots \ldots \ldots \ldots \ldots \ldots$

1.3 PLANEJAMENTO . . . . . . . . . . . . . . . . . . . 4

1.4 APLICAÇÕES EM ESTRUTURAS $\ldots \ldots \ldots \ldots \ldots \ldots \ldots$

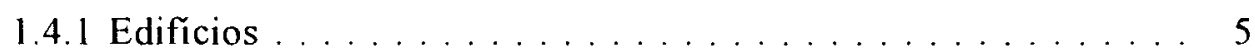

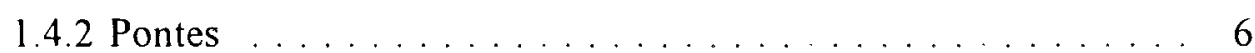

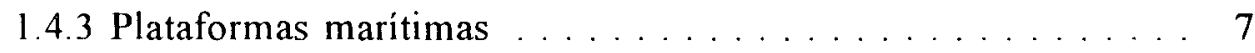

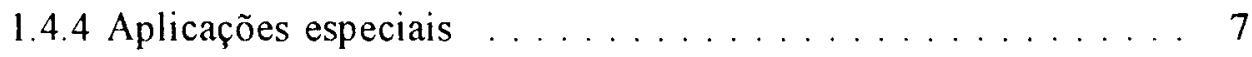

2. COMPOSIÇÃO E PRODUÇÃO $\ldots \ldots \ldots \ldots \ldots \ldots \ldots \ldots$

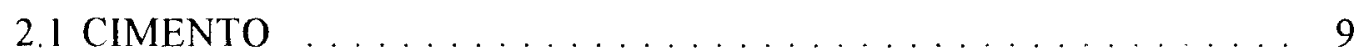

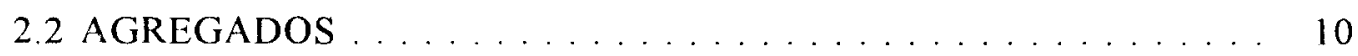

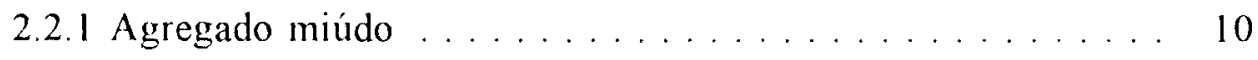

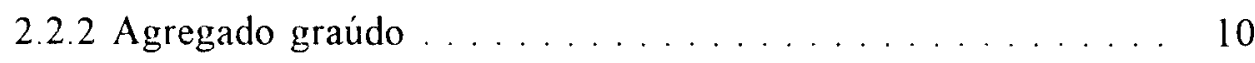

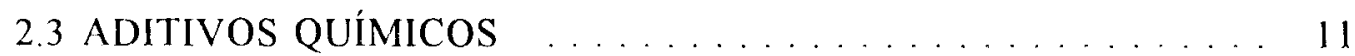

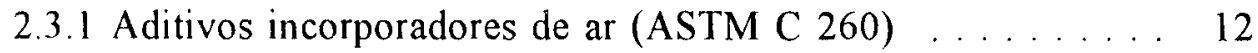

2.3.2 Aditivos retardadores de pega (ASTM C 494 - tipo B) . . . 12

2.3.3 Aditivos redutores de água - Plastificantes (ASTM C 494 tipos A, D e E) . . . . . . . . . . . . . . . . 13

2.3.4 Aditivos Superplastificantes (ASTM C 494 - tipos F e G) . . 13 
2.3.5 Aditivos aceleradores de pega (ASTM C 494 - tipos C e E) 14

2.4 ADIÇÕES MINERAIS . . . . . . . . . . . . . . 14

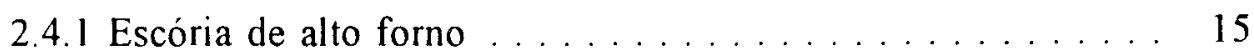

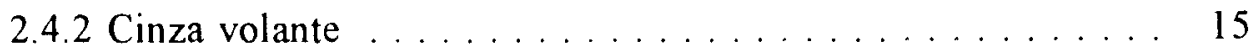

2.4 .3 Microssílica . . . . . . . . . . . . . . . . 16

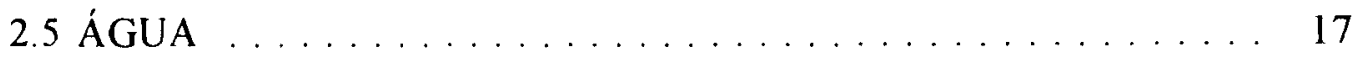

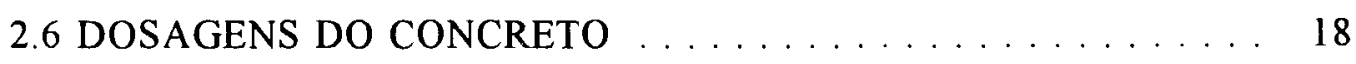

2.6.1 Cimento ..................... 18

2.6 .2 Agregados ................... 18

2.6.3 Aditivos químicos e adições minerais . . . . . . . . . 19

2.6.4 Fator água/cimento e fator água/material cimentante . . . . 19

2.7 PROCEDIMENTOS DE MISTURA . . . . . . . . . . . . 20

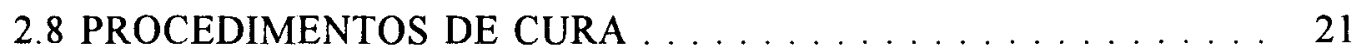

3. PROPRIEDADES MECÂNICAS DO CONCRETO DE ALTA

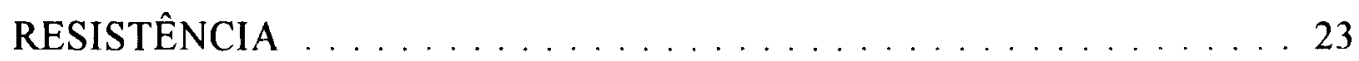

3.1 COMPORTAMENTO NA COMPRESSÃO AXIAL . . . . . . . 23

3.2 MÓdULO DE DEFORMAÇÃO LONGITUDINAL . . . . . . . . . 30

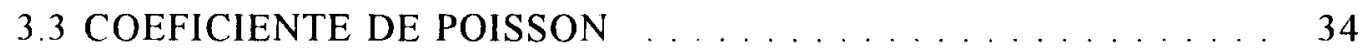

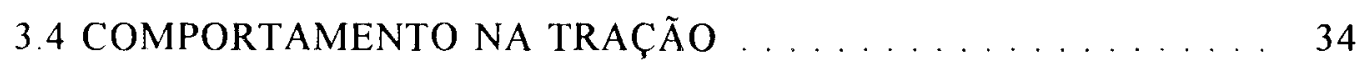

4. PILARES ... . . . . . . . . . . . . . . . 42

4.1 CONTRIBUIÇÃO DAS RESISTÊNCIAS DO AÇO E DO

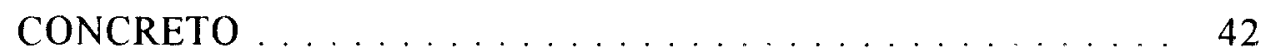

4.2 EFEITO DO CONFINAMENTO DA ARMADURA . . . . . . 44

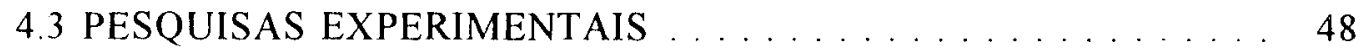

4.4 APLICAÇÕES . . . . . . . . . . . . . . . . 60

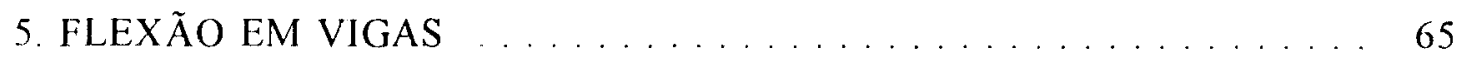

5.1 ANÁLISE GERAL . . . . . . . . . . . . . . 65

5.1.1 Distribuição das tensões de compressão . . . . . . . . 65

5.1 .2 Encurtamento último . . . . . . . . . . . . . . . . 69

5.1 .3 Ductilidade das vigas . . . . . . . . . . . . . . . 71

5.1.4 Flechas causadas por ações de curta e de longa duração . . 74 
5.2.1 Prescrições atuais referentes ao mínimo das armaduras tracionadas .................... 81

5.2 .2 Armaduras mínimas de flexão . . . . . . . . . . 82

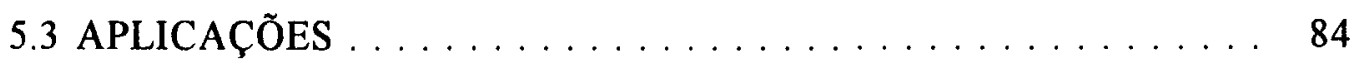

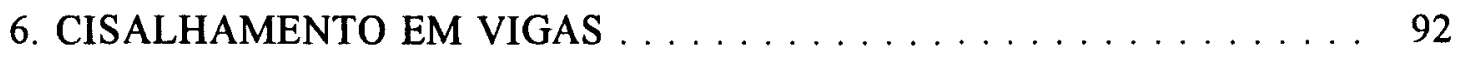

6.1 GENERALIDADES $\ldots \ldots \ldots \ldots \ldots \ldots \ldots \ldots \ldots \ldots$

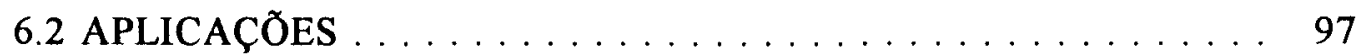

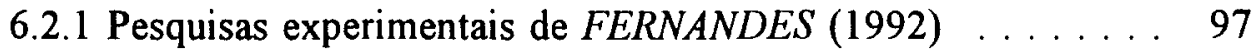

6.2.2 Pesquisas experimentais de MPHONDE \& FRANTZ

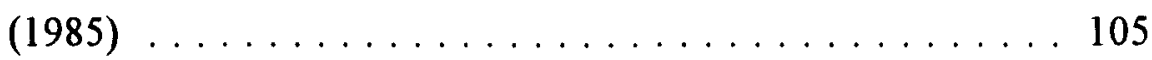

6.2.3 Pesquisas experimentais de LEVI \& MARRO (1989) . . . . 107

6.2.4 Pesquisas experimentais de BERNHARDT \& FYNBOE

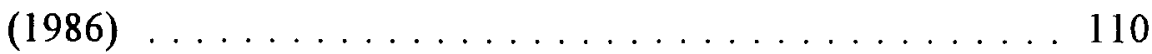

6.2.5 Pesquisas experimentais de THORENFELDT \& DRANGSHOLT (1990) . . . . . . . . . . . . . 112

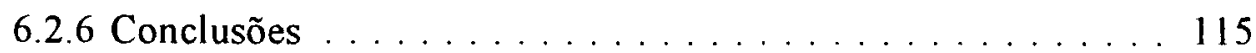

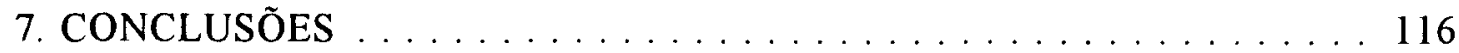

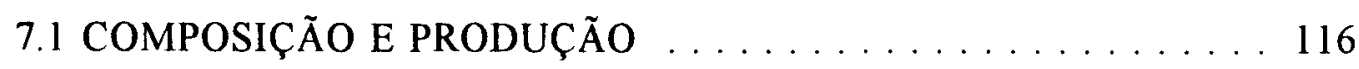

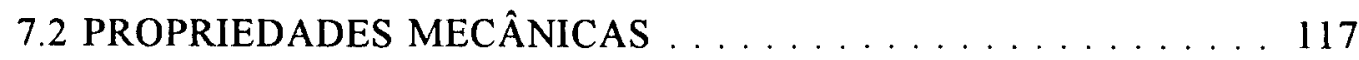

7.3 PROJETO DE PILARES $\ldots \ldots \ldots \ldots \ldots \ldots \ldots \ldots \ldots$

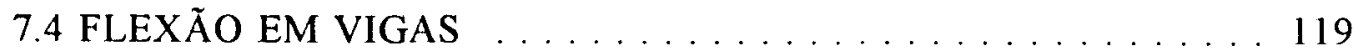

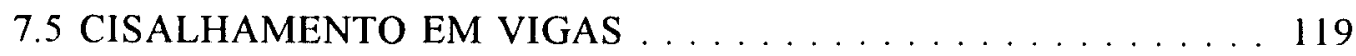

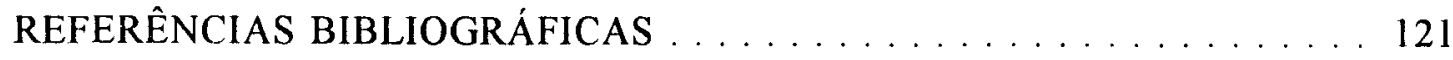




\section{LISTA DE FIGURAS}

FIGURA 3.1 - Tensão/resistência e deformação para concretos sob ação de longa

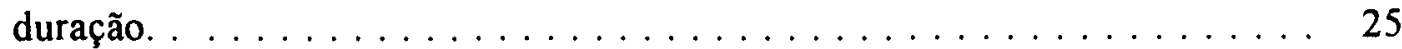

FIGURA 3.2 - Diagramas tensão-deformação típicos do concreto. . . . . . 27

FIGURA 3.3 - Diagramas tensão-deformação para concreto de resistência usual. 28

FIGURA 3.4 - Diagramas tensão-deformação para concreto de alta resistência. 29

FIGURA 3.5 - Ensaio de compressão diametral. . . . . . . . . . . . . 36

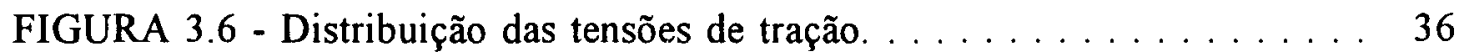

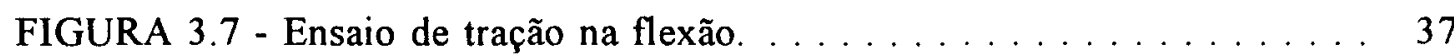

FIGURA 4.1 - Curvas tensão-deformação do aço e do concreto. . . . . . . 43

FIGURA 4.2 - Curvas experimentais de tensão-deformação de pilares com armadura helicoidal, mostrando o efeito da resistência do concreto na ductilidade.

FIGURA 4.3 - Efeito da taxa de armadura e da seção geométrica na ductilidade de pilares de concreto de alta resistência. $\ldots \ldots \ldots \ldots \ldots \ldots$

FIGURA 4.4 - Efeitos da configuração dos estribos e do espaçamento no núcleo de concreto confinado: (a) configuração pobre com grande espaçamento dos estribos: (b) boa configuração com pequeno espaçamento dos estribos.. . . . 52

FIGURA 4.5 - Configurações de estribos utilizadas por CUSSON \& PAULTRE (1994).

FIGURA 4.6 - Diagramas tensão-deformação de corpos-de-prova com armadura helicoidal.

FIGURA 4.7 - Diagramas de tensão-deformação para concretos com resistência à compressão de $80 \mathrm{MPa} . \ldots \ldots \ldots \ldots \ldots \ldots$

FIGURA 4.8 - Características geométricas dos pilares ensaiados por AGOSTINI (1992). 
FIGURA 5.1 - Distribuições de tensões no concreto para vigas retangulares. . 66

FIGURA 5.2 - Parâmetro $k_{2} / k_{1} k_{3}$ do diagrama de tensões versus resistência do concreto. . . . . . . . . . . . . . . . . . . . . 68

FIGURA 5.3 - Encurtamento último $\varepsilon_{\mathrm{cu}}$ do concreto na flexão versus resistência

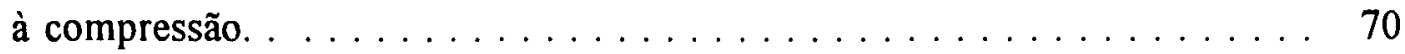

FIGURA 5.4 - Diagramas momento-curvatura para rupturas típicas. . . . . . 72

FIGURA 5.5 - Multiplicadores para flechas produzidas por ações de longa duração. . . . . . . . . . . . . . . . . . . . . . . . . . 76

FIGURA 5.6 - Características e esquemas de carregamento das vigas ensaiadas por PINTO JR (1992) . . . . . . . . . . . . . . . . . . . . . . . . . 85

FIGURA 5.7 - Características e esquemas de carregamento das vigas ensaiadas por

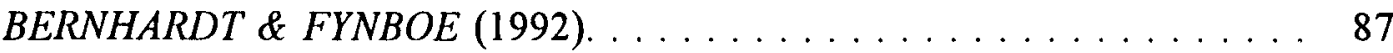

FIGURA 5.8 - Características e esquemas de carregamento das vigas ensaiadas por MARRO (1987) . . . . . . . . . . . . . . . . . . . . . . . . . . . 89

FIGURA 5.9 - Características e esquemas de carregamento das vigas ensaiadas por LAMBOTTE \& TAERWE (1990). . . . . . . . . . . . . . . . . . . . . . 90

FIGURA 6.1 - Dimensões das vigas ensaiadas por FERNANDES (1992). . . . 98

FIGURA 6.2 - Detalhes e esquema de carregamento das vigas ensaiadas por FERNANDES (1992). . . . . . . . . . . . . . . . . . . . . . . 99

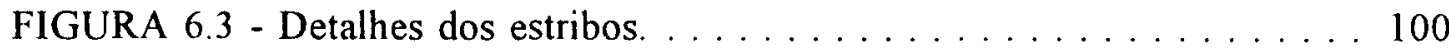

FIGURA 6.4 - Detalhe das vigas ensaiadas por MPHONDE \& FRANTZ (1985).105

FIGURA 6.5 - Detalhe das vigas ensaiadas por LEVI \& MARRO (1989). . . 108

FIGURA 6.6 - Detalhes das vigas ensaiadas por THORENFELDT \& DRANGSHOLT (1990). 


\section{LISTA DE TABELAS}

TABELA 4.1 - Tensões de confinamento produzidas por armaduras helicoidais calculadas pelo $A C I 318 \ldots \ldots \ldots \ldots \ldots \ldots \ldots \ldots \ldots \ldots$

TABELA 4.2a - Resultados de ensaios realizados por AGOSTINI (1992). . . 61

TABELA 4.2b - Resultados de ensaios realizados por AGOSTINI (1992). . . . 62

TABELA 4.3 - Resultados de ensaios realizados por CUSSON \& PAULTRE

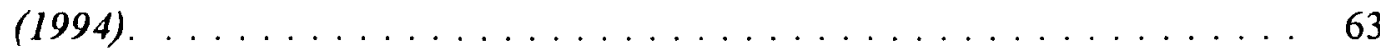

TABELA 5.1 - Índices de ductilidade em vigas obtidos por PASTOR et al. . . 73

TABELA 5.2 - Fator de correção $\eta$ para estimativa de flechas em concretos de

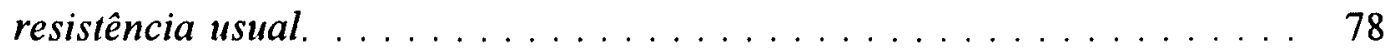

TABELA 5.3 - Valores de momentos últimos teóricos e experimentais - PINTO $J R(1992) \ldots \ldots \ldots \ldots \ldots$. . . . . . . . . . . . . . . . . . . . 86

TABELA 5.4 - Valores de momentos últimos teóricos e experimentais BERNHARDT \& FYNBOE (1986). . . . . . . . . . . . . . . 88

TABELA 5.5 - Valores de momentos últimos teóricos e experimentais - MARRO (1987).

TABELA 5.6 - Valores de momentos últimos teóricos e experimentais LAMBOTTE \& TAERWE (1990).

TABELA 6.1 - Valores efetivos da força cortante para escoamento da armadura longitudinal. . . . . . . . . . . . . . . . . . . . . . . . . 101

TABELA 6.2 - Valores efetivos do grau de armação ao cisalhamento. 101

TABELA 6.3 - Valores teóricos e os experimentais obtidos por FERNANDES (1992).

TABELA 6.4 - Valores teóricos e os cxperimentais obtidos por MPHONDE \&FRANTZ (1985). 
TABELA 6.5 - Valores teóricos e os experimentais obtidos por LEVI \& MARRO (1989).

TABELA 6.6 - Valores teóricos e os experimentais obtidos por BERNHARDT \& FYNBOE (1986)

TABELA 6.7 - Valores teóricos e os experimentais obtidos por THORENFELDT \& DRANGSHOLT (1990). 


\section{LISTA DE SIGLAS}

\begin{tabular}{|c|c|}
\hline $\mathrm{ACI}$ & - American Concrete Institute \\
\hline ARI & - Alta Resistência Inicial \\
\hline ASCE & - American Society of Civil Engineers \\
\hline ASTM & - American Standard Testing Materials \\
\hline CEB & - Comité Euro-International du Béton \\
\hline $\mathbf{C P}$ & - Cimento Portland \\
\hline $\mathrm{EC}$ & - Eurocode \\
\hline FIP & - Fédération Internationale de la Précontrainte \\
\hline IBRACON & - Instituto Brasileiro do Concreto \\
\hline ISO & - International Standard Organization \\
\hline NB & - Norma Brasileira \\
\hline NBR & - Norma Brasileira Registrada \\
\hline NS & - Norwegian Standard \\
\hline RILEM & $\begin{array}{l}\text { - Réunion Internationale des Laboratoires d'Essais et de Recherches sur } \\
\text { les Matériaux et les Constructions }\end{array}$ \\
\hline SP & - Special Publication \\
\hline UNICAMP & - Universidade Estadual de Campinas \\
\hline
\end{tabular}




\section{LISTA DE SÍMBOLOS}

$\alpha \quad$ ângulo de inclinação entre a armadura de cisalhamento e a horizontal;

$\beta_{1} \quad$ fator;

$\gamma_{c} \quad$ coeficiente de minoração da resistência do concreto;

$\gamma_{\mathrm{f}} \quad$ coeficiente de segurança;

$\Delta f_{1 c} \quad$ acréscimo da resistência à compressão do pilar de concreto;

$\Delta_{u} \quad$ deslocamento da viga na carga de ruína;

$\Delta_{\mathrm{y}} \quad$ deslocamento da viga na carga que produz o escoamento da armadura de tração;

$\varepsilon_{\mathrm{c}} \quad$ deformação específica do concreto à compresão;

$\boldsymbol{\varepsilon}_{\mathrm{cu}} \quad$ deformação última do concreto à compressão;

$\varepsilon_{\mathrm{s}} \quad$ deformação específica do aço;

$\xi$ fator dependente do tempo de duração das ações;

$\eta \quad$ fator; grau de armação ao cisalhamento $=\rho_{\mathrm{w}} / \rho_{\mathrm{w}, \mathrm{M}}$;

$\theta$ ângulo de inclinação entre a biela comprimida e a horizontal;

$\lambda$ multiplicador para flecha decorrente de ação de longa duração;

$\mu \quad$ indice de ductilidade na deformação; fator;

$\rho \quad$ taxa de armadura de tração;

$\rho_{1} \quad$ taxa de armadura de tração $=A_{s t} / b_{w} d ;$

$\rho^{\prime} \quad$ taxa de armadura de compressão não-protendida; 
$\rho_{\mathrm{b}} \quad$ taxa de armadura que produz condições balanceadas de deformações;

$\rho_{\ell} \quad$ taxa geométrica de armadura longitudinal;

$\rho_{\mathrm{m}} \quad$ taxa geométrica média de armadura de tração do vão considerado;

$\rho_{\mathrm{m}}^{\prime} \quad$ taxa geométrica média de armadura de compressão do vão considerado;

$\rho_{\min } \quad$ taxa geométrica mínima de armadura;

$\rho_{\mathrm{s}} \quad$ taxa (volumétrica) de armadura helicoidal para o volume do núcleo de concreto;

$\rho_{\mathrm{st}} \quad$ taxa geométrica de armadura transversal;

$\rho_{\mathrm{w}} \quad$ taxa geométrica de armadura transversal;

$\rho_{\mathrm{w}, \mathrm{M}}$ taxa geométrica de armadura transversal calculada de acordo com Mörsch;

$\sigma_{c} \quad$ tensão normal de compressão do concreto;

$\sigma_{\mathrm{cd}} \quad$ valor de cálculo de $\sigma_{\mathrm{c}}$;

$\tau_{c} \quad$ parcela de redução de $\tau_{\text {od }}$ para cálculo da armadura transversal com grau reduzido de armação ao cisalhamento $=V_{c} / b_{w} z$;

$\tau_{\mathrm{d}} \quad$ tensão de cisalhamento;

$\tau_{\mathrm{Rd}} \quad$ resistência básica de cisalhamento;

$\tau_{\mathrm{w}} \quad$ tensão convencional de cisalhamento $=\mathrm{V} / \mathrm{b}_{\mathrm{w}} \mathrm{d}$;

$\tau_{w d} \quad$ valor de cálculo de $\tau_{w}$;

$\tau_{w u} \quad$ valor último de $\tau_{\mathrm{w}}$

$\psi \quad$ coeficiente;

( $\quad$ coeficiente de deformação lenta;

$A_{c} \quad$ área da seção transversal de concreto; área da seção do núcleo de concreto; área da seção de concreto comprimido;

$\mathrm{A}_{\mathrm{g}} \quad$ área bruta da seção de concreto;

A s área da seção transversal da armadura longitudinal tracionada; 
$\mathrm{A}_{\mathrm{s}}^{\prime} \quad$ área da seção transversal da armadura longitudinal comprimida;

$\mathrm{A}_{\mathrm{sc}} \quad$ área da seção transversal da armadura longitudinal comprimida;

$\mathrm{A}_{\mathrm{s}}$ área da seção transversal da armadura longitudinal tracionada;

$\mathrm{A}_{\mathrm{s}, \mathrm{min}}$ área mínima da seção transversal da armadura longitudinal tracionada;

$\mathrm{A}_{\mathrm{sp}} \quad$ área da seção transversal da armadura helicoidal;

$\mathrm{A}_{\mathrm{sw}} \quad$ área da seção transversal dos estribos;

a distância média entre o plano de ruptura e o apoio mais próximo; flecha;

b largura do prisma; largura;

$b_{t} \quad$ largura média da zona de tração;

$b_{w} \quad$ largura da nervura das vigas com seção $T$ ou I;

d diâmetro do cilindro; distância da fibra extrema de compressão até o centróide da armadura de tração; altura útil;

$\mathrm{d}_{\mathrm{c}} \quad$ diâmetro do núcleo de concreto;

$\mathrm{E}_{\mathrm{c}}$ módulo de deformação longitudinal do concreto;

$\mathrm{E}_{\mathrm{cs}}$ módulo de deformação secante do concreto;

$\mathrm{E}_{\mathrm{tr}}$ módulo de deformação longitudinal do concreto tracionado;

$\mathrm{F}_{\mathrm{Rc}} \quad$ força resistente do banzo comprimido;

$F_{R c w}$ força resistente da biela comprimida;

$F_{R t} \quad$ força resistente do banzo tracionado;

$\mathrm{F}_{\mathrm{Rtw}}$ força resistente da armadura transversal;

$\mathrm{f}_{2}$ tensão de confinamento do concreto, calculada usando a tensão real da armadura helicoidal;

$\mathrm{f}_{2}{ }^{\prime}$ tensão (idealizada) de confinamento do concreto produzido pela armadura helicoidal;

$f_{c} \quad$ resistência característica do concreto à compressão; 
$\mathrm{f}_{\mathrm{c} 28}$ resistência média do concreto à compressão aos 28 dias;

$f_{c}^{\prime} \quad$ resistência do concreto à compressão;

$f_{c, e x p} \quad$ valor de $f_{c}$ obtido experimentalmente;

$\mathrm{f}_{\mathrm{cc}} \quad$ resistência do concreto à compressão;

$\mathrm{f}_{\mathrm{cd}} \quad$ resistência de cálculo do concreto à compressão;

$f_{c d l} \quad$ tensão média do concreto para zonas não-fissuradas;

$\mathrm{f}_{\mathrm{cd} 2}$ tensão média do concreto para zonas fissuradas;

$\mathrm{f}_{\mathrm{cj}} \quad$ resistência média do concreto à compressão, prevista para a idade de $\mathrm{j}$ dias;

$\mathrm{f}_{\mathrm{ck}}$ resistência característica do concreto à compressão;

$\mathrm{f}_{\text {ctk }}$ resistência característica do concreto à tração;

$\mathrm{f}_{\mathrm{ctk} 0.05}=0,7 \mathrm{f}_{\mathrm{ctm}}$

$\mathrm{f}_{\mathrm{ctm}} \quad$ resistência média do concreto à tração axial;

$f_{\mathrm{r}} \quad$ resistência à tração do concreto;

$f_{1} \quad$ resistência à tração do concreto;

$\mathrm{f}_{\mathrm{tk}} \quad$ resistência característica do concreto à tração;

$f_{y}$ resistência de escoamento do aço à tração;

$f_{y, \exp } \quad$ valor de $f_{y}$ obtido experimentalmente;

$f_{y c d}$ tensão de escoamento da armadura de compressão;

$f_{y d} \quad$ valor de cálculo de $f_{y}$;

$f_{y k} \quad$ valor característico de $f_{y}$;

$f_{y \ell}$ resistência de escoamento do aço à tração da armadura longitudinal;

$\mathrm{f}_{\mathrm{yw}} \quad$ resistência de escoamento da armadura de cisalhamento;

$\mathrm{f}_{\mathrm{ywd}} \quad$ valor de cálculo de $\mathrm{f}_{\mathrm{yw}}$; 
h altura total da seção transversal;

$I_{\text {cr }} \quad$ momento de inércia da seção de concreto fissurada;

I $\quad$ momento de inércia efetivo;

$I_{\mathrm{g}}$ momento de inércia da seção bruta de concreto em relação ao centro de gravidade, desprezando as armaduras;

k fator;

$\mathrm{k}_{1} \quad$ fator médio para tensão de compressão máxima da viga;

$\mathrm{k}_{2}$ fator da distância da resultante de compressão em relação à posição da linha neutra;

$\mathrm{k}_{3}$ fator de tensão máxima na viga para tensão máxima correspondente a um cilindro axialmente carregado;

€ comprimento do cilindro; comprimento do vão;

$M_{a} \quad$ momento máximo na peça para o qual a flecha é calculada;

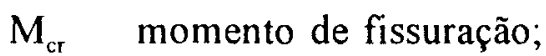

$\mathrm{M}_{\mathrm{d}} \quad$ momento fletor de cálculo;

$M_{n} \quad$ momento resistente na seção;

$M_{r} \quad$ momento fletor de fissuração;

$\mathrm{M}_{\mathrm{u}} \quad$ valor último de $\mathrm{M}_{\mathrm{d}}$;

$M_{u, x x p}$ valor de $M_{u}$ obtido experimentalmente;

P carga de ruptura;

$P_{\text {uexp }} \quad$ carga de ruptura obtida experimentalmente;

$\mathrm{R}_{\mathrm{c}} \quad$ resultante das tensões de compressão da seção transversal;

$R_{s} \quad$ resultante das tensões de tração na seção transversal;

$R_{t} \quad$ resultante das tensões de tração na seção transversal;

raio; 
$\mathrm{S}_{\mathrm{d}} \quad$ valor da solicitação de cálculo;

$\mathrm{S}_{\mathrm{k}} \quad$ valor do solicitação característica;

s passo da armadura helicoidal; espaçamento dos estribos;

$V_{c d} \quad$ valor de cálculo da contribuição do concreto na força cortante;

$V_{d} \quad$ força cortante de cálculo;

$\mathrm{V}_{\mathrm{d}, \text { CEB }}$ força cortante de cálculo obtida através do Código Modelo CEB 90;

$\mathrm{V}_{\mathrm{d}, \mathrm{EC}}$ força cortante de cálculo obtida através do Eurocode - 2;

$\mathrm{V}_{\mathrm{d}, \mathrm{NBR}}$ força cortante de cálculo obtida através da Norma Brasileira NBR 6118 ;

$\mathrm{V}_{\mathrm{Rd}, \max }$ força cortante resistente de cálculo máxima;

$\mathrm{V}_{\mathrm{Rdl}} \quad$ valor de cálculo da contribuição do concreto na força cortante;

$\mathrm{V}_{\mathrm{wd}} \quad$ valor de cálculo da contribuição da armadura transversal na força cortante;

x distância da linha neutra ao ponto de maior encurtamento na seção transversal de uma peça fletida;

W módulo de resistência da seção;

z distância entre $R_{c}$ e $R_{t}\left(R_{s}\right)$;

y altura do diagrama retangular de tensões de compressão do concreto na seção transversal de uma peça fletida;

$y_{t}$ distância do centro de gravidade da seção bruta, desprezando as armaduras, à fibra extrema tracionada. 


\section{RESUMO}

SILVA, I.S. (1995). Concreto de alta resistência: composição, propriedades e dimensionamento. São Carlos. 128p. Dissertação (mestrado) - Escola de Engenharia de São Carlos, Universidade de São Paulo.

Concretos de alta resistência têm sido usados em estruturas, atualmente, em diversas partes do mundo. Entretanto, no Brasil, pouco se conhece sobre seu comportamento.

Este trabalho fornece uma visão geral das aplicações, dos materiais empregados na produção, das propriedades mecânicas e do comportamento estrutural dos concretos de alta resistência.

Resultados experimentais obtidos por alguns pesquisadores, para pilares com carga axial e para vigas sujeitas a flexão e a cisalhamento, são comparados com valores teóricos, calculados com procedimentos usuais relativos a concretos de resistência usual.

Para os pilares, é inquestionável a necessidade do confinamento do núcleo de concreto, utilizando armadura de cintamento. $\mathrm{Na}$ flexão das vigas, as taxas mínimas para armadura longitudinal, sugeridas pelas normas para concretos usuais, não são suficientes; é importante ter valores maiores que esses. E para cisalhamento, as recomendações das normas são satisfatórias.

Palavras-chave: Concreto de alta resistência; Propriedades; Dimensionamento. 


\section{ABSTRACT}

SILVA, I.S. (1995). High-strength concrete: composition, properties and design. São Carlos, 128p. Dissertação (mestrado) - Escola de Engenharia de São Carlos, Universidade de São Paulo.

Nowadays, high-strength concrete has been used in structures all over the world. However, in Brazil, not much is known about its behavior.

This work provides an overview of the applications, the materials employed in production, the mechanical properties, and the structural behavior of high-strength concrete.

Experimental results obtained by several researchers, for columns under axial load and beams under flexure and shear, are confronted with theoretical values, computed by normal procedures relative to normal strength concrete.

For columns, it is unquestionable the need of confinement of the concrete core by transverse reinforcement. In beams under flexure, the minimum rates for longitudinal reinforcement, suggested by the codes for usual concrete, are not enough; it is important to have values greater than those. And for shear, the codes requirements are satisfactories.

Keywords: High-strength concrete; Properties; Design. 


\section{INTRODUÇÃO}

Concretos de alto desempenho são concretos com propriedades que satisfazem os critérios de desempenho como resistência e durabilidade das estruturas. A resistência do concreto é talvez a mais importante de todas as medidas de qualidade, embora outras características possam ser também críticas. Por este motivo, a característica do concreto de alto desempenho enfocada neste trabalho é a resistência.

\subsection{EVOLUÇÃO dO CONCRETO DE ALTA RESISTÊNCIA}

Concretos de alta resistência vem sendo utilizados há bastante tempo. Pisos pavimentados com 9000 anos, encontrados em Yiftah El, Israel, têm resistência à compressão de $40 \mathrm{MPa}$. O concreto de uma barcaça, construída na Grã-Bretanha, na década de 20, tem hoje um nível de resistência entre 75 e $120 \mathrm{MPa}$.

O desenvolvimento do concreto de alta resistência neste século se deu gradualmente. A conceituação também se modificou. Concretos que em décadas passadas pudessem ser considerados de alta resistência, podem não o ser nos dias de hoje. Um concreto da década de 50 com resistência de $34 \mathrm{MPa}$ já era considerado de alta resistência.

$\mathrm{Na}$ década de 60 , concretos com resistências de $41 \mathrm{MPa}$ a $52 \mathrm{MPa}$ foram usados comercialmente. $\mathrm{Na}$ metade da década de 60 , o limite máximo alcançado foi de $96 \mathrm{MPa}$, segundo o "METHODS OF ACHIEVING HIGH STRENGTH 
CONCRETE"' apud NAM et al (1994). E, acredita-se que no final daquela década, alcançou-se um limite de $110 \mathrm{MPa}$.

Para produzir concretos de alta resistência, nos anos 70, foram usados um baixo fator água/cimento e uma quantidade de água além do normal para cura. Admitiu-se que a resistência aumenta com a diminuição da dimensão do agregado e os agregados angulosos eram considerados essenciais para a produção de concretos de alta resistência. A regra básica, para toda década de 70 , era mais cimento e menos água. Entretanto, misturas ricas em cimento são mais resistentes, porém apresentam maior retração e portanto fissuram mais facilmente que as com quantidade usual de cimento.

O uso de aditivos redutores de água aumentou efetivamente a resistência do concreto. A substituição de parte do cimento por cinza volante de boa qualidade aumentou significativamente a resistência do concreto, nas misturas com baixo fator água/cimento, como comentam SCHIMIDT \& HOFFMAN (1975).

Nos anos 80, novos materiais como superplastificantes e microssílica permitiram o uso de um fator água/cimento extremamente baixo, enquanto mantiveram boa trabalhabilidade, tornando o concreto não só de alta resistência, mas também de grande impermeabilidade. A introdução de microssílica e superplastificantes tornou fácil produzir concretos com nível de resistência na faixa de $100 \mathrm{MPa}$.

Não há uma concordância entre os especialistas na aceitação de um valor que possa representar o limite entre concreto de resistência usual e de alta resistência. $O$ posicionamento da maioria, diante da questão, é o de considerar como de alta resistência, com agregados normais, aquele com resistência à compressão superior a $40 \mathrm{MPa}$. Concretos com resistência entre $40 \mathrm{MPa}$ e $80 \mathrm{MPa}$ têm sido utilizados em diferentes tipos de obra, em várias partes do mundo.

\footnotetext{
1 METHODS of achieving high strength concrete. (1967). ACI Journal, v.64, n. 1, p.45-48, Jan apud NAM, C.H. et al. (1994). Microlevel study of integration in high-strength concrete innovation. Journal of Construction Engineering and Management, ASCE, v.117, n.2, p.294-309, June, p.295.
} 
Por sua crescente utilização, o concreto de alta resistência tem atraído pesquisas. Por exemplo, em 1973, uma pasta de cimento com resistência à compressão de $650 \mathrm{MPa}$ foi obtida em laboratório e concreto com resistência à compressão por volta de $250 \mathrm{MPa}$ foi produzido, com agregados especiais, em 1981 [FIP/CEB-197 (1990)].

Porém, as equações de cálculo encontradas nas normas são derivadas de ensaios para resistências menores que $40 \mathrm{MPa}$. A regra usada pelos projetistas é extrapolar, usando essas equações para concretos com resistências até maiores que o dobro daquelas para as quais foram desenvolvidas. Infelizmente, essas normas são frequentemente utilizadas sem nenhuma precaução adicional nos projetos que envolvem concretos de alta resistência.

Por se tratar de um material de natureza frágil, são necessárias mais pesquisas, para que sejam encontradas novas expressões e conclusões que proporcionem um dimensionamento adequado das estruturas confeccionadas com concreto de alta resistência.

\subsection{OBJETIVOS}

A proposta deste trabalho está ligada ao melhor conhecimento do comportamento de vigas e pilares de concreto de alta resistência, buscando verificar se as hipóteses de cálculo e os critérios de projeto adotados para concretos usuais podem ser aceitos quando se empregam concretos de alta resistência.

Será feito, então, um estudo das propriedades mecânicas do material, visando os parâmetros necessários ao projeto estrutural e o estabelecimento de critérios de projeto, que garantam segurança frente aos estados limites último e de utilização. 


\subsection{PLANEJAMENTO}

Na sequência deste trabalho, serão apresentadas as principais aplicações do concreto de alta resistência em estruturas. No capítulo 2 , são consideradas a composição e a produção dos concretos de alta resistência. Para a produção, exige-se uma seleção mais criteriosa, comparando com o de resistência usual, para garantir a resistência especificada e boa trabalhabilidade. Os procedimentos de mistura, em princípio, não são diferentes dos usados para o concreto usual. Algumas mudanças e refinamentos em pontos críticos são necessários. A cura apropriada, num período adequado, é imprescindível para o bom desempenho do concreto de alta resistência.

No terceiro capítulo, estudam-se as propriedades mecânicas do concreto endurecido, tais como comportamento na compressão axial, módulo de deformação longitudinal, coeficiente de Poisson e comportamento na tração. Essas propriedades têm sido, geralmente, baseadas em dados experimentais de concretos com resistência à compressão inferior a $40 \mathrm{MPa}$. Como o concreto de alta resistência se comporta de maneira diferente, surge a necessidade de reexaminar essas propriedades para concretos com resistências maiores.

No quarto capítulo, são analisados o comportamento de pilares de concreto de alta resistência, submetidos apenas a cargas axiais, e os critérios empregados para dimensionamento. É feito, inicialmente, um estudo da contribuição das resistências do aço e do concreto. Tendo em vista o confinamento do núcleo de concreto, para possibilitar uma ruptura mais dúctil e o aumento da resistência, surge a necessidade de avaliar o efeito do confinamento da armadura transversal. E, tomando como referência trabalhos experimentais, são detalhadas as conclusões dos ensaios com pilares de concreto de alta resistência. É feito um estudo comparativo entre valores de cálculo e os experimentais, disponiveis para avaliar a capacidade resistente do pilar.

No quinto capítulo, são descritos alguns aspectos importantes para o comportamento de vigas à flexão, tais como, distribuição das tensões de compressão, encurtamento último, ductilidade das vigas e flechas causadas por cargas de curta $\mathrm{e}$ 
longa duração. E, de posse de alguns trabalhos experimentais, são feitas aplicações que comparam o momento último de cálculo com o experimental.

No sexto capítulo, discute-se o cisalhamento de vigas. Adotando algumas das normas em vigor, elaboradas para concretos usuais, como a $N B R 6118$ (1978), o EUROCODE No2 (EC-2) (1989) e o Código modelo CEB/FIP 90 (CEB-90) (1991), faz-se uma análise e verifica-se a possibilidade de se estender o uso às vigas de concreto de alta resistência.

Por fim, é apresentado o resumo das conclusões obtidas com a realização deste trabalho.

\subsection{APLICAÇÕES EM ESTRUTURAS}

Hoje, são inúmeras as aplicações do concreto de alta resistência. Aqui são citadas algumas: edifícios, pontes, plataformas marítimas e aplicações especiais.

\subsubsection{Edifícios}

Concretos com resistências muito maiores que as usuais podem ser usados em situações nas quais é importante uma redução do peso ou quando a arquitetura impõe o uso de peças mais esbeltas. $O$ concreto de alta resistência permite reduzir as dimensões de pilares de edifícios altos, tornando-os capazes de suportar as mesmas cargas que pilares mais robustos de concreto usual, proporcionando um melhor aproveitamento do espaço útil, principalmente para os pilares dos pavimentos inferiores, onde a redução é maior. Além disso, NILSON (1985) comenta que o custo é menor para o aumento de resistência do concreto do que para o aumento da percentagem de armadura. E lajes e vigas mais esbeltas reduzem a carga permanente, o que é de fundamental importância para os edificios altos.

Os pilares dos edifícios altos têm sido a maior aplicação do concreto de alta resistência em edificios, podendo ser evitados pilares com dimensões que seriam 
inaceitáveis nos pavimentos inferiores. O Lake Point Tower, construído em 1968, tem pilares com resistência de cálculo de $52 \mathrm{MPa}$. Desde 1972, dezenas de edifícios na área de Chicago foram construídos com pilares tendo resistência à compressão da ordem de $62 \mathrm{MPa}$ : Mid-Continental Plaza (1972), Frontier Tower (1973), Water Tower Place (1975), entre outros. O Edificio River Plaza, também em Chicago, construído em 1976, não só possuía concreto com $62 \mathrm{MPa}$ como, também, concreto obtido em laboratório com mais de $75 \mathrm{MPa}$ em dois pilares.

Durante os últimos anos, houve um grande salto na resistência do concreto em edifícios altos, especialmente na região de Seattle, onde, em 1989, o Pacific First Center, com 44 pavimentos foi construído com pilares de $115 \mathrm{MPa}$. A motivação para o uso de concreto de alta resistência é muitas vezes a exigência de um maior módulo de elasticidade.

No Brasil, a obra pioneira em uso de concreto de alta resistência em estruturas de edificios foi o Edificio Trianon, que abriga o Museu de Arte de São Paulo (MASP). Concluído há aproximadamente 30 anos, foi considerado na época um desafio à Engenharia Estrutural. O concreto empregado apresentou uma resistência característica à compressão de $45 \mathrm{MPa}$ aos 28 dias.

\subsubsection{Pontes}

Para pontes com grandes vãos, a combinação do concreto de alta resistência, para reduzir a carga permanente, com a protensão, para controlar as deformações, estendeu os vãos das pontes de concreto para mais de 270 metros.

Durante os últimos anos, houve rápido crescimento de interesse pela durabilidade das pontes que, muito frequentemente, encontram-se expostas a um ambiente hostil. Daí, mesmo em casos em que a alta resistência não seja a propriedade fundamental, o concreto de alta resistência tem sido indicado.

Com o objetivo de reduzir as dimensões das vigas e o peso próprio, o concreto de alta resistência pode ser indispensável para as pontes com grandes vãos.

MACININIS \& THOMPSON (1970) citam, como exemplo, a ponte Willows Bridge, no Canadá, que obteve uma resistência de $69 \mathrm{MPa}$ aos 28 dias. 


\subsubsection{Plataformas marítimas}

$\mathrm{O}$ concreto de alta resistência foi usado em todas as plataformas marítimas (estruturas off-shore) no Mar do Norte, desde que as primeiras plataformas de concreto foram construídas, no início da década de 70 .

Destas estruturas se espera que resistam à corrosão pela água do mar e também aos esforços causados pelo impacto das ondas.

\subsubsection{Aplicações especiais}

Em 1982, na costa ocidental de Karmøy, Noruega, foi construído um túnel submerso para oleodutos. O túnel consiste de 5 elementos grandes de concreto prémoldado, com resistências especificadas à compressão de $60 \mathrm{MPa}$ e $65 \mathrm{MPa}$. O nível de resistência real obtido variou de $65 \mathrm{MPa}$ a $75 \mathrm{MPa}$.

Durante a construção do piso da plataforma Gullfaks $B$, no Mar do Norte, em 1984, foi executada uma parte das fundações provisórias, para uma das três placas circulares de concreto, com resistência especificada à compressão de $85 \mathrm{MPa}$. A resistência média obtida aos 28 dias alcançou $102 \mathrm{MPa}$.

Um concreto com resistência especificada à compressão de $60 \mathrm{MPa}$ foi usado nos elementos pré-moldados para o National Day Parede Grandstand em Abu Dhabi, Emirados Árabes Unidos, em 1983. Uma razão importante para se especificar o concreto de alta resistência foi, além de minimizar a retração e a fluência, garantir a durabilidade num ambiente agressivo e hostil como o do Oriente Médio

A aplicação de concreto leve de alta resistência, nas vigas de cobertura das arquibancadas dos hipódromos Doncaster, na Inglaterra, e Leopardstown, na Irlanda, foi relatada por POITEVIN (1986). A resistência mínima exigida foi de $52 \mathrm{MPa}$ aos 28 dias.

Galpões e barreiras foram projetadas no Japão, com resistência especifícada de $75 \mathrm{MPa}$. Estas estruturas foram utilizadas para proteger as rodovias da neve, avalanches de terra e ruínas de rochas. $O$ peso reduzido dos elementos pré-fabricados, por usar concreto de alta resistência, facilitou o transporte e a instalação. 
O uso de concreto com $69 \mathrm{MPa}$, para postes de concreto protendido, está citado no $A C I 363$ (1984). O concreto de alta resistência foi selecionado para reduzir a seção transversal dos postes. O $A C I 363$ (1984) também se refere ao uso de concreto de alta resistência em estacas para fundações marítimas, nos Estados Unidos, em 1960. As resistências à compressão variaram entre $55 \mathrm{MPa}$ e $68 \mathrm{MPa}$. 


\section{COMPOSIÇÃO E PRODUÇÃO}

A produção do concreto de alta resistência exige uma seleção dos materiais para garantir boa trabalhabilidade e elevada resistência. $\mathrm{O}$ concreto de alta resistência é produzido usando uma variedade de materiais, baseando-se em resultados de ensaios de diversas misturas.

A dosagem é mais criteriosa que para o concreto de resistência usual. Em geral, adições minerais, principalmente, e aditivos químicos são usados e o emprego de um baixo fator água/cimento é considerado essencial.

\subsection{CIMENTO}

As resistências inicial e final e a trabalhabilidade do concreto dependem das características e do teor de cimento. Para um dado tipo de cimento, diferentes marcas têm diferentes desempenhos de resistência, devido às variações na composição e finura.

Quanto ao tipo de cimento a ser empregado, pode-se afirmar que é sempre possivel utilizar o cimento Portland comum (CP - 32, segundo as Normas Brasileiras), a menos que resistência inicial mais alta seja desejada, como no concreto protendido e na produção de pré-moldados de concreto, situação em que se pode utilizar cimento de alta resistência inicial (ARI). É bom lembrar que o cimento Portland comum permite a obtenção de concretos com resistências suficientemente altas em curto prazo. 
Teores elevados de cimento podem resultar no aumento de temperatura no concreto. Quando a elevação de temperatura é considerada como um problema, um cimento com baixo calor de hidratação (ASTM C150, por exemplo) pode ser usado, sem prejudicar as exigências de resistência.

\subsection{AGREGADOS}

Existem alguns aspectos a serem considerados para a escolha dos agregados. Tanto o agregado miúdo quanto o graúdo são utilizados em concreto de alta resistência.

\subsubsection{Agregado miúdo}

O agregado cujo diâmetro máximo não ultrapassa $4,8 \mathrm{~mm}$ é considerado como agregado miúdo; são as areias naturais ou artificiais.

Os agregados miúdos, com partículas de forma arredondada e textura lisa, exigem menos água de amassamento e por esta razão são preferíveis em concreto de alta resistência, como comentam WILLS JR (1967), GAYNOR \& MEININGER (1983).

$B L I C K$ (1973) declarou que uma areia com módulo de finura inferior a 2,5 deu ao concreto uma consistência viscosa, tornando-o difícil de compactar. A areia com um módulo de finura em torno de 3,0 deu uma melhor trabalhabilidade e maior resistência à compressão

\subsubsection{Agregado graúdo}

O $A C I 363$ (1992) mostrou que para se obter resistência à compressão ótima, com alto teor de cimento e baixo fator água/cimento, a máxima dimensão do agregado graúdo deveria se manter entre $9,5 \mathrm{~mm}$ e $12,5 \mathrm{~mm}$. Dimensões máximas de $19 \mathrm{~mm}$ e $25 \mathrm{~mm}$ também têm sido usados com sucesso. CORDON \& GILLESPIE 
(1963) perceberam que aumentos de resistência eram causados pela redução em média da tensão de aderência, devida ao acréscimo da superfície específica individual do agregado.

Dimensões menores de agregados também produzem concretos com maiores resistências, por causa de menores concentrações de tensões ao redor das partículas, que são causadas por diferenças entre o módulo de deformação da pasta e do agregado.

Muitos estudos têm mostrado que a pedra britada produz maiores resistências que o seixo rolado. A maior razão provável para isto é a maior aderência mecânica que pode se desenvolver com partículas angulosas. Entretanto, a angulosidade acentuada deve ser evitada, por causa da alta necessidade de água e da reduzida trabalhabilidade.

Segundo um boletim da "NATIONAL CRASHED STONE ASSOCIATION" apud $A C I 363$ (1992), o agregado ideal deveria ser limpo, cúbico, anguloso, 100\% de agregado britado, com um mínimo de partículas lamelares e alongadas.

\subsection{ADITIVos Químicos}

Os aditivos são substâncias químicas que, dosados em pequenas proporções na mistura do concreto, melhoram algumas propriedades, tanto no concreto fresco como depois de endurecido, com finalidade de facilitar seu preparo e a utilização.

A seleção do tipo, marca e dosagem dos aditivos deve ser baseada no desempenho com os outros materiais utilizados na mistura.

Algumas contribuições que podem ser esperadas dos aditivos selecionados são: o aumento da plasticidade do concreto sem aumentar a quantidade de água, a redução da exsudação e da segregação, o aumento ou a diminuição do tempo de pega, o

1 NATIONAL CRASHED STONE ASSOCIATION. (1975). High strength concrete: manual of concrete materials aggregates, Washington, D.C., 16p. apud AMERICAN CONCRETE INSTITUTE. Committee 363. (1992). State-of-the-art report on high strength concrete. Detroit, $\mathrm{ACI}, \mathrm{p} .6$. 
rápido crescimento da resistência nas primeiras idades, a redução da taxa de evolução do calor de hidratação e o aumento da durabilidade do concreto em condições de exposição especificadas, como comenta PINTO JR (1992).

Os principais aditivos são: incorporadores de ar, retardadores de pega, redutores de água, redutores de água em grande escala e aceleradores de pega.

\subsubsection{Aditivos incorporadores de ar (ASTM C 260)}

Os aditivos incorporadores de ar têm uso recomendado, principalmente, para aumentar a durabilidade de concretos que estão sujeitos a ciclos de congelamento e descongelamento. Outra vantagem importante é a melhor trabalhabilidade da mistura, como a do concreto de alta resistência, que possui um baixo fator água/cimento.

A segregação e a exsudação são reduzidas, sendo tais efeitos devidos à presença das minúsculas bolhas de ar dispersas na pasta de cimento, conferindo lubrificação e coesão à mistura.

$\mathrm{O}$ ar incorporado reduz a resistência do concreto, particularmente nas misturas de alta resistência. Por este motivo, o uso deste aditivo é recomendado exclusivamente em casos que o principal interesse seja melhor durabilidade e resistência às intempéries, mesmo provocando queda de resistência mecânica.

\subsubsection{Aditivos retardadores de pega (ASTM C 494 - tipo B)}

Retardadores são aditivos que retardam a reação de hidratação do cimento. Segundo PINTO JR (1992), os aditivos retardadores são utilizados para aliviar os efeitos prejudiciais de temperaturas elevadas. $O$ uso de um retardador, para controlar a taxa de endurecimento, proporciona algum alívio na queda de resistência causada pela temperatura. Eles são também aplicados para controlar a pega, mantendo, assim, o concreto trabalhável durante todo período de lançamento. São importantes em estruturas grandes, para eliminar juntas frias e descontinuidades.

Deve-se tomar cuidado com o uso de retardadores de pega, que em quantidades indevidas inibem completamente a pega e o endurecimento do concreto. 


\subsubsection{Aditivos redutores de água - Plastificantes (ASTM C 494 - tipos A, D e E)}

São usados com o objetivo de melhorar a consistência do concreto e aumentar a resistência sem aumentar o consumo de cimento e água, mantendo uma boa trabalhabilidade e diminuindo a elevação da temperatura. São eles:

Tipo A - aditivos que são somente redutores de água, de pega normal, e que permitem aumento da resistência do concreto sem afetar o endurecimento.

Tipo D - aditivos redutores retardadores, que também produzem um aumento de resistência com baixa relação água/cimento, porém retardando a pega.

Tipo E - aditivos redutores aceleradores, que não são normalmente empregados em concretos de alta resistência.

Os aditivos redutores de água permitem uma redução de $5 \%$ a $10 \%$ da água necessária para a mesma consistência do concreto, de acordo com o ACI 212 (1981).

\subsubsection{Aditivos Superplastificantes (ASTM C 494 - tipos F e G)}

O superplastificante Tipo $\mathbf{F}$ é o super-redutor com pouca influência sobre a pega e o Tipo G é o super-redutor retardador do tempo de pega.

A composição química dos superplastificantes inclui condensados sulfonados de formaldeído de melamina, condensados sulfonados de formaldeído de naftaleno, lignosulfonatos modificados e ésteres de ácido sulfúrico ou de carboidratos.

Os superplastificantes são empregados no concreto com o objetivo de produzir concretos com relações água/cimento muito baixas. Para obter concretos de alta resistência, conserva-se a quantidade de cimento, reduzindo-se a de água. Incorpora-se superplastificante para compensar a redução da trabalhabilidade.

Os super-redutores podem ser usados com a finalidade de produzir concretos com reduzido conteúdo de cimento, enquanto se mantém a relação água/cimento.

Outra finalidade é de produzir concretos fluidos auto-compactantes e autonivelantes. Nessa aplicação não são alterados nem o fator água/cimento nem a quantidade de cimento. O principal é aumentar a trabalhabilidade sem causar 
nenhuma segregação, de forma que o concreto possa ser lançado, por exemplo, em seções fortemente armadas.

Para evitar segregação, no caso de concretos fluidos, há necessidade de materiais fluidos adicionais. Isso pode ser conseguido com o aumento das frações finas de areia ou pela adição de materiais pozolânicos como a cinza volante.

$\mathrm{O}$ ajuste do aditivo ao cimento, não só no tipo mas também na dosagem, é muito importante, podendo ser a redução de $12 \%$ a $25 \%$ de água.

Quando usados em excesso, podem retardar bastante o tempo de pega e incorporar muito ar, diminuindo a resistência do concreto.

\subsubsection{Aditivos aceleradores de pega (ASTM C 494 - tipos C e E)}

Os aditivos aceleradores (Tipo $\mathbf{C}$ ) e redutores aceleradores (Tipo E) são empregados com a finalidade principal de aumentar a resistência do concreto nas primeiras idades e reduzir o tempo de pega. Outros beneficios podem ser citados: remoção antecipada das fôrmas e antecipar a abertura da obra a outros serviços; redução do tempo necessário para a cura; redução do intervalo de tempo durante o qual as fôrmas estão submetidas a pressões hidráulicas.

Os aceleradores não são normalmente usados em concreto de alta resistência, a menos que a desforma antecipada seja imprescindível. Os aceleradores usados para aumentar o endurecimento são normalmente danosos para o desenvolvimento de resistência a longo prazo. [ ACI 363 (1992)].

\subsection{ADIÇÕES MINERAIS}

As adições minerais são partículas muito finas, que podem ser incorporadas ao concreto, suplementando o cimento ou substituindo parte dele.

Estes compostos usados no concreto são constituídos de grãos com diâmetro menor que o do cimento e, daí, influem nas propriedades do concreto fresco, tais 
como: demanda de água, trabalhabilidade, segregação, exsudação e calor de hidratação do cimento. Influem, também, nas propriedades do concreto endurecido, resultando em aumento da resistência, diminuição da porosidade, controle das reações álcali-agregados e aumento da durabilidade, via redução da permeabilidade.

Os materiais utilizados como adições minerais consistem basicamente de escória de alto forno, cinza volante e microssílica.

\subsubsection{Escória de alto forno}

A escória apropriada para o concreto é um produto não metálico, que é obtido em condição liquefeita, simultaneamente com ferro em alto forno. A escória sofre um resfriamento rápido em água e se solidifica, adquirindo uma textura vítrea e granular, tornando-se um material hidráulico ativo, que atuará no concreto como substituição parcial do cimento.

A escória de alto forno consiste essencialmente de sílica, alumina e cal.

\subsubsection{Cinza volante}

As cinzas volantes são cinzas captadas dos gases na combustão de carvão pulverizado em centrais termoelétricas, constituidas de resíduos finos captados por coletores mecânicos ou precipitadores eletrostáticos dos gases da combustão, antes de serem lançados na atmosfera

A cinza volante para concreto de alta resistência possui duas classes, segundo a ASTM. A cinza volante classe F é normalmente obtida da combustão de antracito ou carvão betuminoso, possui baixo teor de cálcio e tem propriedades pozolânicas, com pequena ou nenhuma propriedade cimentante, tendo grande campo de aplicação nos concretos de alta resistência. A cinza volante classe C é obtida da combustão de lignita, possui alto teor de cálcio e, além de ter propriedades pozolânicas, tem algumas propriedades de cimentação.

Suas partículas se apresentam em forma esférica com diâmetro de 1 a $150 \mu \mathrm{m}$, cor acinzentada e superfície específica média de $4000 \mathrm{~cm}^{2} / \mathrm{g}$. 
A substituição do cimento Portland em termos de sua massa é em torno de $8 \%$ a $10 \%$, em concreto de alta resistência.

\subsubsection{Microssílica}

A microssílica e os aditivos contendo microssílica têm sido usados em concretos de alta resistência com finalidades estruturais e para aplicações superficiais, como materiais de reparo, em situações onde a resistência à abrasão e a baixa permeabilidade são importantes.

Segundo o $A C I 363$ (1992), a microssílica é um subproduto resultante da redução de quartzo de alta pureza com carvão, em fornos aquecidos eletricamente com circulação de ar, na produção de silício e ligas de ferro-silício. A fumaça, na qual tem um alto teor de dióxido de silício amorfo e consiste de partículas esféricas muito finas, é coletada dos gases que escapam dos fornos.

A maioria das partículas da microssílica é menor que um mícron, com diâmetro médio de $0,1 \mu \mathrm{m}$, que é aproximadamente 100 vezes menor que uma partícula média de cimento e apresenta superfície específica média de $200000 \mathrm{~cm}^{2} / \mathrm{g}$. Sua coloração varia em função do teor de carbono presente.

PINTO JR (1992) comenta que a composição química varia muito de forno para forno, de dia para dia, de acordo com a variação das impurezas nas matérias primas. Seus principais componentes são: $\mathrm{SiO}_{2}(85 \%$ a $98 \%), \mathrm{C}(0,2 \%$ a $2,5 \%), \mathrm{K}$ $(0,2 \%$ a $3,5 \%), \mathrm{Na}(0,1 \%$ a $1,5 \%)$ e $\mathrm{Mg}(0,1 \%$ a $2,5 \%)$.

A microssilica classificada (ou não densificada) apresenta algumas desvantagens: em função de sua massa unitária $\left(150 \mathrm{~kg} / \mathrm{m}^{3}\right)$, torna o transporte muito oneroso; por se tratar de um pó muito fino, existe a tendência de aderir aos silos e correias transportadoras e formação de muito pó na utilização.

A microssilica apresenta dois efeitos sobre os concretos de cimento Portland: o efeito pozolânico e o efeito de micro-filler. No primeiro, a microssílica, por ser praticamente só sílica amorfa, reage com grande rapidez com $\mathrm{Ca}(\mathrm{OH})_{2}$ formado da hidratação do cimento. E, no segundo, por ser extremamente fina, a quantidade de grãos de microssílica por grão de cimento (na proporção de $10 \%$ de microssílica em 
relação à massa de cimento) é da ordem de 50000 e esses grãos se alojam nos interstícios da pasta, subdividindo os poros capilares das partículas de cimento em poros de gel.

Algumas das diversas aplicações especializadas para a microssílica são:

a) $\mathrm{Na}$ economia de cimento - por sua altíssima eficiência, o uso criterioso da microssílica ajuda a economizar cimento;

b) Na produção de concreto de altíssima resistência - vários pesquisadores têm utilizado a microssílica para produzir concretos com resistências à compressão da ordem de $100 \mathrm{MPa}$ e maiores, sendo essa, certamente, uma área muito especializada e portanto com aplicação limitada;

c) No controle das reações álcali-agregados - da mesma forma que as cinzas volantes e pozolanas naturais, a microssílica pode ser aplicada para reduzir as reações álcali-agregados no concreto, com a vantagem adicional de que somente pequenas quantidades são necessárias quando comparadas com as dos materiais constituintes das misturas;

d) Na redução à corrosão associada a cloretos e sulfatos - por causa da alta impermeabilidade, os concretos com microssílica oferecem possíveis usos em estruturas de tabuleiros de pontes e de estacionamentos, para conter a corrosão associada aos cloretos, e em solos com sulfatos, para conter o ataque desses ao concreto;

e) No aumento da resistência nas primeiras idades dos concretos com cinzas volantes ou escórias.

\section{5 ÁGuA}

As especificações para a qualidade da água de amassamento para concreto de alta resistência não são mais exigentes do que para o concreto usual. Geralmente, a água para concreto deve ser de qualidade potável, isenta de matérias orgânicas e de substâncias estranhas e nocivas. 


\subsection{DOSAGENS DO CONCRETO}

A dosagem para concreto de alta resistência varia muito, dependendo de muitos fatores. A resistência necessária, a idade do ensaio, as características dos materiais e o tipo de aplicação têm influenciado as dosagens. Além disso, a economia, as especificações estruturais, a fabricação de um modo prático, $\mathrm{o}$ ambiente de cura e também a época do ano têm afetado a seleção das dosagens.

A dosagem do concreto de alta resistência é um processo mais crítico do que do concreto de resistência usual. São considerados fundamentais, em geral, as pozolanas e os aditivos químicos, criteriosamente selecionados, e obtenção de um baixo fator água/cimento (ou fator água/material cimentante).

\subsubsection{Cimento}

Há muitos fatores que podem limitar a quantidade máxima de cimento desejável numa mistura de alta resistência. A resistência do concreto pode diminuir se o cimento for adicionado acima de um dado teor ótimo.

A perda de viscosidade e de trabalhabilidade aumentam à medida que maiores quantidades de cimento são incorporadas à mistura.

Os teores de cimento comuns nos concretos de alta resistência variam de 400 $\mathrm{kg} / \mathrm{m}^{3}$ a $600 \mathrm{~kg} / \mathrm{m}^{3}$, como está descrito no $A C I 363$ (1992).

\subsubsection{Agregados}

Na dosagem do concreto de alta resistência, os agregados podem ter uma consideração muito importante, sendo eles que ocupam o maior volume de qualquer dos ingredientes no concreto.

Como foi comentado anteriormente, as características ideais das partículas do agregado miúdo são: forma arredondada, textura lisa e módulo de finura em torno de 3,0 . 
Nos agregados graúdos, o uso de dimensões menores é geralmente benéfico (entre 9,5 e 12,5 mm) e as pedras britadas aderem melhor à pasta cimentante.

\subsubsection{Aditivos químicos e adições minerais}

Mudanças nas quantidades e combinações destes aditivos e adições afetam as propriedades plásticas e de endurecimento do concreto de alta resistência. Portanto, uma atenção especial tem sido dada aos seus efeitos.

Nos concretos de alta resistência, as adições minerais são usadas para suplementar o cimento Portland de 10 a $40 \%$ por peso do conteúdo do cimento [ACI 363 (1992)]. Nos casos onde um acréscimo líquido no volume dos materiais cimentantes é usado, devido à adição de uma pozolana, faz-se um decréscimo correspondente no volume de areia.

$\mathrm{O}$ uso de cinza volante tem frequentemente causado uma pequena redução na demanda de água da mistura e esta redução no volume de água tem sido compensada por uma adição de areia.

A microssílica aumenta drasticamente a demanda de água da mistura, necessitando o uso de aditivos retardadores e superplastificantes.

$\mathrm{O}$ uso de superplastificante tem provocado grande redução de água, de 12 a $25 \%$. São feitos acréscimos correspondentes no conteúdo de areia, para compensar a perda de volume por redução de água na mistura.

Devido à quantidade relativamente grande de líquido que é adicionado à mistura, na forma de aditivo superplastificante, o peso desses aditivos tem sido, algumas vezes, incluído no cálculo do fator água/material cimentante.

\subsubsection{Fator água/cimento e fator água/material cimentante}

Há uma relação entre o fator água/cimento e a resistência, tanto para concretos de baixa como para concretos de alta resistência. Maiores teores de cimento e menores teores de água produzem maiores resistências. Grandes quantidades de cimento na mistura de concreto, entretanto, também aumentam a demanda de água 
na mistura. E como já foi dito, acréscimos em cimento além de um certo valor nem sempre aumentam a resistência à compressão.

O abatimento (slump) do concreto está relacionado com o fator água/material cimentante e com a quantidade total de água no concreto.

$\mathrm{O}$ uso de superplastificantes tem fornecido menores fatores água/material cimentante e maiores abatimentos.

Os fatores água/material cimentante, para concretos de alta resistência, variam de 0,27 a 0,50 , conforme o $A C I 363$ (1992). A quantidade de aditivos líquidos, particularmente superplastificantes, às vezes, é incluída no fator água/material cimentante.

A resistência à compressão que um concreto desenvolverá, para um dado fator água/material cimentante, varia amplamente, dependendo do cimento, dos agregados e dos aditivos empregados.

\subsection{PROCEDIMENTOS DE MISTURA}

O concreto de alta resistência pode ser inteiramente misturado nos equipamentos dosadores, na central, no caminhão misturador ou por uma combinação dos dois.

Em alguns trabalhos, comenta-se que, devido ao teor de água relativamente baixo. o de cimento elevado e a ausência de agregado graúdo de grandes dimensões, a mistura eficiente de concreto de alta resistência exige maiores cuidados que o concreto usual. Por isso, há uma necessidade de o produtor do concreto verificar o desempenho e a eficiência do misturador antes de fazer a mistura.

Ensaios demonstraram que os aditivos superplastificantes são mais eficientes quando adicionados ao final do ciclo de mistura, depois que todos os ingredientes tenham sido introduzidos e completamente misturados.

O tempo de mistura é medido a partir do momento em que todos os ingredientes estão no misturador. Uma mistura prolongada pode causar uma baixa 
umidade e resultar numa menor trabalhabilidade, o que pode exigir mudanças na mistura para restaurar o abatimento (slump), deste modo reduzindo a resistência potencial.

Aditivos retardadores são usados para prolongar o tempo que o concreto reagirá à vibração, depois de ter sido colocado na fôrma. Reter um pouco de água de amassamento antes que o caminhão chegue à obra é, às vezes, interessante.

\subsection{PROCEDIMENTOS DE CURA}

A cura é o processo utilizado para manter um teor de umidade satisfatório e uma temperatura favorável no concreto, durante a hidratação do cimento, de modo que as propriedades desejadas do concreto possam se desenvolver. A cura é importante na produção do concreto comum e é imprescindível para produzir o concreto de alta resistência.

A resistência potencial e a durabilidade só serão totalmente desenvolvidas se o concreto for submetido a uma cura apropriada por um período adequado, antes de ser utilizado em serviço.

O concreto de alta resistência deve ser curado em idades iniciais, uma vez que, com carência de água livre, uma hidratação parcial pode tornar os capilares descontínuos. E em idades posteriores, numa nova cura, a água não seria capaz de percorrer o interior do concreto e esta hidratação adicional seria interrompida.

Devido ao baixo fator água/cimento empregado, a cura do concreto de alta resistência é bastante solicitada. Para um fator água/cimento abaixo de 0,4 , a hidratação é significativamente reduzida se a água livre não for fornecida. A cura melhora a hidratação do cimento. Para concretos com 0,29 de fator água/cimento, a resistência aos 28 dias de corpos de prova feitos com agregados saturados e curados imersos em água chega a ser de 5,9 $\mathrm{MPa}$ a 6,9 $\mathrm{MPa}$ maior do que de amostras feitas com agregados secos e curadas em câmara úmida, de acordo com o $A C I 363$ (1992). 
O método mais completo de cura com água, porém raramente usado, consiste da imersão total da peça concretada.

Também, nuvens de borrifos com bicos pulverizadores proporcionam uma cura satisfatória, quando a imersão não é exequível. Em superficies verticais, as mangueiras são bastante convenientes. Materiais absorventes como aniagens e mantas conservam a água na superfície tanto horizontal quanto vertical. Soluções como envolver a peça em lona plástica têm sido usadas com sucesso. 


\section{PROPRIEDADES MECÂNICAS DO CONCRETO DE ALTA RESISTÊNCIA}

Serão analisados o comportamento na compressão axial, o módulo de deformação longitudinal, o coeficiente de Poisson e o comportamento na tração.

\subsection{COMPORTAMENTO NA COMPRESSÃO AXIAL}

Para se obter uma elevada resistência, num material multifásico como o concreto, deve-se reduzir a porosidade dos componentes de sua estrutura. Geralmente, a porosidade da pasta e a porosidade da zona de transição entre a pasta e os agregados determinam a resistência do concreto.

MEHTA' apud FERNANDES (1992) menciona que a relação água/cimento é o fator de maior influência na porosidade da pasta e da zona de transição pastaagregado. Por possuir baixa relação água/cimento, o concreto de alta resistência apresenta menor porosidade que o concreto usual.

Outro aspecto interessante é a superficie de fratura do concreto de alta resistência, que é lisa e corta as partículas de agregados, em vez de contorná-las. O mesmo não acontece com o concreto de resistência usual.

' MEITA, P.K. (1986). Concrete - structures, properties and materials. Englewood Cliffs, NJ, Prentice Hall apud FERNANDES, G.B. (1992). Cisalhamento de vigas de concreto de alta resistência. São Paulo. 2v. Tese (doutorado) - Escola Politécnica da Universidade de São Paulo, p.3.2. 
A resistência à compressão axial é o parâmetro mais comum, usado para caracterizar o concreto. Por várias razões, tais como compactação e cura, a resistência característica in situ pode ser menor que a correspondente resistência do ensaio de laboratório. Várias normas assumem um fator de redução de tensão de 0,75 a 0,90 [ ISO' \& NS 3473² apud FIP/CEB 197 (1990)]. No CEB-90 (1991), encontra-se uma relação entre a resistência in situ/ resistência em laboratório igual a $\left(1-f_{c k} / 250\right)$.

A resistência dos concretos submetidos a carga de longa duração é menor que a determinada pelos ensaios de curta duração. Isto é de fundamental importância no projeto de estruturas, desde que isso signifique uma redução no fator de segurança com respeito à resistência, que está geralmente baseada em ensaio a curto prazo. Os resultados dos ensaios a longo prazo indicam que o valor da resistência é de $70 \%$ a $80 \%$ da resistência última a curto prazo, para concreto de resistência usual. Os ensaios realizados por $R \ddot{U} S C H$ (1960), nos concretos de resistência usual, mostraram que a resistência a longo prazo é $25 \%$ inferior à obtida em ensaios a curto prazo. Alguns resultados de ensaios em concretos de alta resistência apresentam diferença menor que as obtidas para concreto de resistência usual. Uma redução de $15 \%$ a $20 \%$ da resistência última foi indicada por SMADI et al (1985). São mostradas na figura 3.1 as curvas tensão-deformação para curta duração e longa duração.

Entretanto, um aumento relativo na resistência a curto prazo, de um concreto de alta resistência após 28 dias, é geralmente menor que em um concreto de nível normal. Isso é devido à falta de água livre que permita o prosseguimento da hidratação, combinada com a possível limitação da capacidade dos agregados. Para

INTERNATIONAL Standard Organization (1987). Methods for assessment of the compressive strength of concrete in structures apud FIP/CEB Working (iroup on High Strength Concrete. (1990). High strength concrete: state of the art report. Bulletin d'Information, n. 197, Aug, p.12.

2 NORWEGIAN STANDARD. (1989). NS 3473 - Concrete structures, design rules. Oslo apud FIP/CEB Working Group on High Strength Concrete. (1990). High strength concrete: state of the art report. Bulletin d'Information, n.197, Aug, p.12. 
um concreto de alta resistência contendo microssílica, MAAGE et al apud FIP/CEB197 (1990) concluíram que um ganho de resistência depois de 28 dias é geralmente menor que para concreto sem microssílica, com o mesmo fator água/cimento.

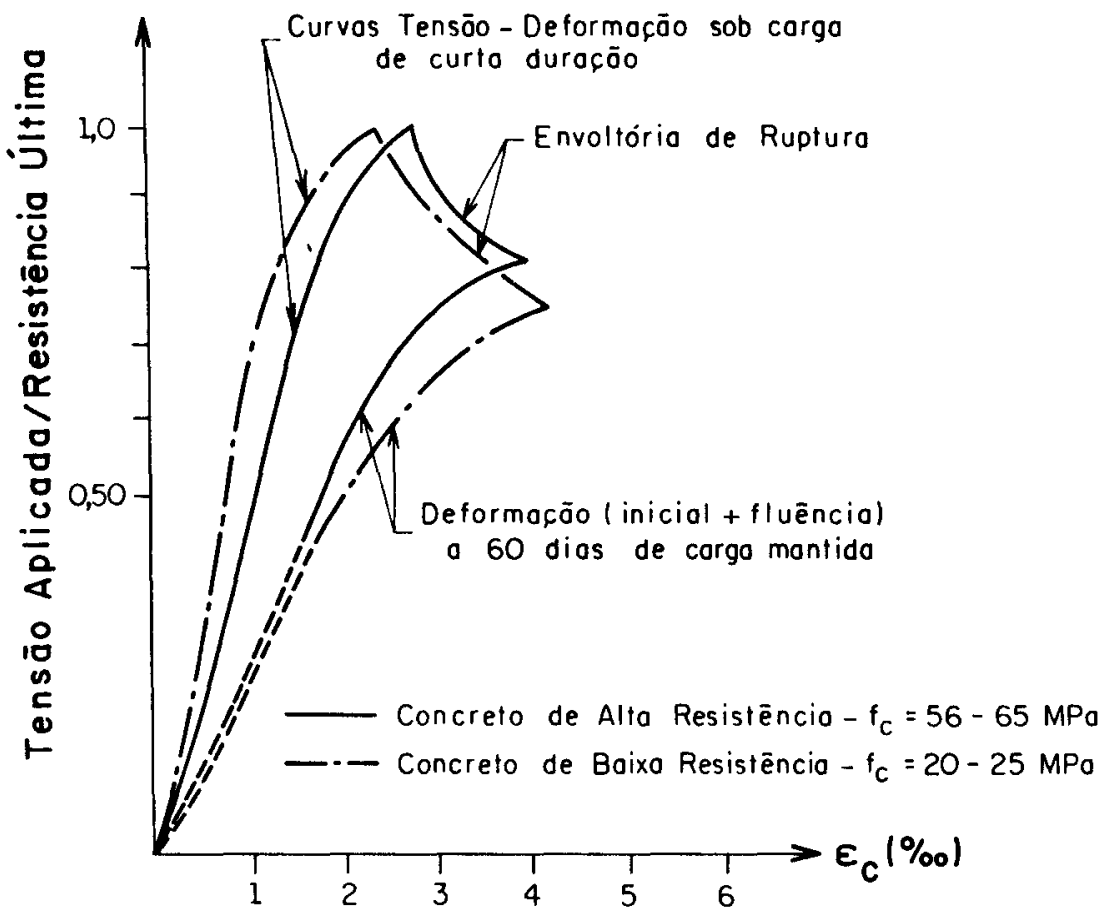

FIGURA 3.1 - Tensão/resistência e deformação para concretos sob ação de longa duração. FONTE: FIP/CEB-197 (1990).

O valor da tensão de cálculo, $\sigma_{\mathrm{cd}}$, é afetado diretamente pela menor perda de resistência, quando há uma solicitação a iongo prazo no concreto de alta resistência. No dimensionamento de estruturas, adota-se o valor: $\sigma_{\mathrm{cd}}=0,85 \mathrm{f}_{\mathrm{cd}}$.

$O$ coeficiente 0,85 é constituído de três fatores: o primeiro, 0,75 , considera a perda de resistência pela ação de cargas que permaneçam atuando períodos que superem algumas semanas; o segundo, 0,95, leva em conta o erro sistemático

1 MAAGE; SMEPLASS; JOHANSEN. (1990). Long-term strength of high strength silica fume concrete. In: INTERNATIONAL SYMPOSIUM ON THE UTILIZATION OF HIGH STRENGTH CONCRETE, 2., Berkeley, California. May. Proc. apud FIP/CEB Working Group on High Strength Concrete. (1990). High strength concrete: state of the art report. Bulletin d'Information, n.197, Aug, p.13. 
cometido com o emprego do corpo de prova padrão; e, finalmente, o terceiro, 1,2, considera o aumento da resistência do concreto após a idade de 28 dias.

Pesquisas feitas por PINTO JR (1992) puderam chegar a um outro coeficiente, 0,70 , admitindo para um concreto de alta resistência outros fatores que correspondem aos anteriormente descritos. As justificativas que ele encontra para o coeficiente adotado são: o coeficiente 0,75 , já que a redução da resistência é de 15 a $20 \%$, assumindo uma redução da de $20 \%$, será alterado para 0,80 .

Nos concretos de alta resistência, há uma tendência de adotar o cilindro de $100 \times 200 \mathrm{~mm}$ em lugar do cilindro padrão de $150 \times 300 \mathrm{~mm}$ para medida da resistência. A relação entre as resistências obtidas nos cilindros $100 \times 200 \mathrm{~mm}$ e aquelas obtidas no cilindro padrão é de 0,90 . Portanto, o coeficiente 0,95 deve ser afetado por esse fator, passando a ser expresso pelo produto $0,9 \times 0,95$

O crescimento da resistência após os 28 dias de idade não é significativo para o concreto de alta resistência, com cimento ARI, podendo alterar o fator 1,2 , muito provavelmente, para 1,0. Utilizando CP 32, deve-se manter o fator 1,2 .

Utilizando o cimento ARI, o coeficiente 0,85 será alterado para:

$0,80 \times(0,9 \times 0,95) \times 1,0=0,68 \propto 0,70$

PINTO JR (1992), em seu trabalho, sugere que para adoção do coeficiente sejam executadas novas pesquisas para que o mesmo seja confirmado.

A forma da curva tensão-deformação do concreto é determinada pelo progresso da microfissuração interna durante a aplicação do carregamento.

NILSON (1987) relata que para tensões da ordem de $65 \%$ da resistência existem poucas microfissuras nos concretos de alta resistência. Começam a surgir microfissuras isoladas na zona de transição por volta de $80 \%$ a $90 \%$ da tensão máxima. Até esse nível observa-se um comportamento praticamente elástico-linear. A partir dai, então, com a evolução de microfissuras, a forma do diagrama tensãodeformação passa a ser curva. Devido à maior resistência na zona de transição, a microfissuração se manifesta a níveis mais altos de tensão nos concretos de alta resistência. A ruptura do material ocorre de maneira brusca e frágil, após ser alcançada a tensão máxima. 
As principais diferenças entre os diagramas de tensão-deformação do concreto de alta resistência e do concreto usual são:

- uma relação tensão-deformação mais linear para uma maior porcentagem da tensão máxima;

- uma deformação ligeiramente maior para uma tensão máxima;

- uma forma mais íngreme da parte descendente da curva;

- deformação última reduzida pode ser observada em classes intermediárias do concreto de alta resistência.

Essas diferenças existem basicamente por causa da maior resistência da zona de transição dos concretos de alta resistência, consequência da melhoria da aderência entre os agregados e a pasta, e a forma mais linear do diagrama reflete a quantidade reduzida de microfissuras até altos niveis de solicitação.

A figura 3.2 apresenta alguns diagramas típicos de tensão-deformação de concretos.

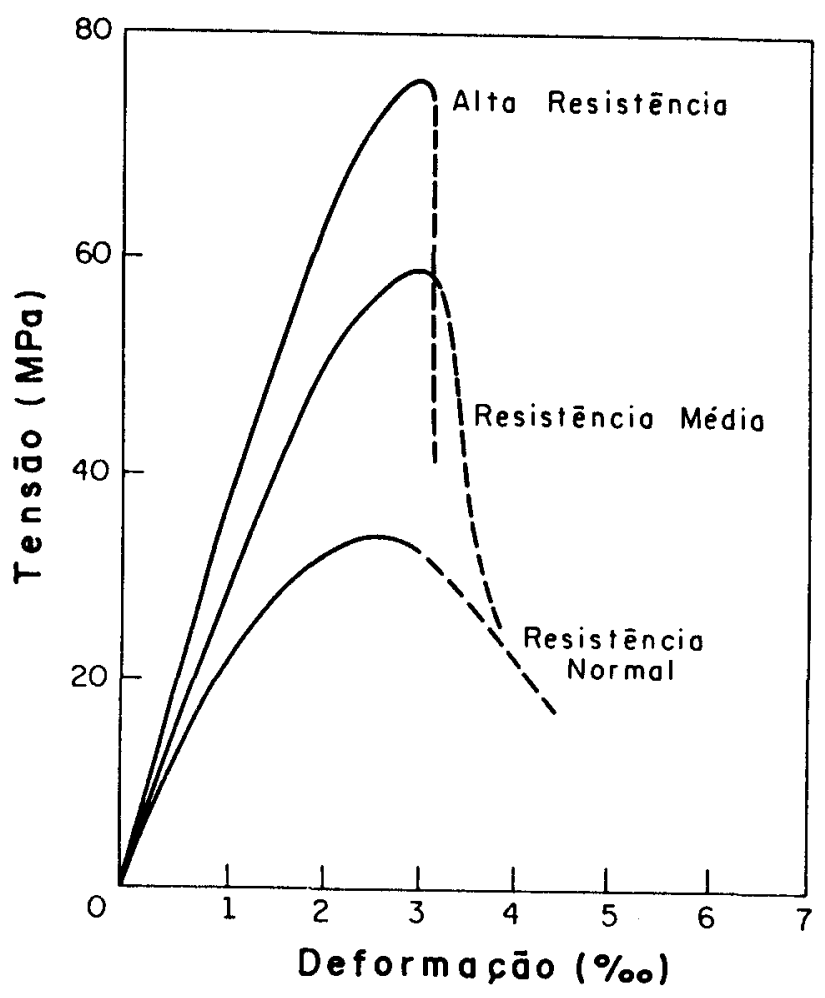

FIGURA 3.2 - Diagramas tensão-deformação típicos do concreto. FONTE: NILSON (1985). 
CARRASQUILLO et al (1981) usaram uma técnica de raio-X para demonstrar que as microfissuras instáveis começam a se desenvolver numa interface entre a pasta e o agregado por volta de $65 \%$ da carga última, para concreto com $31 \mathrm{MPa}$. Quando se aumenta o carregamento, essas fissuras se propagam através da argamassa. Tensões normais e de cisalhamento causam escorregamento e aumento das aberturas de fissuras e, então, uma variação de volume reflete o traçado da relação tensãodeformação.

Para um concreto de alta resistência com $76 \mathrm{MPa}$, essa perda na aderência da pasta e agregado inicia a propagação a $90 \%$ da carga última, resultando numa relação linear de tensão-deformação até esse nível.

A forma do diagrama de tensão-deformação de concretos em compressão axial está rigorosamente relacionada com a natureza dos materiais da mistura. A pasta de cimento e os agregados de pedras naturais são materiais frágeis, como ilustrado na figura 3.3. O concreto composto por esses materiais tem um comportamento dúctil.

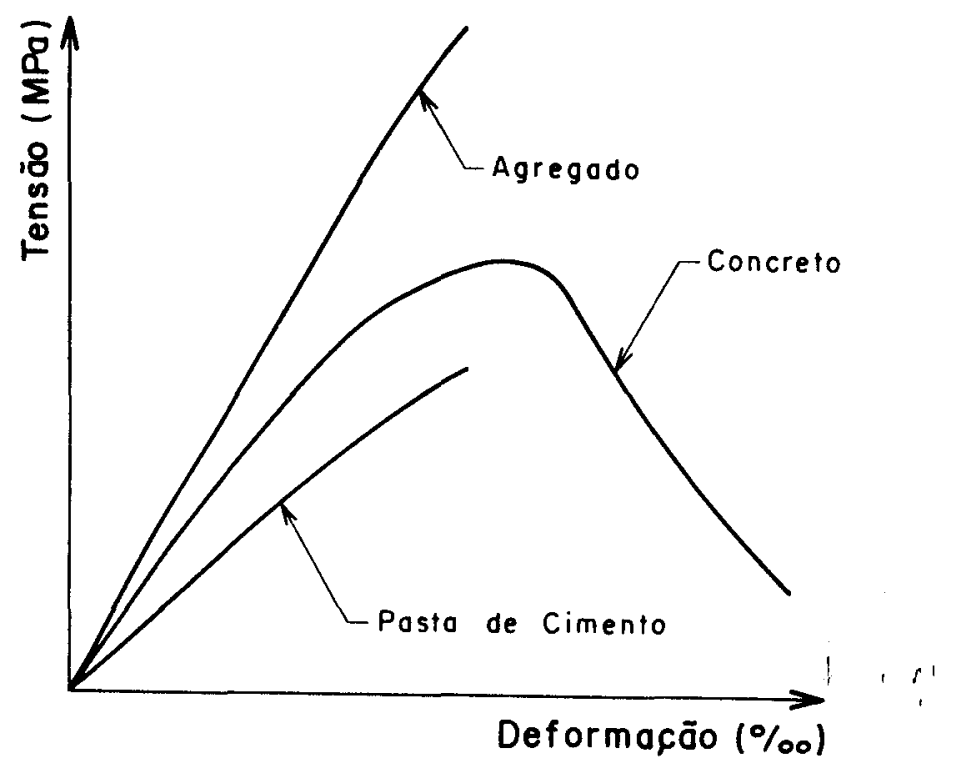

FIGURA 3.3 - Diagramas tensão-deformação para concreto de resistência usual. FONTE: FIP/CEB-197 (1990).

Essa propriedade aparentemente paradoxal pode ser explicada como um resultado da diferença de rigidez que geralmente existe entre a pasta de cimento e os 
agregados, como declara SMEPLASS et al' apud FIP/CEB-197 (1990). Essa diferença resulta das concentrações de tensões nas zonas de contato. Consequentemente, para um certo nível de tensão, começa a se formar uma configuração distribuída de microfissuras. Com o aumento das tensões, uma parte da energia acrescentada será consumida no desenvolvimento da fissura. Nesse estágio, a curva tensão-deformação tenderá a desviar do curso elástico-linear, como mostrado na figura 3.3. Depois do nível de tensão última ter sido alcançado, a microfissura proporcionará uma redistribuição interna de tensão e portanto uma ruptura dúctil.

A diferença na rigidez entre a pasta de cimento e os agregados é muito menor no concreto de alta resistência que no de resistência usual, como ilustrado na figura 3.4. Consequentemente, a distribuição interna de tensões é mais homogênea. Como a tendência de microfissuras antecipadas é reduzida, a curva tensão-deformação é mais linear. Uma menor formação de microfissuras, também, resulta numa ruptura brusca, por causa da capacidade da redistribuição de tensão ser reduzida.

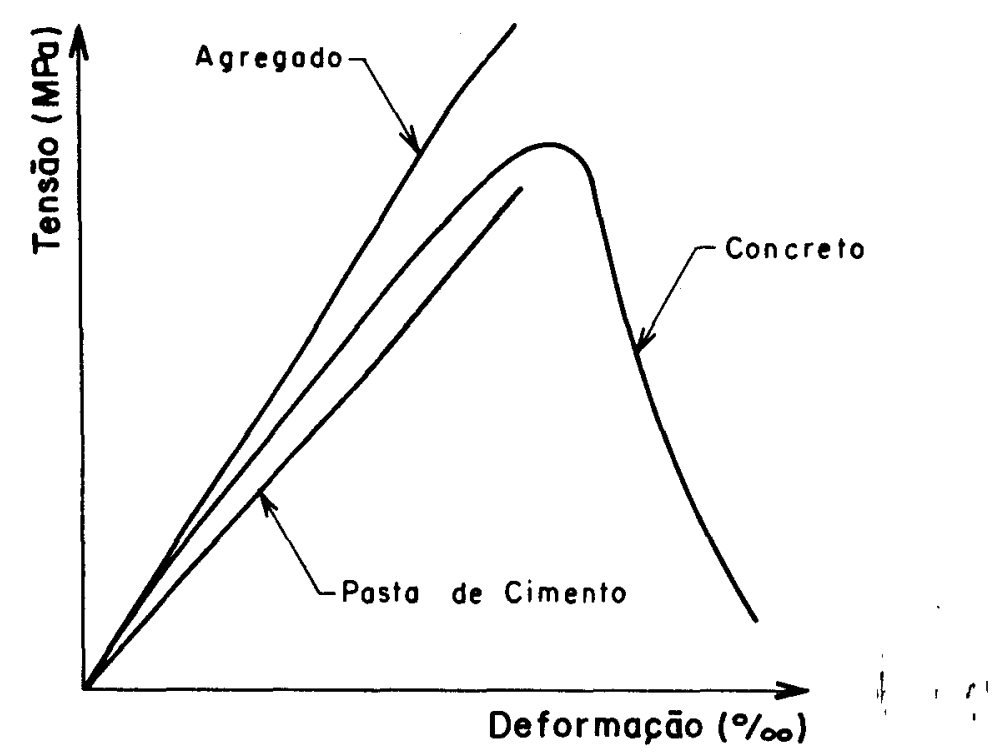

FIGURA 3.4 - Diagramas tensão-deformação para concreto de alta resistência. FONTE: FIP/CEB-197 (1990).

SMEPLASS, S. et al. (1990). Materialutvikling høyfast betong. Cement and Concrete Research Institute. Trondheim, medio apud FIP/CEB Working Group on High Strength Concrete. (1990). High strength concrete: state of the art report. Bulletin d'Information, n.197, Aug, p.14. 
De acordo com este modelo, uma diferença reduzida na rigidez entre os agregados e a pasta de cimento resulta num material de menor ductilidade. Entretanto, a resistência potencial pode ser aumentada como resultado da reduzida microfissuração, antes que a tensão última seja alcançada.

\subsection{MÓDULO DE DEFORMAÇÃO LONGITUDINAL}

O módulo de deformação longitudinal está estreitamente relacionado às propriedades da pasta do cimento, à rigidez dos agregados selecionados e também ao método de sua determinação. Uma vez que a maioria das normas expressa o módulo de deformação como uma função da resistência à compressão, essas expressões apenas estão corretas se a dosagem e a escolha dos materiais forem rigorosas.

Dosagens das misturas para concreto de alta resistência são baseadas em aditivos químicos e pozolânicos, com um baixo fator água/cimento e agregados cuidadosamante selecionados. A influência dessas caracteristicas no módulo de deformação é considerável e a validade das expressões conhecidas para cálculo do módulo de deformação devem ser reavaliadas, por serem as mesmas estabelecidas para concretos de resistência usual.

O módulo de deformação longitudinal do concreto de alta resistência é maior que o apresentado pelos concretos usuais; isso é devido à maior resistência e maior rigidez da pasta e da interface pasta-agregado e, ainda, do retardamento da microfissuração interna apresentado pelos concretos de alta resistência

AHMAD \& SHAH' apud FERNANDES (1992) comentam que, para a mesma trabalhabilidade e para a mesma relação água/cimento, quanto maior a dimensão das

\footnotetext{
AHMAD, S.H.; SHAH, S.P. (1985). Structural properties of high strength concrete and its implications for precast concrete. PCI Journal, v. 30 apud FERNANDES, G.B. (1992). Cisalhamento de vigas de concreto de alta resistência. São Paulo. $2 \mathrm{v}$. Tese (doutorado) - Escola Politécnica da Universidade de São Paulo, p.3.8.
} 
partículas e a proporção de agregado graúdo no concreto, maior se torna o seu módulo de deformação.

De acordo com as normas brasileiras, o módulo de deformação longitudinal é obtido através do diagrama tensão-deformação do concreto sujeito à compressão axial, sob carregamento estático.

Módulo de deformação tangente é o valor numérico da inclinação da reta tangente específica em um ponto genérico do diagrama tensão-deformação. $\mathrm{O}$ módulo de deformação tangente na origem considera a inclinação da reta tangente na origem.

Módulo de deformação secante é o valor numérico da inclinação da reta secante do diagrama tensão-deformação do concreto, passando pelos pontos correspondentes à tensão de $0,5 \mathrm{MPa}$ e à $40 \%$ da tensão última.

A normalização americana $A S T M$ C-469-65 define o valor do módulo de deformação secante como o valor numérico da inclinação da reta secante ao diagrama tensão-deformação do concreto para compressão axial, passando pelos seus pontos correspondentes à origem do diagrama e à tensão para $40 \%$ do valor da carga última. Já o CEB-90 (1991) define como o valor numérico da inclinação da reta secante ao diagrama tensão-deformação do concreto, para compressão axial, passando pelos seus pontos correspondentes à origem do diagrama e ao de tensão de compressão média.

As expressões de normas e recomendações, em sua maioria, abrangem apenas o intervalo de resistências entre $20 \mathrm{MPa}$ e $40 \mathrm{MPa}$; para o uso dessas expressões em concretos de resistências maiores, devem ser feitas revisões e ajustes.

Aqui estão relacionadas algumas expressões:

- No CEB-90 (1991), os valores do módulo de deformação tangente na origem para concreto de densidade normal podem ser estimadosppela resistência característica:

$$
E_{c}=10^{4} \sqrt[3]{I_{c k}+8} \quad(M P a)
$$

E o módulo de deformação secante para análise elástica:

$$
E_{c s}=0,85 E_{c}=8500 \sqrt[3]{f_{c k}+8} \quad(M P a)
$$


- Na Norma Norueguesa NS 3473', apud FIP/CEB-197 (1990), uma expressão para a relação entre o módulo de deformação tangente e a resistência à compressão é, para $\mathrm{f}_{\mathrm{c}}<85 \mathrm{MPa}$ :

$$
E_{c}=9500\left(f_{c}\right)^{0,3} \quad(M P a)
$$

Nada é comentado sobre o módulo secante.

- No $A C I 318$ (1986), estima-se o módulo de deformação tangente na origem através da resistência característica do concreto aos 28 dias de idade:

$$
E_{c}=4730 \sqrt{f_{c}^{\prime}} \quad(M P a)
$$

Também não faz nenhuma abordagem sobre o módulo secante.

- Na NBR 6118 (1978), o módulo de deformação tangente na origem é expresso por:

$$
E_{c}=6600 \sqrt{E_{c j}} \quad(M P a)
$$

$\operatorname{com} \mathrm{f}_{\mathrm{cj}}=\mathrm{f}_{\mathrm{ck}}+3,5 \mathrm{MPa}$.

O módulo secante segundo a Norma Brasileira é determinado pela seguinte expressão:

$$
E_{C S}=0,9 E_{c}
$$

1 NORWEGIAN STANDARD. (1989). NS 3473 - Concrete structures, design rules. Oslo apud FIP/CEB Working Group on High Strength Concrete. (1990). High strength concrete: state of the art report. Bulletin d'Information, n.197, Aug, p.15. 
- CARRASQUILLO et al (1981) propõem a seguinte relação para o concreto de alta resistência para, apenas, o módulo tangente:

$$
E_{c}=3320 \sqrt{t_{c c}}+6900 \mathrm{MPa} \quad(M P a)
$$

para $21 \mathrm{MPa}<\mathrm{f}_{\mathrm{cc}}<83 \mathrm{MPa}$.

FERNANDES (1992) comenta que as previsões citadas anteriormente, feitas por normas e recomendações, comparadas com resultados obtidos experimentalmente, são muito otimistas quando se trata de concreto de alta resistência. A explicação para isso vem do fato de que a resistência do concreto é controlada pela resistência da pasta e da zona de transição pasta-agregado, já a rigidez do concreto depende tanto da rigidez da pasta como dos agregados. Melhorando a qualidade da pasta, a resistência do concreto cresce, porém a sua rigidez não cresce na mesma proporção.

Os resultados apresentam discordância com as afirmações encontradas na literatura, quando comparados com resultados previstos pelas expressões.

BERNHARDT et al, CARRASQUILLO et al (1981), HØISETH et al, TOMASZEWICZ et al concluiram em suas investigações que as expressões presentes no $A C I 318$ (1986) e no $C E B-90$ (1991) superestimam o módulo de deformação para concretos com resistências à compressão acima de $40 \mathrm{MPa}$.

No Brasil, houve uma unanimidade. Apesar do pequeno número de dados experimentais, AGOSTINI (1992), FERNANDES (1992) e PINTO JR (1992) obtiveram pela NBR 6118 (1978) valores maiores que os encontrados experimentalmente em concreto de alta resistência. Eles também concordaram que a estimativa que melhor se aproximava dos resultados de ensaios foi óbtida conforme o CEB-90 (1991).

PINTO JR (1992) acrescenta que a obtenção experimental do módulo de deformação longitudinal secante à $40 \%$ da tensão máxima ficou melhor representada pela proposta da $N B R 6118(1978), \mathrm{E}_{\mathrm{cs}}=0,9 \mathrm{E}_{\mathrm{c}}$, não se devendo, no entanto, tirar conclusões definitivas. 


\subsection{COEFICIENTE de POISSON}

O coeficiente de Poisson é, na faixa elástica, a relação entre a deformação transversal e a longitudinal quando uma peça está submetida à compressão axial.

$\mathrm{Na}$ literatura, por possuir dados experimentais muito limitados para o concreto de alta resistência, pode-se observar uma divergência entre os pesquisadores sobre a relação entre as características do concreto e o coeficiente de Poisson. CARRASQUILLO et al (1982), KAPLAN (1959), MEHTA (1982) e SHIDELER (1957) obtiveram valores do coeficiente sem que, para eles, houvesse nenhuma relação entre o teor de umidade, nível de resistência, idade, tipo de agregado e o coeficiente de Poisson. Por outro lado, PERENCHIO \& KLIEGER (1978) concluíram que o coeficiente de Poisson tende a diminuir com o acréscimo do fator água/cimento. E, ainda, segundo $A H M A D \& S H A H$ (1987), o valor do coeficiente de Poisson depende do nivel de tensões considerado.

O coeficiente de Poisson, no limite elástico, é comparável com a variação esperada de valores para concretos de baixa resistência, aproximadamente de 0,18 a 0,24 . Na faixa inelástica, o acréscimo relativo nas deformações laterais é menor para concreto de alta resistência devido a menor microfissuração. $O$ intervalo variando de 0,17 a 0,24 foi obtido em ensaios realizados na UNICAMP por PINTO JR (1992).

\subsection{COMPORTAMENTO NA TRAÇÃO}

\section{1}

Mesmo que a resistência à tração do concreto seja negligenciada para a resistência de estruturas de concreto armado e protendido, em geral, é uma característica importante para o desenvolvimento da fissura e, portanto, para a estimativa de deformações e da durabilidade do concreto. Outras características tais como aderência e o comprimento de ancoragem da armadura estão estreitamente relacionadas à resistência à tração do concreto. 
Segundo CHEN ${ }^{1}$ apud PINTO JR (1992), existem algumas diferenças entre o diagrama tensão-deformação do concreto submetido à tração axial e o submetido à compressão axial.

Para níveis de tensão abaixo de $60 \%$ da resistência à tração axial, o surgimento de novas microfissuras é desprezível (limite de elasticidade). Acima de $60 \%$, existe uma propagação das microfissuras de aderência.

No estado de tração axial, o intervalo de propagação estável de fissuras é curto, por causa da tendência das fissuras serem menos frequentes que na compressão. A cerca de $75 \%$ da resistência à tração axial inicia-se a propagação instável de fissuras.

PINTO JR (1992) cita a explicação de CHEN para o comportamento frágil da ruptura dos concretos em ensaios de tração axial:

"A direção de propagação da fissura na tração axial é transversal à direção das tensões. $O$ inicio e a propagação de qualquer nova fissura reduzirá a área disponivel carregada, o que causa um aumento das tensões criticas nas extremidades da fissura.

A diminuição da quantidade de fissuras é explicada pelo fato da ruptura na tração ser causada por poucas fissuras de ligação (aquelas que se propagam no interior da argamassa), ao contrário do que ocorre nos estados de tensões de compressão onde essas fissuras são numerosas.

Como consequência da rápida propagação das fissuras, é dificil acompanhar a parte descendente da curva tensão-deformação durante o ensaio." (PINTO JR, 1992, p.2.23)

A resistência à tração geralmente aumenta com a resistência à compressão. Entretanto, o aumento não é de forma diretamente proporcional.

O ensaio de tração axial utilizado para determinar a resistência à tração dos concretos é raramente empregado, já que os dispositivos que fixam o forpo de prova introduzem tensões secundárias que têm de ser consideradas.

Geralmente, utiliza-se o ensaio de compressão diametral para avaliar a resistência à tração. Este ensaio consiste de um corpo de prova cilíndrico que está

1 CHEN. W.F. (1982). Plasticity in reinforced concrete. New York, McGraw-Hill apud PINTO JR., N.O. (1992). Flexão de vigas de concreto de alta resistência. São Paulo. 2v. Tese (doutorado) - Escola Politécnica da Universidade de São Paulo, p.2.21. 
sujeito ao carregamento de compressão ao longo de duas linhas diametralmente opostas, como mostra a figura 3.5 .

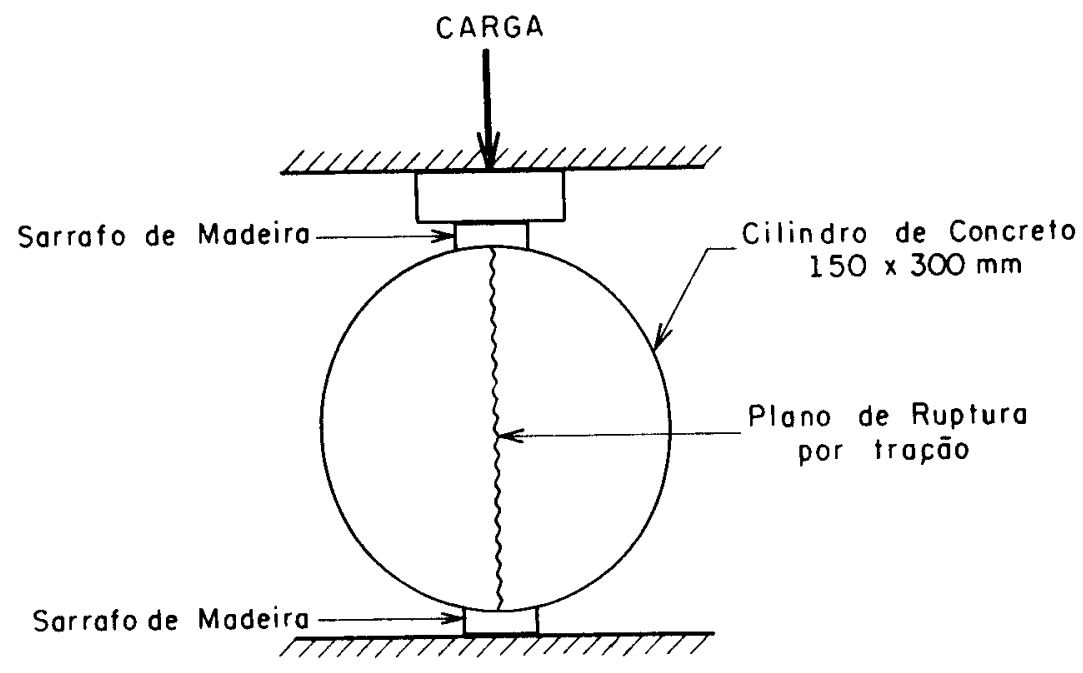

FIGURA 3.5 - Ensaio de compressão diametral.

Ao longo do diâmetro vertical, as tensões de compressão causam tensões transversais de tração. Na figura 3.6 está representada a distribuição das tensões transversais ao longo do diâmetro carregado.

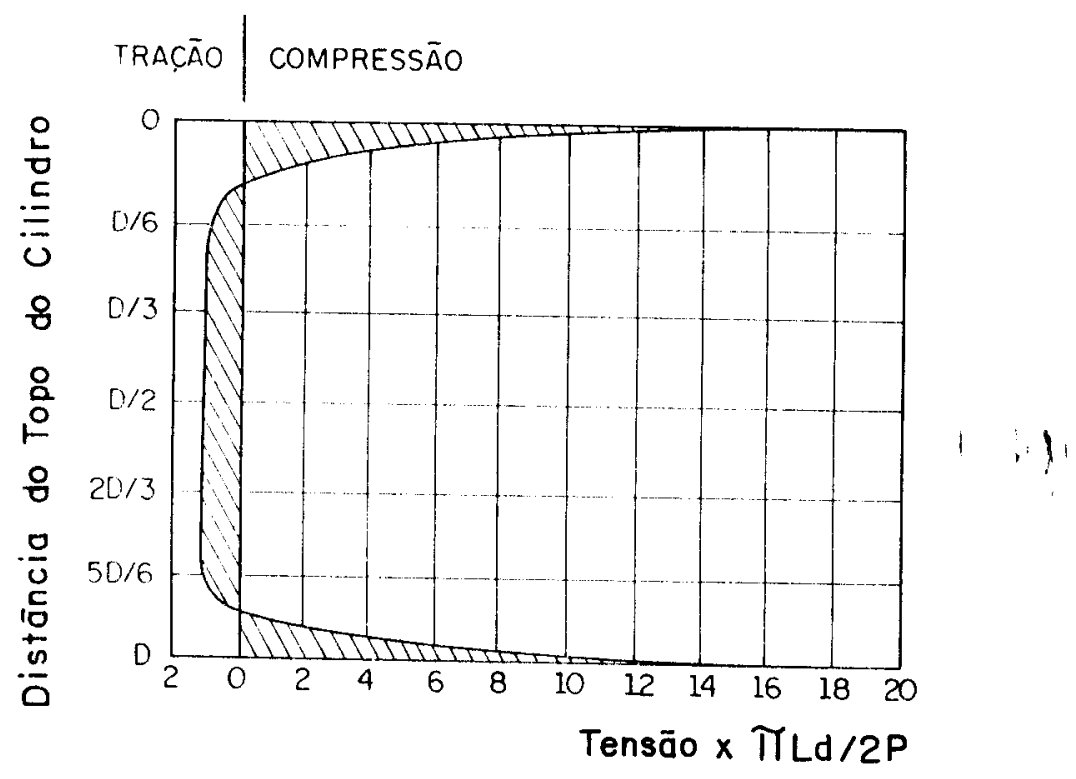

FIGURA 3.6 - Distribuição das tensões de tração. 
A resistência à tração do concreto é calculada pela equação:

$$
f_{t}=\frac{2 \cdot P}{\pi \cdot \ell \cdot d}
$$

onde $P$ é a carga de ruptura, $\ell$ é o comprimento do cilindro e $d$ o seu diâmetro.

Outro ensaio bastante utilizado para quantificar a resistência à tração é o ensaio de tração na flexão, onde um prisma sofre carregamento como mostra o esquema da figura 3.7.

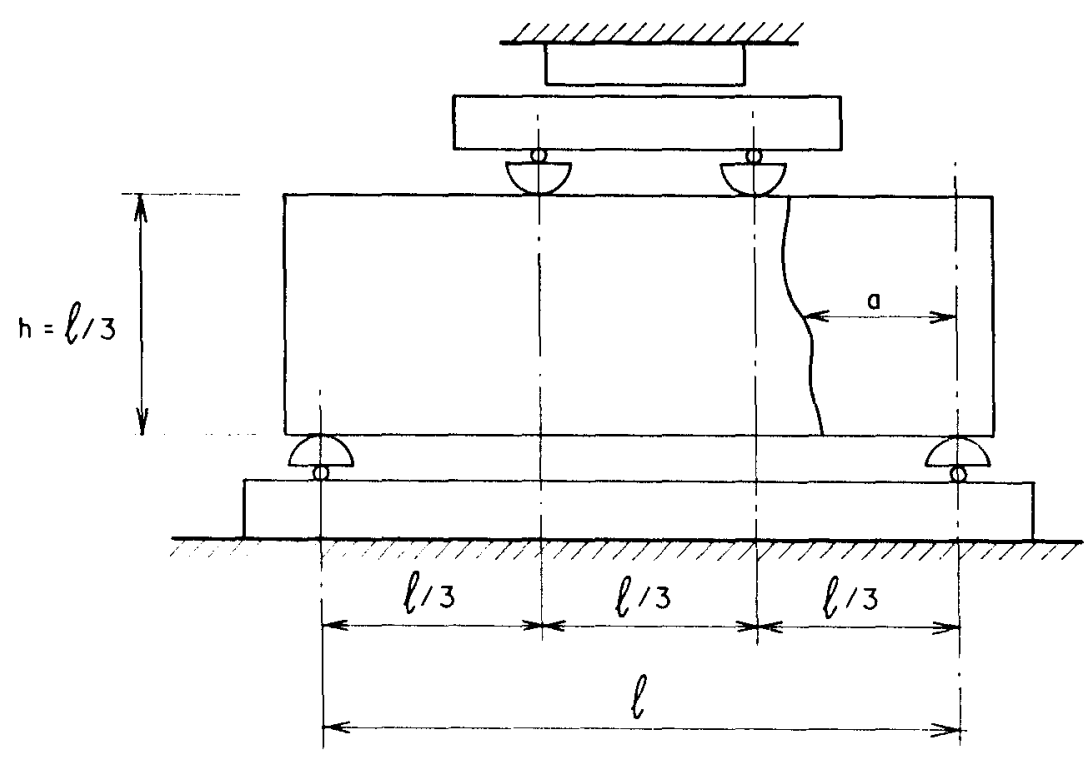

FIGURA 3.7 - Ensaio de tração na flexão

A resistência à flexão correspondente à máxima tensão na ruptura é calculada por:

$$
f_{t}=\frac{P \cdot \ell}{b \cdot h^{2}} \quad \text { para } \ell / 3<a<2 \cdot \ell / 3
$$

onde $l$ é a carga que produz a ruptura, $\ell$ é o comprimento do vão, $b$ a largura do prisma, $h$ a altura e $a$ a distância média entre o plano de ruptura e o apoio mais próximo da viga. 
Se $a$ estiver fora do terço médio, mas estiver a uma distância $a>0,28 \ell$, emprega-se:

$$
f_{t}=\frac{3 \cdot P \cdot a}{b \cdot h^{2}}
$$

Para $a<0,28 \ell$, o resultado do ensaio deverá ser desprezado.

Os estudos citados pelo $A C I 363$ (1992) concluíram que, para concreto com baixa resistência, a resistência à tração na compressão diametral pode chegar a $10 \%$ da resistência à compressão, mas para resistências maiores (acima de $84 \mathrm{MPa}$ ) pode ser reduzido para $5 \%$. A resistência à tração na compressão diametral observada era aproximadamente $8 \%$ maior para concreto feito de agregado britado do que feito de seixo rolado. Além disso, a resistência à compressão diametral era em torno de $70 \%$ da resistência à flexão em 28 dias.

A resistência à tração na compressão diametral corresponde a $7 \%$ da resistência à compressão em concreto de alta resistência utilizado no estudo experimental de FERNANDES (1992).

CARRASQUILLO et al (1982) comentam que a resistência à tração dos concretos de alta resistência na compressão diametral segue aproximadamente a mesma lei de variação para concretos usuais.

O ACI 363 (1984) declara que o módulo de ruptura é aproximadamente 1,4 a 1,6 vezes a resistência à tração na compressão diametral, para concreto de alta e de baixa resistência.

PINTO JR (1992) declara que os resultados do ensaio de flexão superestimam a resistência à tração em 50 a 100\%, comparando com resistência obtida em ensaios de tração axial. Ele cita que o motivo disso é que a hipótese assumida de distribuição linear de tensões ao longo da seção transversal pode não ser verdadeira no instante da ruptura.

MEHTA \& GJORV (1982) comentam algumas relações entre os resultados obtidos de ensaios. A resistência à tração de um ensaio de compressão diametral é de 10 a $15 \%$ maior que a resistência encontrada num ensaio de tração axial. Outra comparação é a relação entre a tensão de tração na flexão e a tensão de tração axial 
que, segundo ele, varia com a qualidade do concreto, chegando a ser $100 \%$ maior nos concretos de baixa resistência, $70 \%$ maior nos de média resistência e entre 50 e $60 \%$ maior nos concretos de alta resistência. $\mathrm{E}$, ainda, comenta que a relação entre as resistências à tração axial e à compressão se situa entre 10 e $11 \%$ para concretos de baixa resistência, 8 e $9 \%$ para os de média e por volta de $7 \%$ para os de alta resistência.

A eq. 3.11 para estimativa da resistência à tração nos ensaios de compressão diametral para concreto com corpos de prova cilíndricos de $100 \times 200 \mathrm{~mm}$ é recomendada por CARRASQUILLO et al (1982):

$$
f_{c t k}=0,54 \sqrt{f_{c k}} \quad(M P a) \text { desde que } 21 M P a<f_{c k}<83 M P a
$$

e para ensaio em flexão simples, para prismas de $100 \times 100 \times 350 \mathrm{~mm}$ :

$$
f_{c t k}=0,94 \sqrt{t_{c k}} \quad(M P a) \text { desde que } 21 M P a<f_{c k}<83 M P a
$$

A resistência média à tração na compressão diametral depende das condições de cura da amostra; por exemplo, com cura em água se obtém menor resistência à tração. [FII/CEB $197(1990)]$.

Na Norma Norueguesa NS 3473 (1989), a resistência à tração axial é usada no lugar da resistência à tração na compressão diametral do concreto. A resistência à tração axial assume valores por volta de $2 / 3$ da resistência à tração na compressão diametral. A seguinte equação aproximada é usada para o cálculo da resistência à tração axial característica:

$$
f_{c t k}=0,3\left(f_{c k}\right)^{0,6}(\mathrm{MPa}) \text { válida para } f_{c k} \leq 105 \mathrm{MPd}
$$

A eq. (3.13) é base para o cálculo da resistência à tração na Norma Nornegucsa. A resistência à tração não aumenta para resistência à compressão cúbica acima de $75 \mathrm{MPa}$.

O CEB-90 (1991) relaciona a resistência média do concreto à tração axial com a resistência característica à compressão conforme se indica na expressão: 


$$
f_{c t m}=0,30\left(f_{c k}\right)^{2 / 3}(\mathrm{MPa}) \text { para } f_{c k} \leq 80 \mathrm{MPa}
$$

A Norma Brasileira NBR 6118 (1978) propõe para os concretos com resistência superior a $18 \mathrm{MPa}$ a seguinte correlação:

$$
f_{c t k}=0,06 f_{c k}+0,7 \quad(M P a)
$$

FERNANDES (1992), em seu trabalho de pesquisa, analisou corpos de prova cilíndricos submetidos à compressão diametral. Com resultados experimentais, ele pôde concluir que, quando estes resultados foram comparados aos que seriam previstos pelas expressões, mostraram boa concordância entre as propostas para resistências até $50 \mathrm{MPa}$. Para resistências superiores, os dados experimentais se ajustaram melhor às propostas de CARRASQUILLO et al e à Norma Norueguesa. E que a proposta da $N B R 6118$, modificada, pode se aproximar das anteriores para resistências mais altas.

PINTO JR (1992) verificou em seus ensaios que, em média, as relações entre as resistências à tração e à compressão se situavam ao redor de $6 \%$ na compressão diametral e 10\% na tração por flexão. As resistências à tração na compressão diametral ficam bem representadas pela equação proposta por CARRASQUILLO et al. A resistência à tração axial, dentro da faixa considerada, ficou melhor avaliada pela equação proposta pela Norma Norueguesa.

O valor 0,70 utilizado para determinar a tensão de cálculo $\left(\sigma_{\mathrm{cd}}\right)$ no dimensionamento de estruturas, sugerido por PINTO JR (1992), substitui o valor 0,85 usado no concreto de resistência usual, assume uma perda de resístêncìa menor $(0,8$ em vez de 0,75$)$ que para o concreto usual, considera o crescimento da resistência, após 28 dias, pouco significativo e leva em conta a tendência em adotar o cilindro de $100 \times 200 \mathrm{~mm}$ em lugar do cilindro padrão. Deve-se ressaltar que, para a adoção deste coeficiente, devem ser executadas novas pesquisas para que o mesmo seja confirmado. 
A forma do diagrama tensão-deformação do concreto é determinada pela progressão da microfissuração interna durante a aplicação do carregamento. Comparando com o diagrama tensão-deformação do concreto de resistência usual, a forma do diagrama para o concreto de alta resistência é mais linear, com deformação ligeiramente maior para tensão máxima e mais íngreme na parte descendente da curva, caracterizando a ruptura de maneira frágil, após ser alcançada a tensão máxima.

O módulo de deformação longitudinal do concreto de alta resistência é maior que os apresentados pelos concretos usuais, sendo que o crescimento não ocorre de maneira proporcional. Ensaios realizados no Brasil obtiveram melhores estimativas com o uso da equação do CEB-90 (1991).

O intervalo de variação do coeficiente de Poisson de acordo com a literatura adotada, no limite elástico, para o concreto de alta resistência, é comparável ao do concreto de baixa resistência, variando de 0,18 a 0,24 .

As resistências à tração na compressão diametral ficam bem representadas pela equação proposta por CARRASQUILLO et al, de acordo com ensaios realizados por FERNANDES (1992) e PINTO JR (1992) para resistências à compressão acima de $50 \mathrm{MPa}$. 


\section{PILARES}

Os pilares, na prática, não estão sujeitos a ações verdadeiramente axiais. Momentos fletores, devidos à aplicação de ações excêntricas, relacionadas com o monolitismo da estrutura, estão geralmente associadas às ações axiais. Entretanto, é interessante, à primeira vista, analisar o comportamento de pilares submetidos apenas a ação axial.

\subsection{CONTRIBUIÇÃO DAS RESISTÊNCIAS DO AÇO E DO CONCRETO}

No concreto de alta resistência, a curva tensão-deformação é mais linear e a deformação correspondente à tensão máxima é maior, comparada com o concreto de baixa resistência

A resistência última é a característica de principal interesse no cálculo de pilares de concreto. A prática atual de projeto, no cálculo da resistência característica de uma peça carregada axialmente, é assumir uma adição das resistênçị̧ do concreto e do aço.

A justificativa para isso é vista na figura 4.1, retirada do $A C I 363$ (1992), que mostra curvas típicas de tensão-deformação de concretos com diferentes níveis de resistência à compressão, com os quais a armadura tem uma resistência de escoamento de $414 \mathrm{MPa}$ (a curva relativa ao aço é desenhada numa escala vertical diferente, por conveniência). A hipótese comum considera as deformações do 
concreto e do aço idênticas, em qualquer estágio de carregamento, antes que a capacidade máxima do concreto seja alcançada.

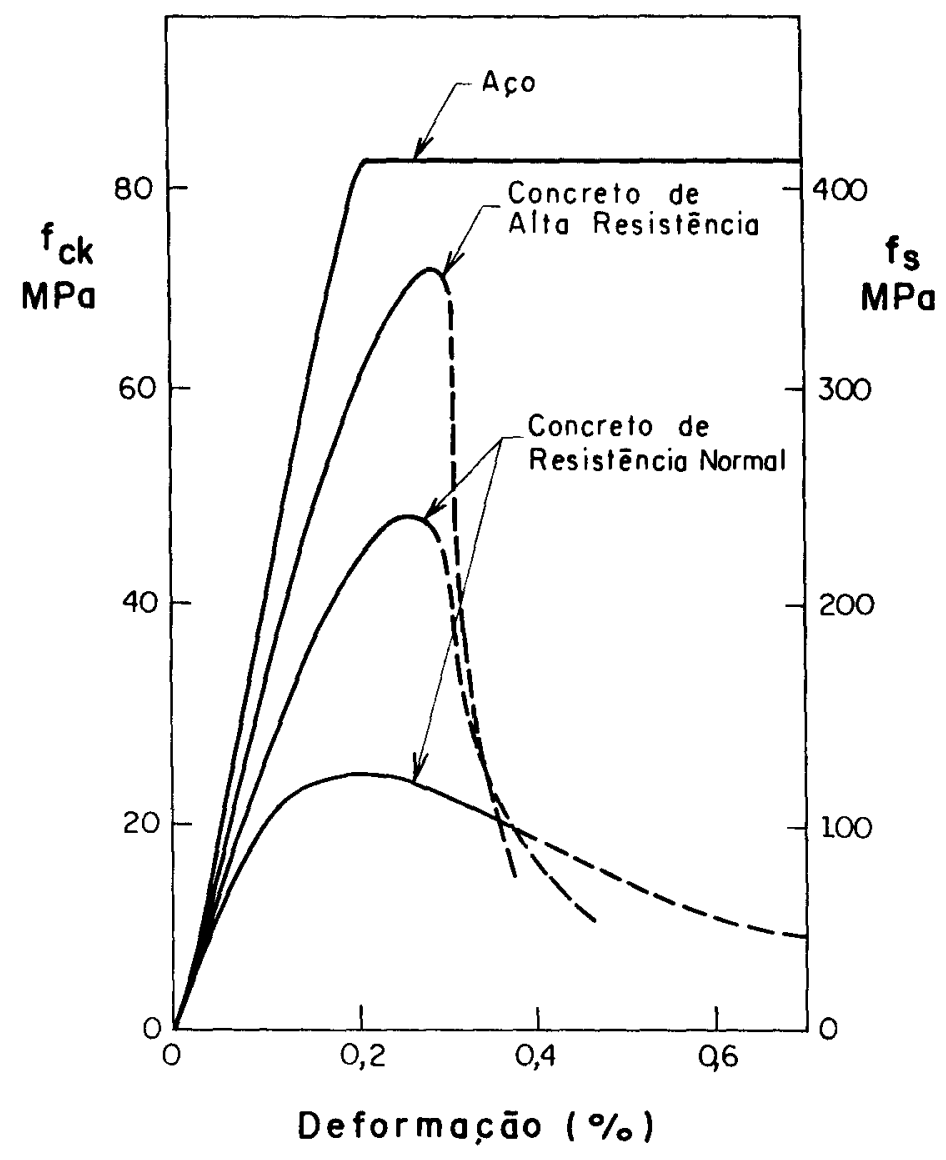

FIGURA 4.1 - Curvas tensão-deformação do aço e do concreto. FONTE: ACI 363 (1992).

Nos concretos de baixa resistência, o comportamento do limite elástico do diagrama tensão-deformação começa a se pronunciar por voltá le $0,1 \%$ de deformação. E em $0,2 \%$ de deformação, a inclinação da curva se aproxima de zero e pode se supor uma deformação plástica com pequeno ou nenhum acréscimo de tensão.

Quando o concreto alcança o limite elástico, o aço ainda não entrou em escoamento e é capaz de absorver maior parte das ações. A variação, em geral, da tensão de escoamento de uma armadura comum é de 400 a $500 \mathrm{MPa}$. A armadura, então, começa a escoar em torno do mesmo nível de deformação em que o concreto 
alcança sua resistência máxima. Desta forma, o concreto está na sua tensão máxima, o aço está na tensão de escoamento $f_{y}$ e a resistência do pilar é estimada por:

$$
P=0,85 f_{c} A_{c}+f_{y} A_{s}
$$

onde:

$\mathrm{f}_{\mathrm{c}}$ resistência à compressão do concreto

$f_{y} \quad$ resistência de escoamento do aço

$A_{c} \quad$ área da seção transversal de concreto

$\mathrm{A}_{\mathrm{s}} \quad$ área de aço

O fator 0,85 é usado para justificar a diferença observada na resistência do concreto usual nos pilares, comparada com o concreto de mesma mistura nos ensaios de compressão com cilindro padrão.

Uma análise semelhante envolve os pilares de concreto de alta resistência, com exceção do aço que escoará antes que o concreto alcance sua resistência máxima. Entretanto, o aço continuará a escoar a uma tensão praticamente constante, antes que ocorra a ruptura completa do concreto. A previsão da resistência pode continuar baseada na eq. (4.1). Resultados experimentais, citados no ACI 363 (1992), também apóiam o uso do fator 0,85 para concreto de alta resistência.

A armadura com deformação de escoamento maior que a deformação máxima do concreto, geralmente não pode ser utilizada, porque os pilares rompem imediatamente depois que a deformą̧ão última é alcançada, além de ser antieconômico, pois não há um bom aproveitamento da armadura

\subsection{EFEITO DO CONFINAMENTO DA ARMADURA}

A armadura transversal em pilares, preferivelmente na forma helicoidal, tem dois beneficios no comportamento de pilares: (a) aumenta muito a resistência do núcleo do concreto, confinando-o contra expansão lateral, que é proveniente do efeito de Poisson quando está sob ação do carregamento e (b) aumenta a capacidade de 
deformação axial do concreto, permitindo uma ruptura mais gradual e dúctil. Segundo o FIP/CEB- 197 (1990), as armaduras helicoidais são mais eficazes no confinamento do núcleo que estribos quadrados ou retangulares.

Com o aumento da capacidade de carga, o concreto do pilar cintado apresenta uma deformação muito grande que chega a valer aproximadamente 10 vezes a deformação máxima de um pilar não cintado. 0 cobrimento de concreto situado fora da armadura helicoidal não pode suportar deformações tão grandes e se rompe antes de alcançar a carga máxima. Por este motivo, para o cálculo da carga de ruptura, considera-se a seção do núcleo confinado como seção resistente de concreto.

A base para cálculo da armadura helicoidal, antes de 1977 e em versões posteriores do $A C I 318$, é o efeito de fortalecimento dado pela armadura, que deve ser, no mínimo, igual à resistência desprendida do pilar, quando o revestimento de concreto, externo à armadura, se rompe sob ação do carregamento. A equação do $A C I$ 318 para a taxa (volumétrica) mínima de armadura helicoidal é:

$$
\rho_{s}=0,45\left(\frac{A_{g}}{A_{c}}-1\right) \frac{f_{c}}{f_{y}}
$$

onde

$\rho_{\mathrm{s}} \quad$ taxa (volumétrica) de armadura helicoidal para o volume do núcleo de concreto

$A_{g} \quad$ área bruta da seção do concreto

$A_{c} \quad$ área da seção do núcleo de concreto

$f_{c}$ resistência à compressão do concreto

$f_{y} \quad$ resistência de escoamento da armadura helicoidal

O aumento de resistência à compressão de pilares, fornecido pela armadura helicoidal, é baseado numa relação obtida experimentalmente para o ganho de resistência, dado por:

$$
\Delta f_{1 c}=4,0 f_{2}^{\prime}
$$


onde:

$\Delta \mathrm{f}_{\mathrm{lc}} \quad$ acréscimo da resistência à compressão do pilar de concreto;

$\mathrm{f}_{2}^{\prime} \quad$ tensão (idealizada) de confinamento do concreto produzido pela armadura helicoidal.

$O$ 'fator de confinamento' 4,0 é determinado por investigações experimentais, sendo que este valor pode ser reduzido; 3,0 é o valor encontrado por BJERKELI et al (1990), para concretos com resistência à compressão cilíndrica acima de $80 \mathrm{MPa}$. $K O N G$ (1983) propôs 3,0, também, baseado em ensaios triaxiais usando a pressão da água como força de confinamento. A proposta de $K O N G$ (1983) foi confirmada pelos ensaios descritos por JENSEN \& BJERKELI' apud FIP/CEB-197 (1990), que também utilizaram pressão de água como força de confinamento.

A tensão de confinamento do concreto produzida pela armadura helicoidal $f_{2}^{\prime}$ é calculada considerando que o aço da armadura escoou, usando a equação de tração en tubo de parede fina

$$
2 A_{s p} f_{y}=f_{2}^{\prime} d_{c} s \quad \text { ou } \quad f_{2}^{\prime}=\frac{2 A_{s p} f_{y}}{d_{c} s}
$$

onde, além das grandezas já definidas, têm-se:

$A_{\mathrm{sp}} \quad$ área da seção transversal da armadura helicoidal;

$\mathrm{d}_{\mathrm{c}} \quad$ diâmetro do núcleo de concreto;

$\mathrm{s}$ passo da armadura helicoidal.

Trabalhos realizados por AHMAD \& SHAH (1982), BJERKELL, et al (1990), DAL BUSCO (1988) e MARTINEZ et al (1984) mostram que à pressão de confinamento lateral, causada pela armadura helicoidal ou estribos, tem efeito menor no acréscimo da tensão última do concreto e nas deformações de núcleos de pilares

IENSEN, IIJ; BIERKELI, L. Effect of water pressure on concrete structures. Water ahsorption, static strength and strain development tests. SINTEF report STF65A90006a apud FIP/CEB Working Group on High Strength Concrete. (1990). High strength concrete: state of the art report. Bulletin d'Information, n.197, Aug, p.38. 
de concreto de alta resistência, comparado com o de baixa resistência. $A H M A D \&$ SHAH (1982) também descobriram que a tensão na armadura helicoidal sujeita à ação máxima em pilares de concreto de alta resistência é sempre significativamente menor que a tensão de escoamento suposta na eq. (4.2).

Estas conclusões são compatíveis com os resultados de pesquisas experimentais da Universidade de Cornell, realizadas por MARTINEZ et al (1984). $\mathrm{Na}$ pesquisa de Cornell, uma tensão de confinamento "efetiva" $f_{2}\left(1-s / d_{c}\right)$ foi usada na avaliação dos resultados, onde $\mathrm{f}_{2}$ é a tensão de confinamento do concreto, calculada usando a tensão real da armadura helicoidal, sempre menor que $f_{y} . O$ termo $\left(1-s / d_{c}\right)$ reflete a redução na eficácia das espiras associadas com o aumento de espaçamento entre os fios da armadura helicoidal. Assim, uma versão aperfeiçoada da eq. (4.3a) é:

$$
\Delta f_{1 c}=4,0 f_{2}\left(1-s / d_{c}\right)
$$

Segundo o ACI 363 (1992), do ponto de vista de resistência, a atual equação do $A C I 318$, para a taxa mínima da armadura helicoidal, pode ser usada seguramente em pilares de alta resistência, tão bem quanto para pilares de concreto de baixa resistência.

Os resultados de BJERKELI et al (1990) e MARTINEZ et al (1984) mostram que, nos pilares cintados, a deformação, correspondente à tensão última, decresce e a inclinação do trecho descendente da curva tensão-deformação aumenta com o acréscimo da resistência do concreto. As curvas tensão-deformação registradas para pilares circulares com 3,1\% de armadura helicoidal e nenhum cobrimento de concreto estão apresentados na figura 4.2. As tensões e deformações apresentadạs são relativas às tensões últimas e deformações correspondentes de pilares não-armádos.

Pode-se concluir que pilares de concreto de alta resistência exigem uma quantidade consideravelmente maior de armadura de confinamento para se obter o mesmo comportamento dúctil verificado em concreto de baixa resistência.

BJERKELI et al (1990) ensaiaram pilares e observaram que o cobrimento de concreto $(20 \mathrm{~mm})$ rompeu a um nível de deformação correspondente à tensão última do concreto. $\mathrm{O}$ rompimento ocorreu repentinamente, mas foi anunciado por um ruido, 
quando se desenvolveram as pequenas fissuras, em torno de 85 a $90 \%$ da carga de rompimento do cobrimento.

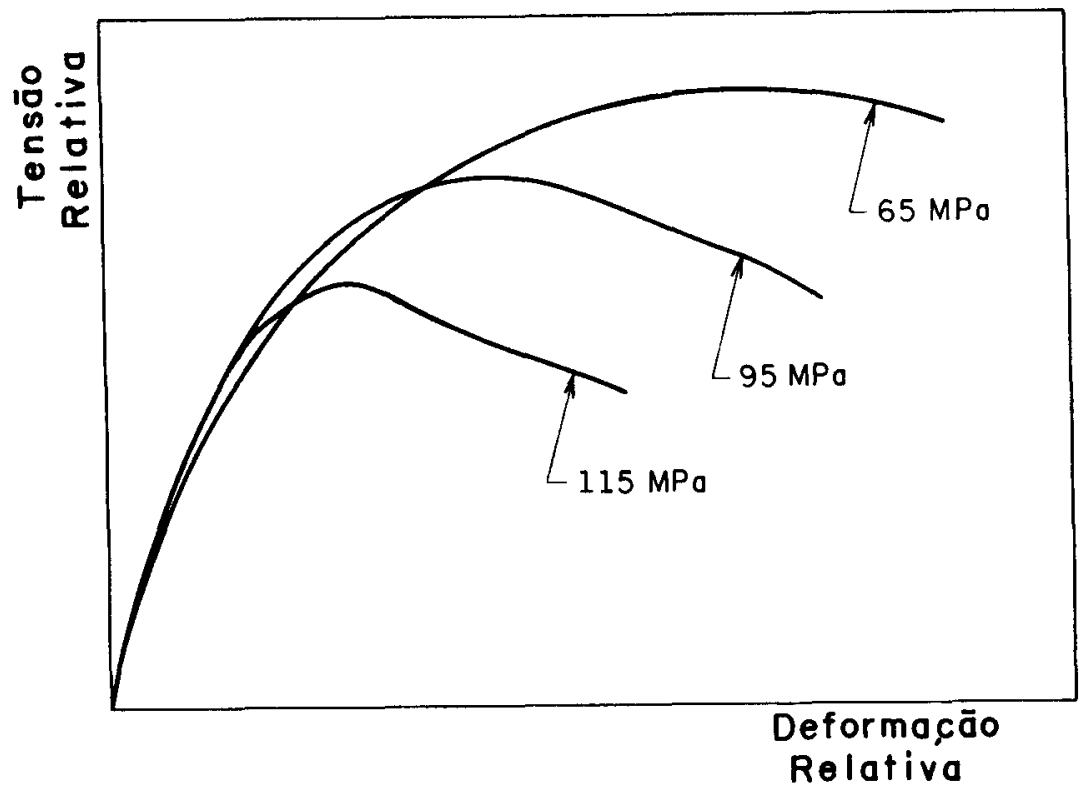

FIGURA 4.2 - Curvas experimentais de tensão-deformação de pilares com armadura helicoidal, mostrando o efeito da resistência do concreto na ductilidade. FONTE: FIP/CEB-197 (1990).

Por ser a maioria dos modelos baseada num número limitado de resultados de ensaios, há uma necessidade de executar ensaios mais gerais. A partir desses modelos, se usariam os resultados dos ensaios para analisar a influência de parâmetros no comportamento do concreto confinado. São exemplos dos tais parâmetros: dimensões e características geométricas das amostras, taxa, resistência e espaçamento da armadura de confinamento, distribuição da armadura longitudinal e o valor da resistência do concreto.

\subsection{PESQUISAS EXPERIMENTAIS}

A influência da característica geométrica da seção e da taxa de armadura de confinamento no comportamento do diagrama tensão-deformação de pilares 
concreto de alta resistência (com resistência cúbica de $95 \mathrm{MPa}$ aos 28 dias) estão ilustradas na figura 4.3 e foram analisadas por BJERKELI et al (1990). São comparadas as curvas tensão-deformação de pilares circulares (figura 4.3a) e de pilares quadrados (figura 4.3b), com a mesma dimensão da seção transversal (150 $\mathrm{mm}$ ). Os pilares foram concretados sem cobrimento para as armaduras. As tensões e deformações dos pilares, com $1,1 \%$ e $3,1 \%$ de taxa de armadura de confinamento, são apresentadas e comparadas com as tensões últimas e deformações correspondentes de pilares não-armados. Pode se concluir com a figura 4.3 que o acréscimo da taxa de armadura de confinamento aumentará as tensões últimas e as deformações correspondentes e reduzirá a inclinação da parte descendente da curva tensãodeformação. As magnitudes dessas melhorias são, entretanto, dependentes fortemente da seção geométrica. $\mathrm{O}$ aumento da resistência é primeiramente influenciado por uma elevada taxa de armadura de confinamento.

Não há ainda uma concordância geral da eficácia da armadura helicoidal para aperfeiçoar a ductilidade de pilares de concreto de alta resistência, isto é, para aumentar a deformação limite e o achatamento da parte descendente do diagrama tensão-deformação depois do ponto de tensão máxima. Um relatório de $A H M A D \&$ SHAH (1982) indica que o confinamento de armaduras helicoidais é tão eficaz no achatamento da parte descendente da curva para pilares de concreto de alta resistência como para pilares de concreto de baixa resistência.

Entretanto, o trabalho da Universidade de Cornell, realizado por MARTINEZ et al (1984) mostrou significantes diferenças. Foram feitas curvas experimentais de tensão-deformação para diferentes níveis de resistência de pilares de concreto, variando a armadura helicoidal. E se observou que, para $\phi$ concreto de alta resistência, além de a deformação correspondente à tensão máxima ser muito menor, a tensão cai bruscamente, logo após o valor máximo.

Baseado em evidências, pode-se concluir que pilares de concreto de alta resistência com armadura de confinamento helicoidal apresentam ganho de resistência, como é previsto pelas equações, mas suas propriedades depois da tensão máxima podem ser deficientes se comparadas com pilares de baixa resistência. 


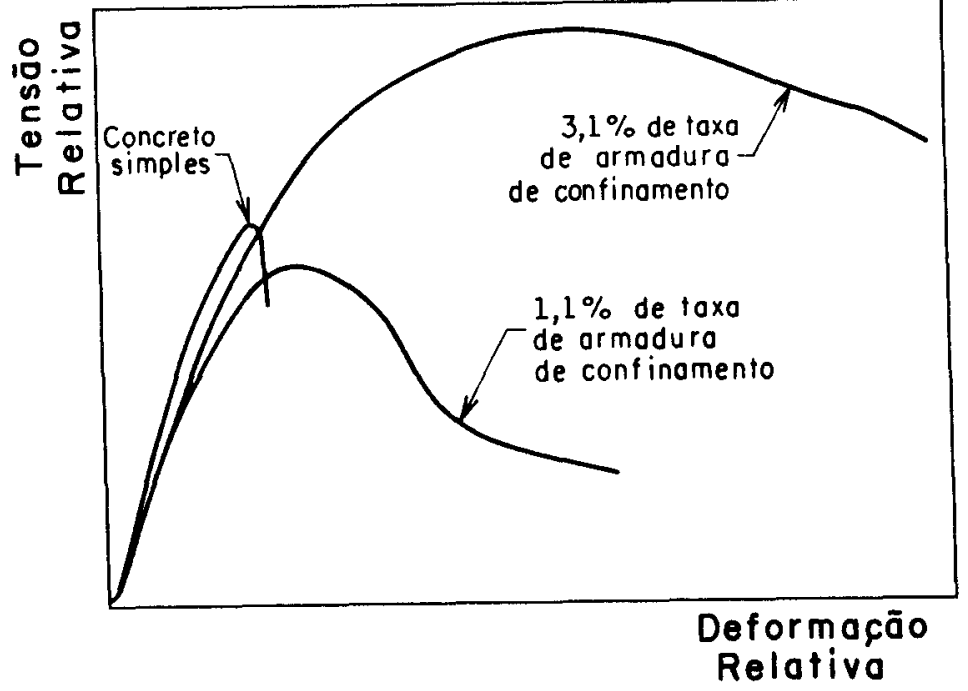

(a) Pilares circulares com resistência cúbica de $95 \mathrm{MPa}$.

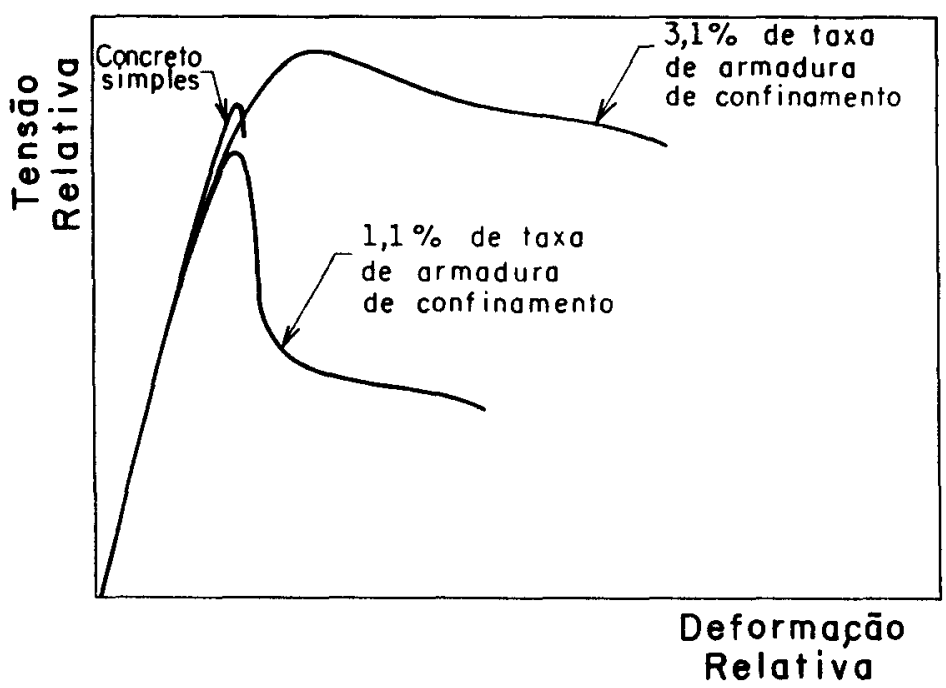

(b) Pilares quadrados com resistência cúbica de $95 \mathrm{MPa}$.

FIGURA 4.3 - Efeito da taxa de armadura e da seção geométrica na ductilidade de pilares de concreto de alta resistência. FONTE: FIP/CEB-197 (1990).

Uma outra observação interessante e importante, no que se refere a pilares com armaduras helicoidais, é que, geralmente, o nível da tensão de confinamento correspondente a armaduras calculadas pelo $A C I 318$ é um pouco baixo para todos os pilares. 
TABELA 4.1 - Tensões de confinamento produzidas por armaduras helicoidais calculadas pelo $\mathrm{ACI} 318$.

\begin{tabular}{|c|c|c|c|c|}
\hline $\begin{array}{c}d_{c} \\
(\mathbf{m m})\end{array}$ & $\mathbf{A}_{\mathrm{g}} / \mathbf{A}_{\mathrm{c}}$ & $\rho_{\mathbf{s}}$ & $\begin{array}{c}f_{2}\left(1-s / d_{c}\right) \\
(M P a)\end{array}$ & $\begin{array}{c}\mathrm{s} \\
(\mathrm{mm})\end{array}$ \\
\hline \multicolumn{5}{|c|}{ tipo de barra da armadura helicoidal: $\# 3^{*}$} \\
\hline 381 & 1,44 & 0,0099 & 1,64 & 75 \\
\hline 1270 & 1,12 & 0,0028 & 0,57 & 81 \\
\hline \multicolumn{5}{|c|}{ tipo de barra da armadura helicoidal: $\# 5^{*}$} \\
\hline 381 & 1,44 & 0,0330 & 5,69 & 64 \\
\hline 1270 & 1,12 & 0,0093 & 1,81 & 68 \\
\hline
\end{tabular}

" NOTAÇÃO ADOTA PELO ACI 318.

A tensão de confinamento se torna significativamente menor para pilares de diâmetro maior, assumindo que as especificações para cobrimento permanecem constantes, seguindo diretamente a eq. (4.2). Para pilares mais largos, a razão $A_{g} / A_{c}$ se torna menor, consequentemente, a taxa de armadura helicoidal exigida se torna menor e a tensão de confinamento efetiva se torna proporcionalmente menor. Estão na tabela 4.1 as tensões de confinamento produzidas pelas armaduras helicoidais calculadas pelo $A C I 318$ para concretos de baixa e alta resistências, para diâmetros dos núcleos de pilares de 381 e $1270 \mathrm{~mm}$.

Os ensaios mostram que, para o concreto de baixa resistência, a redução na tensão de confinamento de 1,64 para $0,57 \mathrm{MPa}$, obtida por meio do $A C I 318$, produzirá um pilar com uma capacidade muito grande de deformação sem perda significante de resistência. Para o concreto de alta resistência, a reduçâo da tensão de confinamento de 5,69 para 1,81 MPa produz um pilar sem, verdadeiramente, nenhuma capacidade de deformação depois do pico. Mesmo a maior tensão de confinamento 5,69 MPa produz um pilar com a desvantagem de queda brusca de resistência imediatamente depois da tensão de pico, segundo MARTINEZ et al (1984). 
CUSSON \& PAULTRE (1994) ensaiaram pilares de concreto de alta resistência confinados com estribos retangulares, solicitados à compressão axial, e chegaram às seguintes conclusões:

a) Apenas a área do núcleo de concreto, delimitada pelas armaduras, deve ser considerada no cálculo da resistência à compressão axial de pilares de concreto de alta resistência. Isso devido ao comportamento dos pilares de concreto de alta resistência ser caracterizado pelo rompimento brusco do cobrimento de concreto que resulta numa perda da capacidade axial.

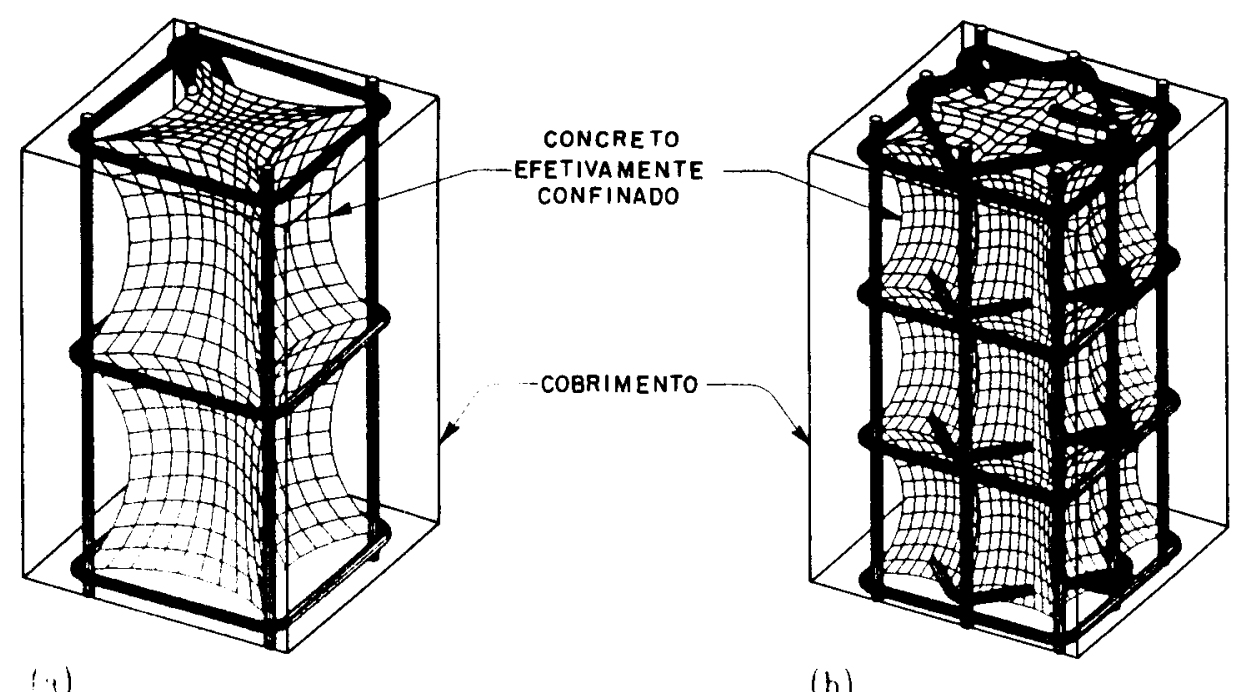

FIGURA 4.4 - Efeitos da configuração dos estribos e do espaçamento no núcleo de concreto confinado: (a) configuração pobre com grande espaçamento dos estribos: (b) boa configuração com pequeno espaçamento dos estribos. FONTE: CUSSON \& PAULTRE (1994).

b) Apesar da menor eficiência do confinamento do concreto de alta resistência comparado com o de baixa resistência, o ganho maior de resistência e o comportamento dúctil de pilares cintados de concreto de alta resistência foram obtidos quando foi usado detalhamento adequado de armaduras longitudinal e transversal. A figura 4.4 mostra o efeito benéfico das armaduras longitudinais e transversais no confinamento do núcleo. A melhoria na resistência de, aproximadamente, 50 e 100\% 
e na ductilidade em torno de 10 e 20 vezes maior que o concreto não confinado foram registradas para amostras bem confinadas, com concretos de 99,9 $\mathrm{MPa}$ e 52,6 MPa, respectivamente.

c) $\mathrm{O}$ aumento na resistência à compressão do concreto resulta num decréscimo de ganho na resistência e na rigidez do concreto confinado, isto é, a razão não é proporcional entre essas variáveis. Por outro lado, aumentando significativamente a taxa de armadura transversal se acentuam os ganhos de resistência e de rigidez do concreto confinado.

d) Um acréscimo da tensão de escoamento do estribo resultou num ganho maior de resistência e de rigidez, apenas para amostras bem confinadas com taxas elevadas de armadura lateral.
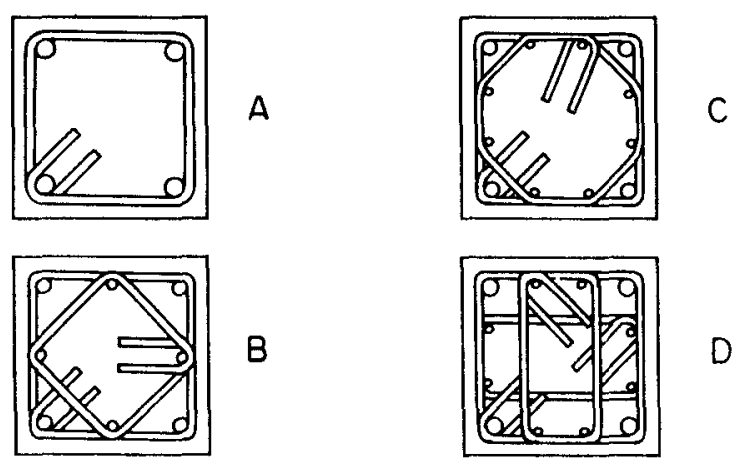

FIGURA 4.5 - Configurações de estribos utilizadas por CUSSON \& PAULTRE (1994).

Os resultados dos ensaios também indicam que a configuração $\mathrm{A}$, mostrada na figura 4.5, não é efetiva no confinamento do núcleo de concreto e não deveria ser usada quando se exige um comportamento dúctil. Por outro lado, os resultados indicam que as configurações de estribos $\mathrm{B}, \mathrm{C}$ e $\mathrm{D}$ são totalmente eficazes no confinamento do núcleo de concreto. A redução do espaçamento resulta num aumento de resistência e de rigidez do concreto confinado. $O$ aumento na taxa de armadura longitudinal resulta num ganho de resistência e de rigidez apenas para amostras bem confinadas com altas taxas de armadura transversal. 
O comportamento de pilares de concreto de alta resistência, com armadura de confinamento, sujeitos a carregamento axial e a força cortante, foi examinado por ABDEL-FATTAH \& AHMAD (1989). Eles concluíram que o efeito da tensão de cisalhamento é menos significante nas características de tensão-deformação do concreto confinado do que no concreto simples. Como resultado da aplicação de tensões cisalhantes, na ausência ou presença de tensões de compressão, é reduzida a ductilidade pós-pico do concreto.

SHEIKH, SHAH \& KHOURY (1994) realizaram ensaios em pilares de concreto de alta resistência sujeitos a carregamentos axial e lateral cíclico combinados, para simular a ação de terremotos, e compararam com amostras semelhantes feitas com concreto de resistência usual. Dos resultados obtidos, eles concluíram que:

a) Um acréscimo significante na taxa de armadura de confinamento melhorou o comportamento do pilar;

b) Apenas a amostra que tinha, aproximadamente, o dobro da armadura transversal exigida por norma, foi capaz de obter um resultado estável, enquanto que a amostra que estava de acordo com as especificações de norma, para taxa de armadura transversal, mostrou razoável ductilidade;

c) As amostras de concreto de alta resistência com mesma taxa de armadura transversal e testadas sob mesmo nivel de carga axial mostraram comportamento relativamente frágil quando comparadas com a amostra de concreto de resistência usual;

d) E a armadura de confinamento calculada de acordo com o Código de Construção da Norma Americana pôde estimar satisfatoriamente o comportamento para a situação analisada.

AGOSTINI (1992) ensaiou corpos-de-prova cilíndricos de $100 \times 200 \mathrm{~mm}$ em concreto simples, concreto armado e concreto armado somente com armadura transversal. A primeira decisão tomada para minimizar a fragilidade dos corpos-deprova de concreto de alta resistência foi optar por uma armadura helicoidal de confinamento. Para o cálculo da taxa de armadura helicoidal foi utilizada a eq. (4.2). 
Para os corpos-de-prova dos concretos que alcançaram de $60 \mathrm{MPa}$ a $80 \mathrm{MPa}$ de resistência à compressão, ocorreu a ruptura da armadura que serviu como confinamento do núcleo, tornando dúctil a ruptura do concreto e, logo após a ruptura do revestimento, o concreto se rompeu.

Para os corpos-de-prova com resistência à compressão em torno de $40 \mathrm{MPa}$, a armadura helicoidal serviu como armadura de cintamento, pois a resistência do concreto cresceu e a ruptura ocorreu pelo esmagamento do núcleo do concreto, sendo que a ruptura da casca ocorreu a $75 \%$ da tensão de ruptura do corpo-de-prova. A figura 4.6 apresenta os resultados desses ensaios realizados por AGOSTINI (1992)

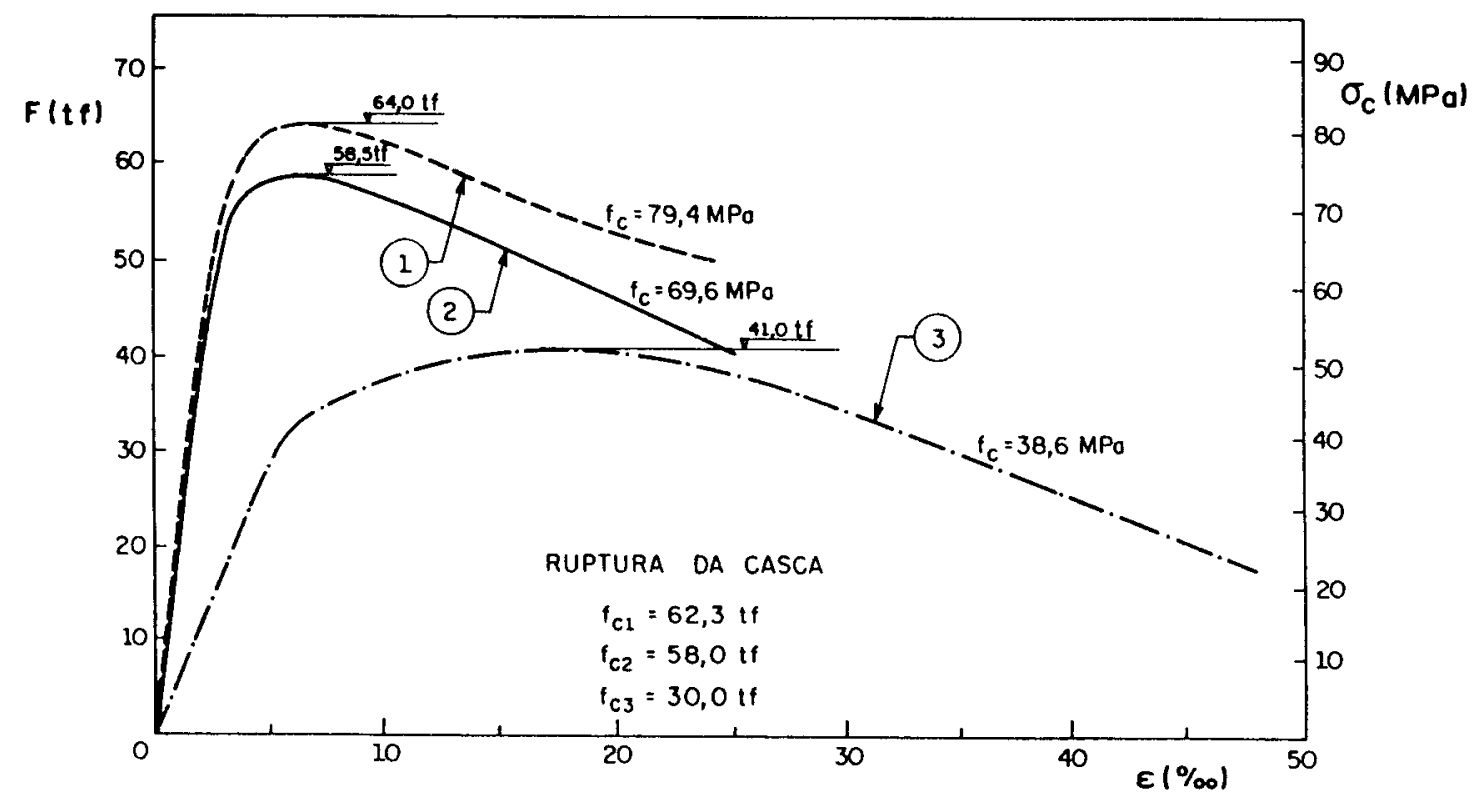

FIGURA 4.6 - Diagramas tensão-deformação de corpos-de-prova com armadura helicoidal.

$\mathrm{Na}$ figura 4.7, apresentam-se os diagramas tensão-deformação do concreto obtidos com corpos-de-prova com armadura helicoidal. Comparando os diagramas, verifica-se o efeito de ductilização proveniente da presença da armadura de confinamento. 


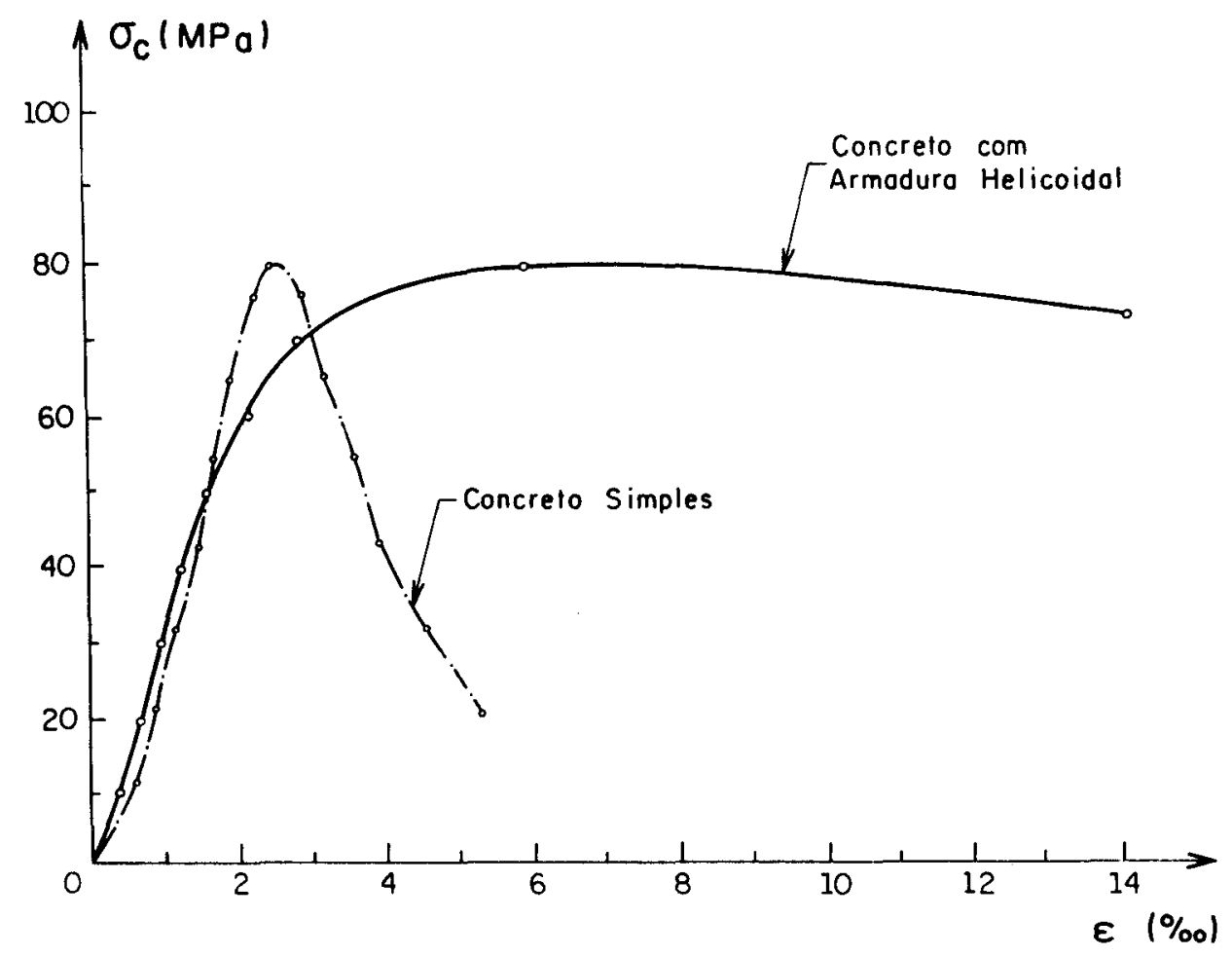

FIGURA 4.7 - Diagramas de tensão-deformação para concretos com resistência à compressão de $80 \mathrm{MPa}$.

AGOSTINI (1992), depois, ensaiou dois pilares com forma prismática $(100 \times 100 \times 400 \mathrm{~mm})$, cujas características geométricas estão apresentadas na figura 4.8. Os pilares foram armados longitudinalmente com seis barras de $10 \mathrm{~mm}$ de diâmetro, aço CA 50A, com tensão de escoamento de $541 \mathrm{MPa}$ e transversalmente com uma armadura de diâmetro $4,2 \mathrm{~mm}$, aço CA 60B, em forma de mola cujo diâmetro projetado é de $8,0 \mathrm{~cm}$ e passo de $2,0 \mathrm{~cm}$, com tensão de escoamento de 725 $\mathrm{MPa}$.

O primeiro pilar foi executado com um concreto usual, que possuía aos 28 dias de idade uma resistência $\mathrm{f}_{\mathrm{c} 28}=24,8 \mathrm{MPa}$. A ruptura da casca ocorreu com a carga de $240 \mathrm{kN}$, que correspondeu a $55,2 \%$ da carga última $435 \mathrm{kN}$. Analisando-se o resultado, pôde-se concluir que a armadura helicoidal cintou o núcleo de concreto, permitindo um acréscimo de tensão de 1,75 vezes em relação aos valores obtidos nos ensaios dos corpos-de-prova cilíndricos aos 28 dias. 

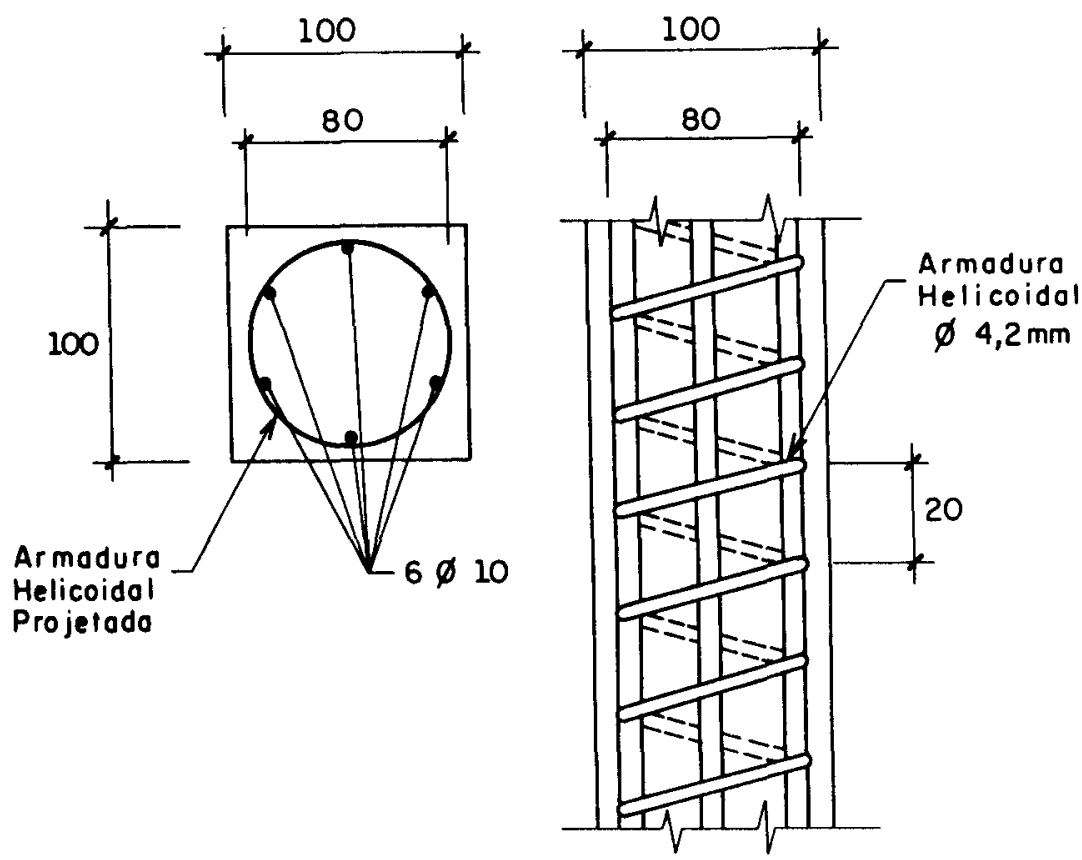

FIGURA 4.8 - Caracteristicas geométricas dos pilares ensaiados por AGOSTINI (1992).

No segundo pilar, usou-se concreto de alta resistência com $\mathrm{f}_{\mathrm{c} 28}=60,2 \mathrm{MPa}$. A ruptura da casca aconteceu juntamente com a carga última de $499 \mathrm{kN}$. A armadura helicoidal, nesse caso, apenas confinou o núcleo, evitando uma ruptura frágil. $O$ curioso é que a tensão última deste pilar foi $49,9 \mathrm{MPa}$, valor inferior à tensão obtida nos ensaios de corpos-de-prova cilíndricos de 60,2 MPa.

AGOSTINI (1992) partiu para o estudo de novos pilares solicitados à compressão simples, calculados com base nas normas.

Foram executados pilares prismáticos de $120 \times 120 \times 720 \mathrm{~mm}$, com taxas de armaduras longitudinais e transversais diferentes, traços, tipos de cura e, consequentemente, resistências à compressão diferentes.

Foram constatadas rupturas frágeis, em todos os pilares ensaiados, por meio de diagramas carga-deformação. E nos pilares de maior resistência pôde-se definir claramente a ocorrência de um regime elastofrágil, independente das taxas de armaduras longitudinais e transversais. 
Com a ruptura do concreto, os estribos se abriram e as armaduras longitudinais flambaram. Esses resultados mostraram que as taxas de armaduras longitudinais e transversais eram insuficientes. Isso comprovou a necessidade de rever as taxas mínimas para os pilares de concreto de alta resistência.

AGOSTINI (1992) também observou um encurtamento no concreto em torno de $0,5 \%$ no instante da ruptura, o dobro dos $0,25 \%$ relativos para os corpos cilindricos de concreto simples.

As armaduras longitudinais e transversais dos pilares definiram um núcleo de concreto que passava a ser a seção resistente. Esta foi a justificativa encontrada para que as deformações no pilar armado fossem maiores que as deformações no pilar sem armaduras.

Foram executados, posteriormente, pilares com dimensões de $80 \times 80 \times 480 \mathrm{~mm}$, apenas com armaduras longitudinais, com finalidade de confirmar as configurações dos diagramas carga-deformação dos pilares de concreto de alta resistência com armaduras usuais. E outros pilares foram executados, só que, com armaduras usuais, dimensões geométricas iguais aos anteriores e taxas de armaduras transversais diferentes.

Verificou-se que os pilares com armadura longitudinal, mesmo sem a presença da armadura transversal, definiram um núcleo resistente menor que a seção transversal e, como consequência, as deformações desses pilares foram maiores que as dos pilares feitos com concreto simples.

AGOSTINI (1992) comenta que esses resultados foram equivalentes aos obtidos por YONG (1988), no trabalho sobre comportamento da armadura transversal de confinamento de concretos de alta resistência solicitados à compressão simples.

Ele completa: "Independente das dimensões dos pilares, constatou-se que as armaduras definem um núcleo resistente de concreto e que o regime elastofrágil só poderia ser suavizado, ou evitado, com o uso de altas taxas de armaduras transversais, para confinar este núcleo resistente de concreto."

Foram executados e analisados pilares de concreto de alta resistência com armaduras de confinamento, em decorrência dos valores e comportamento obtidos para os pilares com taxas de armaduras usuais. 
Para dimensões $80 \times 80 \times 480 \mathrm{~mm}$, a armadura longitudinal correspondia à taxa de $4,44 \%$ em relação à seção transversal de concreto. Utilizou-se a eq. (4.2), vista anteriormente, para o cálculo da armadura transversal, que foi adotada para os corposde-prova cilíndricos usados como referência. A taxa das armaduras transversais de confinamento, baseada na de referência, variou de $1,50 \%$ a $3,00 \%$.

As armaduras transversais foram eficientes no confinamento do núcleo de concreto do pilar, evitando a ruptura frágil.

Ocorreu um regime elastofrágil com ruptura sem aviso para o ensaio de pilares com a taxa de armadura transversal de $1,50 \%$. Nos outros pilares ocorreram físsuras visíveis e, em seguida, ruptura da casca.

Nos diagramas carga-deformação de pilares armados transversalmente com estribos duplos, observou-se que, apesar da taxa de armadura transversal ter sido maior que $2,25 \%$, o confinamento do núcleo foi insuficiente, ainda que não ocorresse ruptura frágil.

Para verificar a importância do espaçamento dos estribos na eficiência do confinamento, foram ensaiados pilares com a mesma taxa de armadura transversal, onde a diferença estava apenas no espaçamento dos estribos.

Como resultado, pôde-se observar que os pilares com menores espaçamentos obtiveram melhor confinamento. Os estribos devem ser individuais e estar bem assentes nas barras longitudinais.

AGOSTINI (1992) realizou ensaios em pilares de concreto de alta resistência, com armadura de confinamento, nas dimensões $120 \times 120 \times 720 \mathrm{~mm}$.

Com características semelhantes às dos pilares anteriormente analisados, estes possuíam 4 ou 6 barras de $12,5 \mathrm{~mm}$ como armadura longitudinal, que correspondiam às taxas de $3,53 \%$ e $5,29 \%$, respectivamente. $\mathrm{E}$ as taxas de armaduras transversais foram $2,25 \%$ e $3,00 \%$.

Os resultados encontrados para os pilares ensaiados foram os seguintes: a) O diagrama de carregamento-deformação do concreto apresentou um trecho curvo para as cargas próximas da carga de ruptura, mostrando que a armadura de confinamento foi suficiente para garantir uma ruptura com aviso. 
b) As deformações no concreto foram superiores aos valores obtidos nos ensaios de pilares sem armaduras, pois a seção resistente de concreto correspondeu ao núcleo de concreto confinado pelas armaduras. A deformação no instante da ruptura foi em torno de $0,35 \%$, sendo de $0,23 \%$ para pilares não-armados.

c) A relação entre a seção de concreto do núcleo e a seção transversal do pilar cresceu, para os pilares com dimensões maiores, ao mesmo tempo que aumentou a eficiência das armaduras de confinamento. As cargas de ruptura foram até $20 \%$ maiores que as cargas previstas. Este fato comprova a ocorrência de cintamento do núcleo de concreto pelas armaduras transversais.

d) Os pilares com dimensões maiores possibilitaram um melhor assentamento dos estribos e assim ocorreram pequenas diferenças nos diagramas de carregamentodeformação dos estribos instrumentados.

e) A existência de uma excentricidade acidental, decorrente da heterogeneidade inevitável do concreto, causou flexão oblíqua em uns pilares e flexo-compressão em outros. Em pilares com 6 barras longitudinais, quase não existiu o efeito das excentricidades acidentais, que foi compensado pela homogeneidade da distribuição das armaduras.

f) A definição da carga de ruptura dependeu do núcleo do concreto. Inicialmente, as fissuras nas superficies dos pilares eram visíveis, até que ocorriam as rupturas das cascas com o acréscimo de carga até $20 \%$.

\subsection{APLICAÇÕES}

Para a avaliação do desempenho de pilares executados com concreto de alta resistência, analisou-se a carga de ruína prevista, que foi comparada com o valor obtido em ensaio. A carga de ruina prevista é encontrada a partir da eq. (4.1), sendo composta da soma das contribuições da armadura e do concreto, como foi visto no início deste capítulo. 
É importante lembrar que as amostras ensaiadas possuem características distintas, não podendo, portanto, ser tiradas conclusões definitivas.

Os pesquisadores que contribuíram para esta comparação foram AGOSTINI (1992) e CUSSON \& PAULTRE (1994). Os valores são apresentados a seguir.

a) AGOSTINI (1992) - Primeira série de pilares

Primeiramente, foram ensaiados pilares com as dimensões de $80 \times 80 \times 480 \mathrm{~mm}$.

Os valores da resistência à compressão do concreto foram obtidos através de ensaios com corpos-de-prova cilíndricos de $100 \times 200 \mathrm{~mm}$. Por isso, para transformar em valores correspondentes ao cilindro padrão, tiveram que ser multiplicados por 0,9 (valor recomendado por AGOSTINI, 1992). Na tabela 4.2a, pode-se observar os resultados encontrados.

TABELA 4.2a - Resultados de ensaios realizados por AGOSTINI (1992).

\begin{tabular}{|c|c|c|c|c|c|c|c|c|}
\hline PILARES & $\begin{array}{c}\mathbf{A}_{\mathbf{c}} \\
\mathbf{c m}^{2}\end{array}$ & $\begin{array}{c}\mathbf{f}_{\mathbf{c}} \\
\mathbf{M P a}\end{array}$ & $\begin{array}{c}\mathbf{A}_{\mathbf{s}} \\
\mathbf{c m}^{2}\end{array}$ & $\begin{array}{c}\mathbf{f}_{\mathbf{y}} \\
\mathbf{M P a}\end{array}$ & $\begin{array}{c}\rho_{\mathbf{s t}} \\
\%\end{array}$ & $\begin{array}{c}\mathbf{P} \\
\mathbf{k N}\end{array}$ & $\begin{array}{c}\mathbf{P}_{\mathbf{u}, \mathbf{e x p}} \\
\mathbf{k N}\end{array}$ & $\mathbf{P}_{\mathbf{u}, \mathbf{e x p}} \mathbf{P}$ \\
\hline PL4T150I & 60,68 & 63,4 & 3,14 & 499 & 1,50 & 483,7 & 353,0 & 0,73 \\
\hline PL4T150II & 60,68 & 63,4 & 3,14 & 499 & 1,50 & 483,7 & 378,0 & 0,78 \\
\hline PL4T175I & 60,68 & 66,6 & 3,14 & 499 & 1,75 & 500,2 & 417,0 & 0,83 \\
\hline PL4T175II & 60,68 & 66,6 & 3,14 & 499 & 1,75 & 500,2 & 417,0 & 0,83 \\
\hline PL4T200I & 60,68 & 68,4 & 3,14 & 499 & 2,00 & 509,5 & 427,0 & 0,84 \\
\hline PL4T200II & 60,68 & 68,4 & 3,14 & 499 & 2,00 & 509,5 & 466,0 & 0,91 \\
\hline PL4T225I & 60,68 & 63,9 & 3,14 & 499 & 2,25 & 486,3 & 400,0 & 0,82 \\
\hline PL4T225II & 60,68 & 63,9 & 3,14 & 499 & 2,25 & 486,3 & 408,0 & 0,84 \\
\hline
\end{tabular}


TABELA 4.2a - Resultados de ensaios realizados por AGOSTINI (1992). (Continuação).

\begin{tabular}{|c|c|c|c|c|c|c|c|c|}
\hline PILARES & $\begin{array}{c}\mathbf{A}_{\mathbf{c}} \\
\mathbf{c m}^{2}\end{array}$ & $\begin{array}{c}\mathbf{f}_{\mathbf{c}} \\
\mathbf{M P a}\end{array}$ & $\begin{array}{c}\mathbf{A}_{\mathbf{s}} \\
\mathbf{c m}^{2}\end{array}$ & $\begin{array}{c}\mathbf{f}_{\mathbf{y}} \\
\mathbf{M P a}\end{array}$ & $\begin{array}{c}\rho_{\mathbf{s}} \\
\%\end{array}$ & $\begin{array}{c}\mathbf{P} \\
\mathbf{k N}\end{array}$ & $\begin{array}{c}\mathbf{P}_{\mathrm{u}, \mathrm{exp}} \\
\mathbf{k N}\end{array}$ & $\mathbf{P}_{\mathrm{u}, \mathrm{exp}} / \mathbf{P}$ \\
\hline PL4T250I & 60,68 & 69,3 & 3,14 & 499 & 2,50 & 514,1 & 490,0 & 0,95 \\
\hline PL4T250II & 60,68 & 69,3 & 3,14 & 499 & 2,50 & 514,1 & 532,0 & 1,03 \\
\hline PL4T275I & 60,68 & 63,7 & 3,14 & 499 & 2,75 & 485,2 & 388,0 & 0,80 \\
\hline PL4T275II & 60,68 & 63,7 & 3,14 & 499 & 2,75 & 485,2 & 450,0 & 0,93 \\
\hline PL4T300I & 60,68 & 69,8 & 3,14 & 499 & 3,00 & 516,7 & 472,0 & 0,91 \\
\hline PL4T3001I & 60,68 & 69,8 & 3,14 & 499 & 3,00 & 516,7 & 464,0 & 0,90 \\
\hline
\end{tabular}

b) AGOSTINI (1992) - Segunda série de pilares

AGOSTINI (1992) ensaiou também pilares em escala maior $(120 \times 120 \times 720$ $\mathrm{mm}$ ). Os resultados estão mostrados na tabela $4.2 \mathrm{~b}$.

TABELA 4.2b - Resultados de ensaios realizados por AGOSTINI (1992).

\begin{tabular}{|c|c|c|c|c|c|c|c|c|}
\hline PILARES & $\begin{array}{c}\mathbf{A}_{\mathbf{c}} \\
\mathbf{c m}^{2}\end{array}$ & $\begin{array}{c}\mathbf{f}_{\mathbf{c}} \\
\mathbf{M P a}\end{array}$ & $\begin{array}{c}\mathbf{A}_{\mathbf{s}} \\
\mathbf{c m}^{2}\end{array}$ & $\begin{array}{c}\mathbf{f}_{\mathbf{y}} \\
\mathbf{M P a}\end{array}$ & $\begin{array}{c}\rho_{\mathbf{s t}} \\
\mathbf{\%}\end{array}$ & $\begin{array}{c}\mathbf{P} \\
\mathbf{k N}\end{array}$ & $\begin{array}{c}\mathbf{P}_{\mathrm{u}, \mathrm{exp}} \\
\mathbf{k N}\end{array}$ & $\mathbf{P}_{\mathrm{u}, \mathrm{exp}} \mathbf{P}$ \\
\hline PL4T225I & 138,92 & 75,8 & 5,08 & 544 & 2,25 & 1171,4 & 1450,0 & 1,24 \\
\hline PL4T225II & 138,92 & 75,8 & 5,08 & 544 & 2,25 & 1171,4 & 1376,0 & 1,17 \\
\hline PL6T225I & 136,38 & 66,0 & 7,62 & 544 & 2,25 & 1179,6 & 1376,0 & 1,17 \\
\hline PL6T225II & 136,38 & 66,0 & 7,62 & 544 & 2,25 & 1179,6 & 1385,0 & 1,17 \\
\hline PL4T300I & 138,92 & 75,3 & 5,08 & 544 & 3,00 & 1165,5 & 1200,0 & 1,03 \\
\hline PL4T300II & 138,92 & 75,3 & 5,08 & 544 & 3,00 & 1165,5 & 1325,0 & 1,14 \\
\hline
\end{tabular}


c) CUSSON \& PAULTRE (1994)

CUSSON \& PAULTRE (1994) ensaiaram pilares com as dimensões de $23,5 \times 23,5 \times 140,0 \mathrm{~cm}$. Os dados mais importantes para a análise estão resumidos na tabela 4.3.

TABELA 4.3 - Resultados de ensaios realizados por CUSSON \& PAULTRE (1994).

\begin{tabular}{|c|c|c|c|c|c|c|c|c|}
\hline PILARES & $\begin{array}{c}A_{c} \\
\mathbf{c m}^{2}\end{array}$ & $\begin{array}{c}\mathbf{f}_{\mathrm{c}} \\
\mathbf{M P a}\end{array}$ & $\begin{array}{c}A_{1} \\
\mathbf{c m}^{2}\end{array}$ & $\begin{array}{c}\mathbf{f}_{\mathbf{y}} \\
\mathbf{M P a}\end{array}$ & $\begin{array}{l}\rho_{31} \\
\%\end{array}$ & $\begin{array}{c}P \\
k N\end{array}$ & $\begin{array}{c}P_{u, \exp } \\
k N\end{array}$ & $\mathbf{P}_{\mathrm{u}, \mathrm{exp}} / \mathbf{P}$ \\
\hline $\mathbf{1 A}$ & 540,25 & 95,4 & 12,0 & 406 & 2,80 & 4868,1 & 4244,0 & 0,87 \\
\hline $1 \mathrm{~B}$ & 540,25 & 95,4 & 12,0 & 450 & 3,40 & 4920,9 & 4679,0 & 0,95 \\
\hline $1 \mathrm{C}$ & 540,25 & 95,4 & 12,0 & 450 & 3,60 & 4920,9 & 4716,0 & 0,96 \\
\hline $1 D$ & 540,25 & 100,4 & 12,0 & 450 & 4,80 & 5150,5 & 5001,0 & 0,97 \\
\hline $1 \mathrm{D1}$ * & 368,25 & 100,4 & 12,0 & 450 & 4,80 & 3682,7 & 5136,0 & 1,39 \\
\hline $2 A$ & 540,25 & 96,4 & 12,0 & 406 & 2,00 & 4914,0 & 4657,0 & 0,95 \\
\hline $2 B$ & 540,25 & 96,4 & 12,0 & 450 & 2,20 & 4966,8 & 4388,0 & 0,88 \\
\hline $2 \mathrm{C}$ & 540,25 & 96,4 & 12,0 & 450 & 2,30 & 4966,8 & 4525,0 & 0,91 \\
\hline $2 \mathrm{D}$ & 540,25 & 96,4 & 12,0 & 450 & 3,10 & 4966,8 & 4635,0 & 0,93 \\
\hline $3 \mathbf{A}$ & 540,25 & 98,1 & 12,0 & 406 & 1,40 & 4992,1 & 4371,0 & 0,88 \\
\hline 3B & 540,25 & 98,1 & 12,0 & 450 & 2,50 & 5044,9 & 4410,0 & 0,87 \\
\hline $3 \mathrm{C}$ & 540,25 & 98,1 & 12,0 & 450 & 2,60 & 5044,9 & 4499,0 & 0,89 \\
\hline 3D & 532,25 & 98,1 & 12,0 & 450 & 3,50 & 4978,2 & $466 A, 0$ & 0,92 \\
\hline $4 \mathrm{~A}$ & 532,25 & 93,1 & 20,0 & 420 & 2,80 & 5052,0 & 4606,0 & 0,91 \\
\hline $4 B$ & 532,25 & 93,1 & 20,0 & 406 & 3,40 & 5024,0 & 4882,0 & 0,96 \\
\hline $4 \mathrm{C}$ & 532,25 & 93,1 & 20,0 & 406 & 3,60 & 5024,0 & 4864,0 & 0,96 \\
\hline 4D & 532,25 & 93,1 & 20,0 & 406 & 4,80 & 5024,0 & 4863,0 & 0,96 \\
\hline
\end{tabular}


TABELA 4.3 - Resultados de ensaios realizados por CUSSON \& PAULTRE (1994). (Continuação).

\begin{tabular}{|c|c|c|c|c|c|c|c|c|}
\hline PILARES & $\begin{array}{c}\mathbf{A}_{\mathbf{c}} \\
\mathbf{c m}^{2}\end{array}$ & $\begin{array}{c}\mathbf{f}_{\mathbf{c}} \\
\mathbf{M P a}\end{array}$ & $\begin{array}{c}\mathbf{A}_{\mathbf{s}} \\
\mathbf{c m}^{2}\end{array}$ & $\begin{array}{c}\mathbf{f}_{\mathbf{y}} \\
\mathbf{M P a}\end{array}$ & $\begin{array}{c}\rho_{\mathbf{s t}} \\
\mathbf{\%}\end{array}$ & $\begin{array}{c}\mathbf{P} \\
\mathbf{k N}\end{array}$ & $\begin{array}{c}\mathbf{P}_{\mathbf{u}, \mathbf{e x p}} \\
\mathbf{k N}\end{array}$ & $\mathbf{P}_{\text {u,exp }} \mathbf{P}$ \\
\hline 5A & 532,25 & 99,9 & 20,0 & 420 & 2,80 & 5359,6 & 4728,0 & 0,88 \\
\hline 5B & 532,25 & 99,9 & 20,0 & 406 & 3,40 & 5331,6 & 5073,0 & 0,94 \\
\hline 5C & 532,25 & 99,9 & 20,0 & 406 & 3,60 & 5331,6 & 5214,0 & 0,97 \\
\hline 5D & 532,25 & 99,9 & 20,0 & 406 & 4,80 & 5331,6 & 5457,0 & 1,02 \\
\hline 6B & 532,25 & 115,9 & 20,0 & 436 & 4,90 & 6115,5 & 5395,0 & 0,87 \\
\hline 6D & 532,25 & 113,6 & 20,0 & 467 & 4,80 & 6073,4 & 5545,0 & 0,91 \\
\hline 7B & 532,25 & 75,9 & 20,0 & 436 & 4,90 & 4305,8 & 4954,0 & 1,14 \\
\hline 7D & 532,25 & 67,9 & 20,0 & 467 & 4,80 & 4005,9 & 4701,0 & 1,17 \\
\hline 8B & 523,25 & 52,6 & 20,0 & 436 & 4,90 & 3251,7 & 4530,0 & 1,37 \\
\hline 8D & 523,25 & 55,6 & 20,0 & 467 & 4,80 & 3449,4 & 4532,0 & 1,31 \\
\hline
\end{tabular}

"O pilar IDI difere dos demais por não possuir cobrimento.

d) Análise dos resultados

Baseando-se nos resultados apresentados nas tabelas $4.2 \mathrm{a}, 4.2 \mathrm{~b}, 4.3$, pode-se constatar que, para as baixas taxas de armadura transversal, o valor da carga de ruptura dos pilares não chegou a alcançar o valor previsto pela eq. (4.1). Para os pilares que possuíam uma distribuição mais densa da armadura transversal, a carga de ruína alcançou, em geral, valores próximos ou superiores aos previstos, chegando a ser $37 \%$ maior, como foi mostrado na tabela 4.3 . Esse comportamento comprova que a capacidade resistente do pilar solicitado à compressão axial cresce com o aumento do confinamento do núcleo de concreto, graças à armadura transversal. 


\section{FLEXÃO EM VIGAS}

Como nos pilares, as propriedades dos materiais, apresentadas no Capítulo 3, afetam também o comportamento das vigas de concreto de alta resistência.

\subsection{ANÁLISE GERAL}

Os textos existentes levantam dúvidas sobre a aplicabilidade, às vigas de concreto de alta resistência, das hipóteses empregadas para o dimensionamento de concreto de resistência usual.

\subsubsection{Distribuição das tensões de compressão}

A distribuição das tensões de compressão em vigas está diretamente relacionada à forma da curva tensão-deformação. Consequentemente, para concreto de alta resistência, que mostra diferenças na forma, como mostrado na figura 4.1, é razoável esperar diferenças na distribuição das tensões de compressão na flexão, particularmente para ações próximas da máxima.

A parte ascendente íngreme e linear da curva e a queda brusca após a tensão máxima ser alcançada influenciam na posição e na magnitude da resultante de compressão no concreto, nas vigas submetidas à flexão.

Como prática atual nos Estados Unidos, apresentada no $A C I 318$ (1989), o ajuste das seções da viga está geralmente baseado num estado hipotético de ruptura 
do concreto com ações de cálculo. A figura 5.1 a mostra a forma parabólica comum da distribuição das tensões de compressão de uma viga feita com concreto de baixa resistência. $\mathrm{O}$ momento resistente pode ser calculado conhecendo as forças internas $R_{s}$ e $R_{c}$ e o braço de alavanca entre elas.
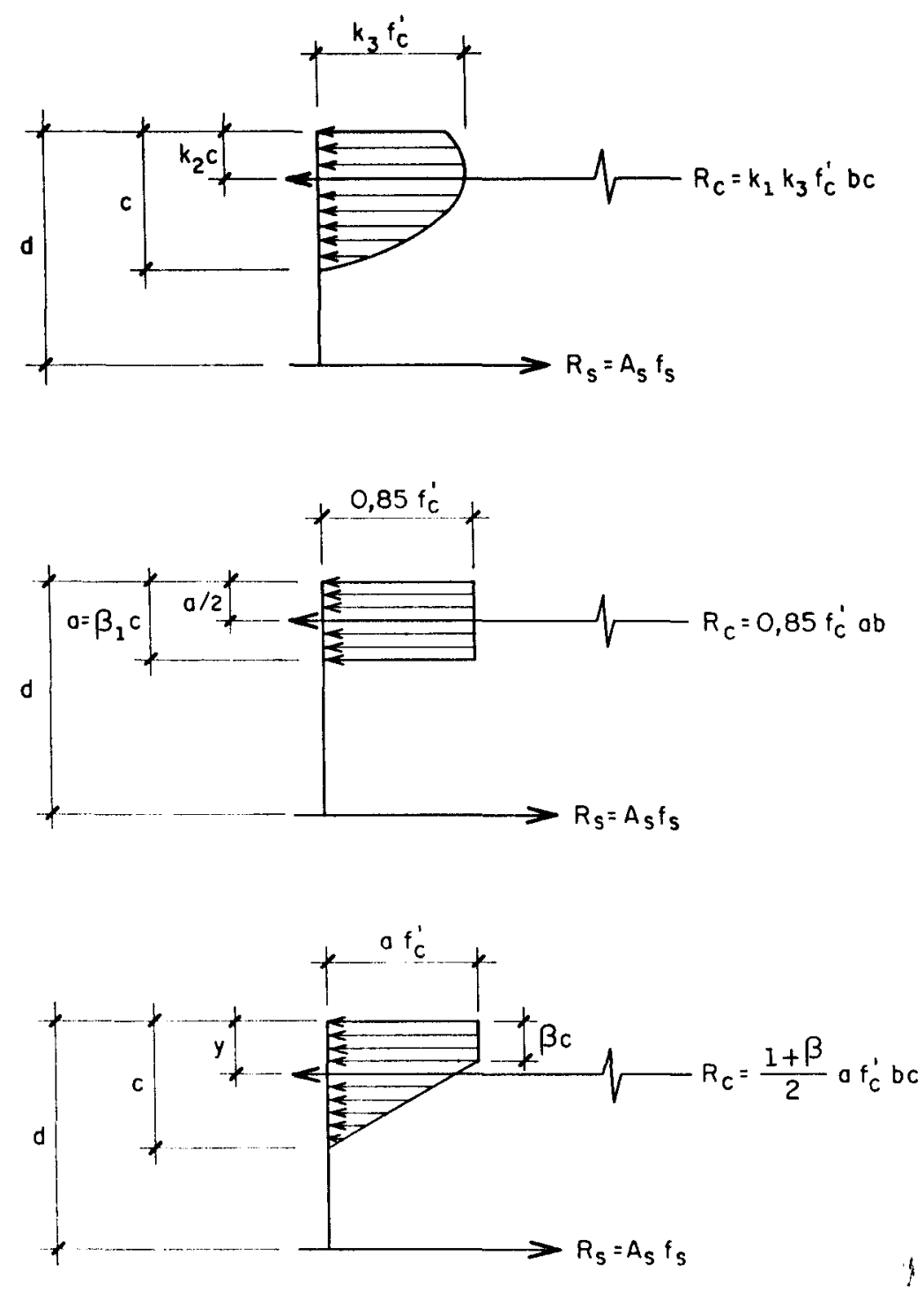

FIGURA 5.1 - Distribuições de tensões no concreto para vigas retangulares. FONTE: $A C I 363$ (1992).

A forma real da distribuição das tensões de compressão no início da fissuração, altamente variável para um dado intervalo de resistências de concreto, pode ser considerada irrelevante se se conhece a magnitude da resultante de 
compressão $R_{c}$ e o nível onde atua na viga. Eles podem ser estabelecidos por três parâmetros característicos, para uma dada distribuição de tensões (ver fig 5.1a)

$\mathrm{k}_{1}$ fator médio para tensão de compressão máxima na viga;

$\mathrm{k}_{2}$ fator da distância da resultante de compressão em relação à posição da linha neutra;

$\mathrm{k}_{3}$ fator de tensão máxima na viga para tensão máxima correspondente a um cilindro axialmente carregado.

SWARTZ et al (1985) concluem, em suas pesquisas, que o diagrama de distribuição das tensões de compressão na ruptura tem a forma parabólica-retangular. Certamente, é também possível aproximá-la por um retângulo.

Em cálculos usuais, é conveniente trabalhar com uma distribuição de compressão retangular equivalente, mostrada na figura $5.1 \mathrm{~b}$, com a magnitude da resultante de compressão e a linha de ação iguais às anteriores. Essa distribuição equivalente é recomendada pelo $A C I 318$ (1989). Assumindo-se $0,85^{\prime} \mathrm{f}_{\mathrm{c}}{ }^{\prime}$ como o valor uniforme de compressão do concreto, é suficiente o parâmetro $\beta_{1}$ para definir a magnitude e a linha de ação.

NILSON (1985) considera que o uso da distribuição retangular dá bons resultados para todas as resistências do concreto e nenhuma modificação parece necessária.

Para o concreto de alta resistência, de acordo com o $A C I 363$ (1992), a curva tensão-deformação é mais linear que parabólica. Portanto, suspeita-se que os parâmetros do diagrama de tensão possam ser diferentes. Pesquisas experimentais, realizadas por PASTOR et al apud ACI 363 (1992), têm confirmado que existem diferenças e têm sido propostas alternativas para o diagrama retangular de tensões, tais como na figura $5.1 \mathrm{c}$.

PASTOR, J.A. et al. (1984). Behavior of high strength concrete beams. Cornell University. Research Report No 84-3 apud AMERICAN CONCRETE INSTITUTE. Committee 363. (1992). State-of-the-art report on high strength concrete. Detroit, ACI, p.33. 
O ACI $318 R$ (1989) sugere, baseado num diagrama retangular equivalente, que a resistência à flexão de uma viga subarmada com armadura simples pode ser calculada por:

$$
M_{n}=A_{s} f_{y} d\left(1-0,59 \rho \frac{f_{y}}{f_{c}^{\prime}}\right)
$$

onde:

$M_{n} \quad$ momento resistente na seção (in-lb);

$\mathrm{A}_{\mathrm{s}} \quad$ área de armadura de tração $\left(\mathrm{in}^{2}\right)$;

$\mathrm{f}_{\mathrm{y}}$ tensão de escoamento da armadura (psi);

d distância da fibra extrema de compressão até o centróide da armadura de tração (in);

$\rho$ taxa da armadura de tração em relação à área útil da seção;

$f_{c}{ }^{\prime} \quad$ resistência do concreto à compressão (psi).

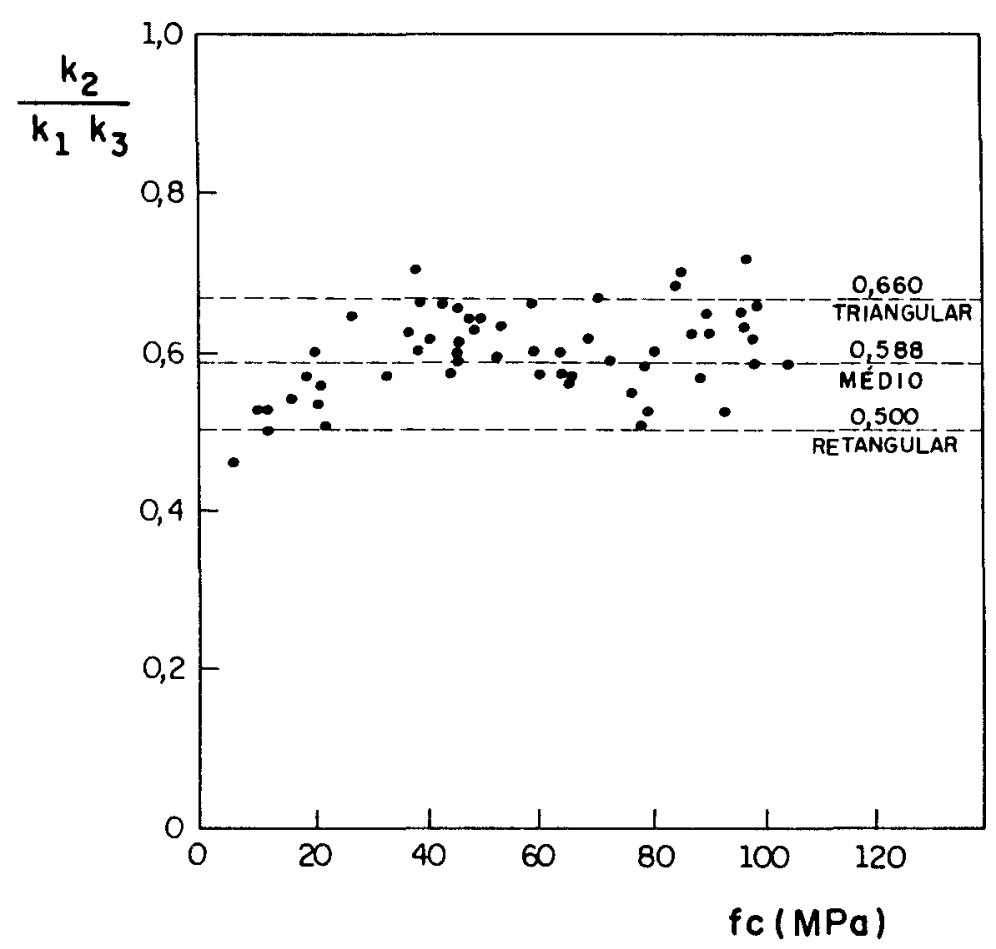

FIGURA 5.2 - Parâmetro $\mathrm{k}_{2} / \mathrm{k}_{1} \mathrm{k}_{3}$ do diagrama de tensões versus resistência do concreto. FONTE: ACI 363 (1992). 
$O$ coeficiente 0,59 equivale $a k_{2} / k_{1} k_{3}$. A variação experimental de $k_{2} / k_{1} k_{3}$, com a resistência à compressão do concreto, se baseia em várias pesquisas, como mostra a figura 5.2, retirada do $A C I 363$ (1992). Um estudo detalhado indica que existem diferenças significativas nos valores de $\mathrm{k}$, dependendo da resistência do concreto, mas está claro na figura 5.2 que o coeficiente combinado está bem representado pela constante 0,59 .

Para vigas subarmadas, os métodos apresentados no $A C I 318$ (1989) podem ser usados sem mudanças, pelo menos para concretos com resistências acima de $83 \mathrm{MPa}$. E, ainda, a resistência à flexão é determinada pela armadura de tração e a influência da distribuição das tensões de compressão é menos importante.

Para vigas superarmadas, que não são permitidas pelo $A C I 318$ (1989), ou para peças com combinações de flexão e compressão, podem ocorrer diferenças significativas. A resistência à flexão das vigas superarmadas é mais dependente da distribuição das tensões de compressão. A posição da resultante de compressão se torna mais importante à medida que aumenta a zona de compressão da viga.

PINTO JR (1992) conclui, com base nos resultados apresentados por SWARTZ et al (1985), que tudo indica que a distribuição parabólica-retangular das tensões de compressão, bem como sua simplificação para retangular, usualmente adotada para concretos de resistência usual, pode também ser empregada para os concretos de alta resistência.

Portanto, para seções subarmadas, parece que há um consenso na adoção dos diagramas parábola-retângulo ou retangular, também para concretos de alta resistência.

\subsubsection{Encurtamento último}

Enquanto o concreto de alta resistência alcança sua tensão máxima de compressão com a deformação ligeiramente maior que para o concreto de baixa resistência, o encurtamento último é menor para o concreto de alta resistência, nos ensaios de compressão axiais e nos ensaios de vigas, segundo o ACI 363 (1992). 
Tem-se admitido que este resultado seja, aparentemente, devido à energia liberada do equipamento de ensaio.

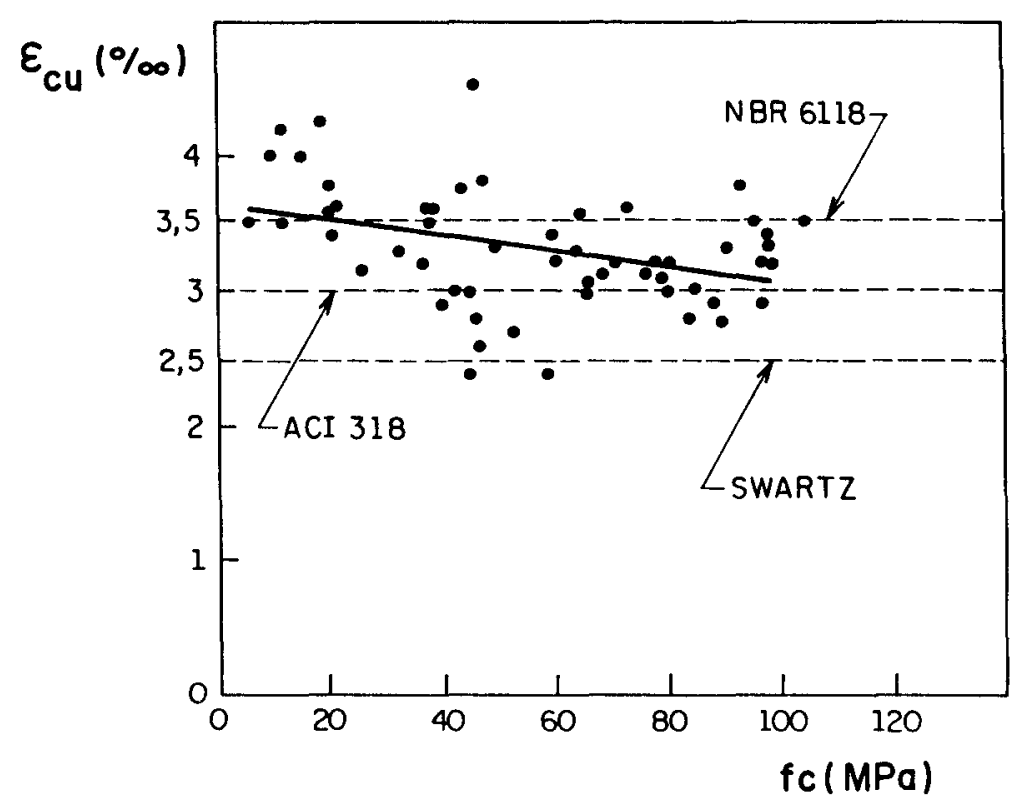

FIGURA 5.3 - Encurtamento último $\varepsilon_{\mathrm{cu}}$ do concreto na flexão versus resistência à compressão. FONTE: ACI 363 (1992).

A figura 5.3 mostra o encurtamento do concreto na ruptura da face extrema comprimida de vigas de concreto simplesmente armadas ou pilares com carga excêntrica sem armadura lateral de confinamento. $O$ valor constante 0,003 para o encurtamento na fibra mais comprimida do concreto, prescrito pelo ACI 318 (1989), representa tão satisfatoriamente os resultados experimentais para alta resistência quanto para o concreto de baixa resistência, embora não seja tão conşervativo para concreto de alta resistência.

O valor 0,0025 do encurtamento último é proposto por $S W A R T Z$ et al (1985); não leva em consideração o fato do encurtamento último ser função da duração do processo de carregamento, da forma da seção transversal e da posição da linha neutra da seção, não tendo justificativa o valor por eles proposto. 
PINTO JR (1992) observa, conforme a figura 5.3, que o valor proposto por SWARTZ et al que é bem inferior aos encontrados por KAAR et al apud ACI 363 (1992) e que o valor atualmente adotado pela $N B R 6118$ (1978) é superestimado para resistências entre 60 e $100 \mathrm{MPa}$.

MARRO (1987), em ensaios realizados com vigas de concreto de alta resistência, verificou que o encurtamento $\varepsilon_{\mathrm{c}}$ medido teve um leve decréscimo com o aumento de resistência e em nenhum caso os valores foram maiores que 0,004 .

PINTO JR (1992) não propõe nenhum valor e conclui que são necessárias mais pesquisas para uma correta avaliação, pelo fato de não ter tido acesso ao trabalho de $K A A R$ et al (1978), que possibilitaria a verificação da metodologia empregada para a obtenção dos valores de encurtamento último.

Portanto, parece prudente considerar $\varepsilon_{\mathrm{cu}}=0,003$, conforme prescreve o $A C I$ 318 (1989), para concretos de alta resistência.

\subsubsection{Ductilidade das vigas}

É necessário que as estruturas apresentem sinais evidentes de alarme na forma de fissuras e grandes deformações, na iminência do colapso. Estes sinais caracterizam a chamada ruptura dúctil, o oposto do que ocorre nas rupturas frágeis.

$\mathrm{Na}$ figura 5.4, são mostradas esquematicamente as diferenças de comportamento, representadas por diagramas momento-curvatura para rupturas típicas.

Um aspecto importante, com respeito à ductilidade das vigas de concreto de alta resistência, se refere às influências das armaduras de compressão e ao espaçamento dos estribos.

KAAR, P.H.; HANSON, N.W.; CAPELL, H.T. (1978). Stress-strain characteristics of high strength concrete. In: DOUGLAS McHENRY INTERNATIONAL SYMPOSIUM ON CONCRETE STRUCTURES. Proc. Detroit, ACI, p. 161-185. (SP-55) apud AMERICAN CONCRETE INSTITUTE. Committee 363. (1992). State-of-the-art report on high strength concrete. Detroit, ACI., p.34. 


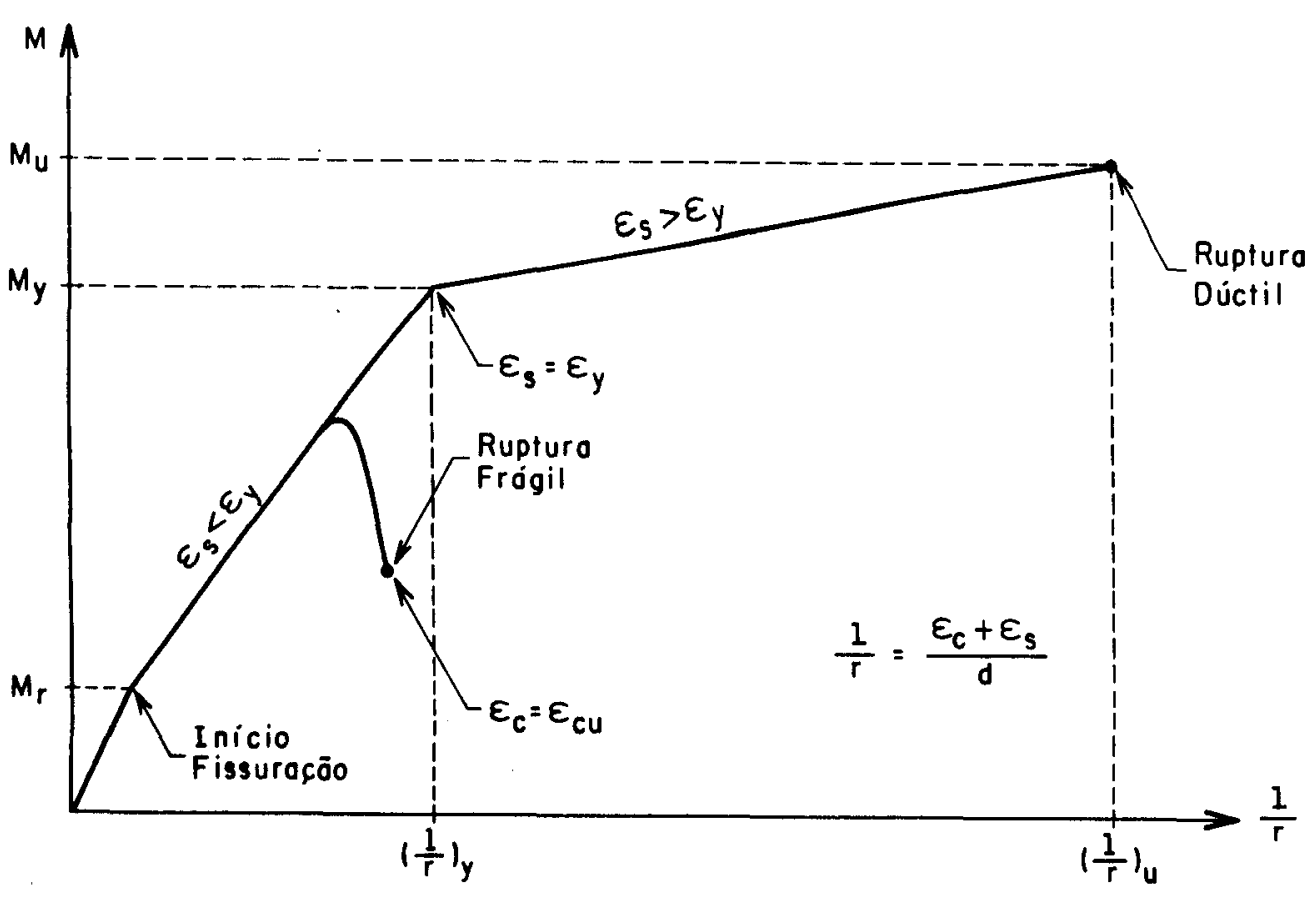

FIGURA 5.4 - Diagramas momento-curvatura para rupturas típicas. FONTE: PINTO JR (1992).

Levando em consideração a menor capacidade de encurtamento último do concreto de alta resistência na compressão, torna-se necessário avaliar a ductilidade das vigas feitas de concreto de alta resistência. $O$ índice de ductilidade na deformação $\mu$ é definido como:

$$
\mu=\frac{\Delta_{u}}{\Delta_{y}}
$$

onde:

$\Delta_{u} \quad$ deslocamento da viga na ação de ruína;

$\Delta_{y} \quad$ deslocamento da viga na ação que produz o escoamento da armadura de tração.

PASTOR et al (1984) realizaram ensaios em vigas de concreto de resistências usual e alta, cujos resultados estão resumidos na tabela 5.1. As vigas da série $A$, com armaduras simples e sem estribos, possuíam resistência à compressão variando de 26 
a $64 \mathrm{MPa}$. Para as vigas de alta resistência, a taxa de armadura tracionada variou de $0,29 \rho_{\mathrm{b}}$ a $1,11 \rho_{\mathrm{b}}$, onde $\rho_{\mathrm{b}}$ é a taxa de armadura que conduz à ruptura do concreto simultaneamente com o escoamento da armadura.

TABELA 5.1 - Índices de ductilidade em vigas obtidos por PASTOR et al.

\begin{tabular}{|c|c|c|c|c|c|c|c|c|c|}
\hline \multicolumn{3}{|c|}{ SÉRIE A } & \multicolumn{6}{c|}{ SÉRIE B } \\
\hline VIGA & $\begin{array}{c}\mathrm{f}_{\mathrm{c}}^{\prime} \\
(\mathrm{MPa})\end{array}$ & $\rho / \rho_{\mathrm{b}}$ & $\mu=\Delta_{\mathrm{u}} / \Delta_{\mathrm{y}}$ & VIGA & $\begin{array}{c}\mathrm{f}_{\mathrm{c}}^{\prime} \\
(\mathrm{MPa})\end{array}$ & $\rho / \rho_{\mathrm{b}}$ & $\mathrm{A}_{\mathrm{z}}^{\prime} / \mathrm{A}_{\mathrm{s}}$ & $\begin{array}{c}\mathrm{s}^{*} \\
(\mathrm{~mm})\end{array}$ & $\mu=\Delta_{\mathrm{u}} / \Delta_{\mathrm{y}}$ \\
\hline $\mathrm{A} 1$ & 26 & 0,51 & 3,54 & $\mathrm{~B} 1$ & 59 & 0,57 & 0,50 & 305 & 2,36 \\
$\mathrm{~A} 2$ & 45 & 0,52 & 2,84 & $\mathrm{~B} 2$ & 59 & 0,55 & 1,00 & 305 & 2,64 \\
$\mathrm{~A} 3$ & 59 & 0,29 & 2,53 & $\mathrm{~B} 3$ & 59 & 0,57 & 0,50 & 152 & 4,88 \\
A4 & 59 & 0,64 & 1,75 & $\mathrm{~B} 4$ & 58 & 0,59 & 1,00 & 152 & 8,32 \\
A5 & 64 & 0,87 & 1,14 & $\mathrm{~B} 5$ & 59 & 0,56 & 0,50 & 76 & 5,61 \\
A6(a) & 60 & 1,11 & 1,07 & $\mathrm{~B} 6$ & 58 & 0,58 & 1,00 & 76 & 6,14 \\
\hline
\end{tabular}

Os resultados da série $A$ mostram uma ductilidade bem menor para as vigas com resistências maiores. O indice de ductilidade da viga superarmada de alta resistência foi extremamente baixo quando comparado com a viga Al de resistência usual.

Baseado nesses resultados, a série $B$ foi desenvolvida. Suas vigas possuíam quantidades variadas de armadura de compressão (50 a 100\% da armadura tracionada) e armadura de confinamento na forma de estribos com espaçamentos de 76, 152 e $305 \mathrm{~mm}$. Todas as vigas eram de concreto de alta resistência e comparáveis com a viga $\mathrm{A} 4$ da série $A$, que não tinha estribos e nem armadura de compressão.

Das vigas B1 e B2, comparadas com a viga A4, pôde-se concluir que estribos com espaçamento de $305 \mathrm{~mm}$ aumentaram o índice de ductilidade, mas não significativamente. $\mathrm{O}$ indice de ductilidade aumentou acentuadamente quando o 
espaçamento entre os estribos foi reduzido para $152 \mathrm{~mm}$ nas vigas B3 e B4, mas não mostraram a mesma tendência quando o espaçamento foi mais reduzido para $76 \mathrm{~mm}$.

Uma comparação entre as vigas B3 e B4 indica um efeito benéfico em adicionar mais armadura de compressão, embora esse fato não seja claramente refletido numa comparação das vigas B5 e B6.

$\mathrm{O}$ problema da fragilidade das vigas de concreto de alta resistência não existe para as vigas subarmadas, da mesma forma que não existe para as vigas de resistência usual, pois em geral se usam estribos.

Os resultados dos ensaios, realizados por PINTO JR (1992), mostraram que as vigas subarmadas de concreto de alta resistência normalmente armadas apresentam comportamento dúctil.

\subsubsection{Flechas causadas por ações de curta e de longa duração}

NILSON' apud PINTO JR (1992) comenta que as flechas produzidas por ações de curta duração, previstas pelas equações constantes do $A C I 318$ (1986), são satisfatórias para vigas deformadas de concreto de alta resistência, onde as flechas são calculadas utilizando um momento de inércia efetivo. A equação para momento de inércia efetivo $\mathrm{I}_{\mathrm{e}}$, apresentada também pelo $A C I 318$ (1989) é:

$$
I_{e}=\left(\frac{M_{C r}}{M_{a}}\right)^{3} I_{g}+\left[1-\left(\frac{M_{C r}}{M_{a}}\right)^{3}\right] I_{C r}
$$

onde:

$\mathrm{M}_{\mathrm{cr}} \quad$ momento fletor de fissuração;

$\mathrm{M}_{\mathrm{a}} \quad$ momento fletor máximo na peça para o qual a flecha é calculada;

1 NILSON, A.H. (1988). Concreto de alta resistência - desempenho como material e comportamento estrutural. In: $30^{\mathrm{a}}$ REUNIÃO ANUAL DO IBRACON apud PINTO JR., N.O. (1992). Flexão de vigas de concreto de alta resistência. São Paulo. 2v. Tese (doutorado) - Escola Politécnica da Universidade de São Paulo, p. 3.14. 
$\mathrm{I}_{\mathrm{g}}$ momento de inércia da seção bruta de concreto em relação ao centro de gravidade, desprezando as armaduras;

$\mathrm{I}_{\mathrm{cr}} \quad$ momento de inércia da seção fissurada de concreto.

E o momento de fissuração é calculado por:

$$
M_{c r}=\frac{f_{r} I_{g}}{y_{t}}
$$

$\mathrm{f}_{\mathrm{r}}$ resistência à tração do concreto, obtida em ensaios ou por meio da equação:

$$
f_{r}=7,5 \sqrt{f_{c}^{\prime}}
$$

$\mathrm{y}_{\mathrm{t}}$ distância do centro de gravidade da seção bruta, desprezando as armaduras, à fibra extrema tracionada.

As deformações de longa duração, devidas à deformação lenta e à retração, são atualmente calculadas com o uso de multiplicadores para as deformações elásticas calculadas. Este procedimento é geralmente válido para peças de concreto de alta resistência, mas dados experimentais indicam que os multiplicadores podem ser menores, por causa do coeficiente de deformação lenta tipicamente menor para concreto de alta resistência. De acordo com o ACI 318 (1989), as deformações adicionais de longa duração são obtidas usando o seguinte multiplicador:

$$
\lambda=\frac{\xi}{1+50 \rho^{\prime}}
$$

onde:

$\rho^{\prime} \quad A_{s}^{\prime} / b . d$, taxa de armadura de compressão;

$\xi$ fator dependente do tempo de duração do carregamento, conforme mostra a figura 5.5, tirada do $A C I 318 R$ (1989). 


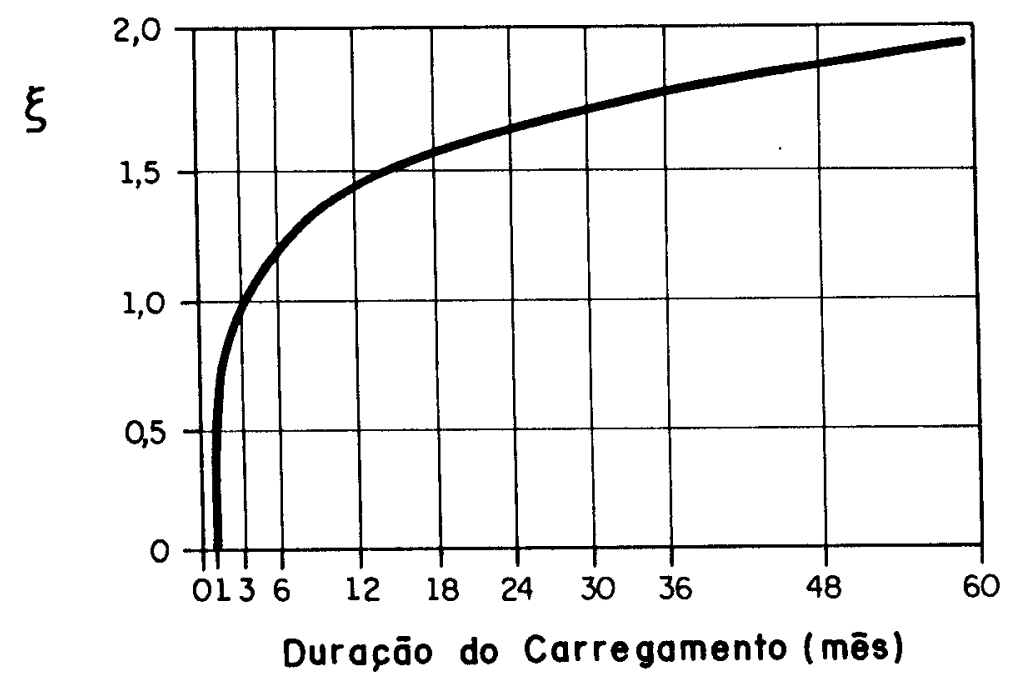

FIGURA 5.5 - Multiplicadores para flechas produzidas por ações de longa duração. FONTE: ACI 318 (1989).

NILSON (1985), para investigar o efeito da resistência do concreto em deformações de ações duradouras, ensaiou nove vigas, com resistências de $21 \mathrm{MPa}$ a $62 \mathrm{MPa}$, algumas com e outras sem armaduras de compressão. Ações permanentes foram colocadas em todas as nove vigas e conservadas no local por três anos.

Ele pôde evidenciar dois fatos. Primeiro, que as vigas de concreto de alta resistência, naturalmente, sofreram deformações significativamente menores para ação duradoura que as vigas de menor resistência, como esperado, proveniente do menor coeficiente de deformação lenta. Segundo, a influência da armadura de compressão é menos significativa para vigas de concreto de alta resistência que pạra as de baixa resistência. A transferência do esforço no concreto comprimido para a armadura de compressão, característica das vigas de concreto de baixa resistência com elevada deformação lenta, é muito reduzida para as vigas de concreto de alta resistência, para as quais a deformação lenta é muito menor. 
Estudos comparativos, feitos por LUEBKEMAN et al apud NILSON (1985), mostram que um coeficiente $\mu$ pode ser usado para considerar o material, a princípio, levando-o à equação:

$$
\lambda=\frac{\mu \xi}{1+50 \mu \rho^{\prime}}
$$

onde $\mu$ é uma função da resistência à compressão do concreto que pode ser expressa por:

$$
\mu=1,3-0,00725 f_{c}^{\prime}
$$

na qual $f_{c}^{\prime}$ é a resistência à compressão do concreto em $\mathrm{MPa}$, sendo que $\mu$ não pode ser maior que 1,0 e nem menor que 0,7 . Isso resulta em nenhuma mudança na equação do $A C I 318$ (1989) para resistências de concreto menores que $41 \mathrm{MPa}$ e fornece um ajuste dos dados experimentais para resistências maiores de concreto. São necessários mais dados, particularmente, para resistências entre $62 \mathrm{MPa}$ e $83 \mathrm{MPa}$, antes que uma declaração definitiva possa ser feita.

SWAMY (1985) ensaiou algumas vigas com concretos de alta resistência e avaliou o comportamento das flechas. Os resultados mostraram que, para as ações usadas nas vigas, as flechas em um ano variaram de 1,82 a 2,75 vezes a flecha imediata. A relação vão-flecha em um ano variou de 125 a 322. As flechas máximas estimadas variaram de 2,1 a 3,25 vezes a flecha elástica; baseadas no $A C I 318$ (1978) também ficaram dentro desta variação.

O método prático seguinte é proposto pelo $C E B-90$ (1991) para uma estimativa de flechas de estruturas de concreto, levando em consideração os efeitos de fissuração e de deformação lenta.

Com relação às flechas de longa duração, a estrutura pode ser avaliada pelas seguintes relações:

LUEBKEMAN, C.H.; NILSON, A.H.; SLATE, F.O. (1985). Sustained load deflection of high strength concrete beams, Departament of Structural Engineering, Cornell University, Feb apud NILSON, A.H. (1985). Design implications of current research on high strength concrete. In: RUSSEL, H.G. High-strength concrete. Detroit, ACI, p.85-118. (SP-87), p.92. 
No caso de estrutura não fissurada $\left(M_{d}<M_{r}\right)$ :

$$
a=(1+\varphi) \cdot a_{c}
$$

Em todos os casos onde é esperada a físsuração $\left(M_{d} \geq M_{r}\right)$ :

$$
a=\left(\frac{h}{d}\right)^{3} \cdot \eta \cdot\left(1-20 \rho_{m}^{\prime}\right) \cdot a_{c}
$$

com $M_{r}=W_{c} f_{c t}$, onde:

$a_{c} \quad$ flecha elástica calculada com rigidez $E_{c} I_{c}$ da seção bruta (desprezando a armadura);

$\mathrm{M}_{\mathrm{d}}$ momento fletor de cálculo na seção do meio do vão da viga, obtido para combinação frequente das ações;

$\rho_{\mathrm{m}} \quad$ taxa geométrica média de armadura de tração do vão considerado;

$\rho_{m}^{\prime} \quad$ taxa geométrica média de armadura de compressão do vão considerado;

$\eta \quad$ fator de correção (ver tabela 5.2), incluindo os efeitos da armadura, fissuração e deformação lenta.

TABELA 5.2 - Fator de correção $\eta$ para estimativa de flechas em concretos de resistência usual.

\begin{tabular}{|c|c|c|c|c|c|c|c|}
\hline$\rho_{\mathrm{m}}(\%)$ & 0,15 & 0,2 & 0,3 & 0,5 & 0,75 & 1,0 & 1,5 \\
\hline$\eta$ & 10 & 8 & 6 & 4 & 3 & 2,5 & 2 \\
\hline
\end{tabular}

As flechas de longa duração podem ser consideravelmente teduzidas se o concreto de alta resistência for usado no lugar do concreto comum. As razões estão relacionadas à melhoria das propriedades dos concretos de alta resistência, como o módulo de deformação longitudinal, a resistência à tração e o coeficiente de deformação lenta.

Segundo o FIP/CEB-197 (1990), as equações (5.4) e (5.5) são suficientemente gerais e levam em consideração os parâmetros médios que governam as flechas de 
longa duração. Portanto, eles também são válidos para estruturas feitas com concreto de alta resistência, exceto para o fator de correção $\eta$, que é calculado usando um coeficiente de deformação lenta $\varphi=2,5$, que é um valor médio razoável sob condições usuais para o concreto comum.

Para o concreto de alta resistência, os valores de deformação lenta podem ser consideravelmente reduzidos. Este efeito favorável pode ser introduzido na estimativa das flechas, modificando o fator $\eta$, dado na tabela 5.2 , da seguinte maneira:

$$
\eta(\varphi)=\frac{5+\varphi}{7,5} \eta
$$

Pela NBR 6118 (1978), a flecha em vigas pode ser determinada considerandose apenas o estádio II.

$\mathrm{O}$ módulo de deformação longitudinal $\mathrm{E}_{\mathrm{c}}$ adotado é o módulo de deformação secante do concreto que se supõe $90 \%$ do módulo de deformação tangente na origem, no caso de ações de curta duração.

Para ações de longa duração, a flecha final pode ser avaliada como o produto da flecha imediata respectiva pela relação das curvaturas final e inicial na seção de maior momento em valor absoluto, calculadas através de:

$$
\frac{1}{I}=\frac{\left|\varepsilon_{c}\right|+\varepsilon_{s}}{d}
$$

fazendo $\varepsilon_{\mathrm{c}}$ final igual a 3 vezes o valor de $\varepsilon_{\mathrm{c}}$ inicial e $\varepsilon_{\mathrm{s}}$ constante e igual ao seu valor inicial.

$\varepsilon_{\mathrm{c}}$ final pode ser tomado como 2 vezes o valor inicial, para ações de longa duração aplicadas 6 meses, ou mais, após a concretagem.

É necessário verificar a validade dessas prescrições para vigas com concreto de alta resistência.

Os ensaios realizados por PINTO JR (1992) mostraram que as vigas de concreto de alta resistência têm maior deformabilidade depois da fissuração e uma fissuração menos difusa, em comparação com aquelas que ocorrem nas vigas executadas com concretos usuais. 
NILSON (1985) concluiu que as flechas produzidas por ações de curta duração de vigas de concreto armado são muito bem previstas pelos procedimentos do $A C I$ 318 e que as flechas causadas por ações duradouras são menores que as previstas pelas equações, por causa da baixíssima deformação lenta.

\subsection{ARMADURAS MINIMAS DE FLEXÃO DAS VIGAS}

A fissuração é quase inevitável em estruturas de concreto armado sujeitas a flexão, cortante, torçor ou tração, resultantes ou de ações diretas ou de recalques de apoio. A fissuração deve ser geralmente limitada a um nivel esperado para não prejudicar o funcionamento e a durabilidade da estrutura ou causar aparência inaceitável.

As armaduras mínimas de flexão têm como objetivo garantir que a ruína, se ocorrer, seja gradual e precedida de sinais de advertência. Para que isso ocorra é necessário que a tração fornecida ao concreto fissurado seja transferida para a armadura, levando a armadura tracionada ao escoamento antes da ruptura do concreto comprimido.

Como consequência desses aspectos, exige-se que as peças fletidas respeitem certos valores mínimos para suas armaduras de tração, evitando que ocorra uma ruptura brusca.

$\mathrm{O}$ aumento da intensidade das ações diretas ou recalques de apoio provocam aumento das solicitações das peças estruturais. Essas solicitações podem atingir valores tais, suficientes para causar a fissuração do concreto.

Não entram na consideração das armaduras mínimas de flexão os estados de coação, causados por deformações inibidas de retração ou de temperatura. $\mathrm{O}$ início da fissuração provoca a queda de rigidez do material, nesses estados de coação interna, dando-se um processo de relaxação das tensões internas. $O$ processo de fissuração é progressivo nesses casos. 


\subsubsection{Prescrições atuais referentes ao mínimo das armaduras tracionadas}

O Texto Base da NBI (1993) apresenta, em seu item 15.1.2.2a, os valores recomendados para o cálculo de armaduras longitudinais de vigas:

"As armaduras longitudinais de vigas devem respeitar os seguintes limites:

Valores mínimos:

Armaduras de tração:

$$
\begin{aligned}
& A_{s, \text { min }}=0,25 \% \cdot b_{t} \cdot d \text {, para aço CA25 } \\
& A_{s, \text { min }}=0,15 \% \cdot b_{t} \cdot d \text {, para aços CA50 e CA60 }
\end{aligned}
$$

sendo $b_{t}$ a largura média da zona de tração, no caso de vigas $T$ onde a linha neutra corta a mesa de compressão o valor de $b_{\mathfrak{t}}$ deve considerar só a alma desta. "

A expressão presente no $A C I 318$ (1989) para a taxa mínima de armadura:

$$
\rho_{\min }=\frac{1,38}{f_{y}}, \quad \text { para } f_{y} \text { em } M P a
$$

é deduzida baseando-se em que o momento resistente da seção fissurada deve ser igual ao momento que causou a fissura na peça, com base na tensão de ruptura. Segundo CARRASQUILLO et al (1981) \& MARTINEZ et al (1982), desde que a tensão de ruptura seja maior para concreto de alta resistência que para concreto de resistência menor, fica evidente que a resistência do concreto deve ser incluída numa versão revisada da eq. (5.8). Com a tensão de ruptura tomada por $0,62 \sqrt{f_{c}^{\prime}}(\mathrm{MPa})$, pode se mostrar que:

$$
\rho_{\text {min }}=\frac{0,22 \sqrt{f_{c}^{\prime}}}{f_{y}} \geq \frac{1,38}{f_{y}}
$$

seria uma equação apropriada para todas as resistências do concreto entre $21 \mathrm{MPa}$ e $83 \mathrm{MPa}$. 
Segundo NILSON (1985), a eq. (5.9) é apropriada apenas para $f_{c}^{\prime}$ abaixo de $34 \mathrm{MPa}$. Acima desse valor de resistência, é gradativamente não-conservativo e, em níveis extremos de variação da resistência, pode ser $50 \%$ maior.

O CEB-90 (1991) prescreve um item para taxa minima de armadura longitudinal em vigas:

$$
\rho_{s}=\frac{A_{s}}{b_{t} \cdot d}
$$

onde $b_{t}$ representa a largura média da zona tracionada do concreto.

Na viga $T$, se a linha neutra no estado limite último é localizada na mesa, a largura da mesa não é levada em conta na avaliação de $b_{\mathfrak{\imath}}$.

$$
\rho_{s} \geq\left\{\begin{array}{l}
0,0015 \text { para aços classe } S 400 \text { e } 5500 \\
0,0025 \text { para aços classe S220 }
\end{array}\right.
$$

\subsubsection{Armaduras mínimas de flexão}

Para se obterem as armaduras mínimas de flexão, impõe-se a hipótese de que a armadura tracionada escoa, quando, em virtude das solicitações externas, a seção fissura.

Quando as solicitações superam muito os valores de cálculo $S_{d}=\gamma_{f} S_{k}$ devem produzir um sinal de advertência na iminência da ruptura. Esse sinal de advertência é a fissuração.

Aqui, é desprezada a fissuração provocada por estados de coação, já que, nesses casos, eles causam rupturas de tração progressivas, que ocorrem com a relaxação dos esforços internos atuantes.

A tensão na armadura pode chegar a um valor igual a $f_{y k}$, resistência característica de escoamento, na peça fissurada. A diferença entre $f_{y k}$ e a resistência à ruptura é suficiente para o objetivo dessa armadura.

A finalidade é proporcionar um sinal de advertência efetivo antes da estrutura alcançar o colapso, mesmo sofrendo uma situação mais enérgica que a permitida para a consideração dos estados limites últimos. 
A armadura mínima de flexão é determinada pela expressão:

$$
A_{s, \min } f_{y k} z_{I I}=M_{r}
$$

sendo $z_{\text {II }}$ o braço de alavanca dos esforços internos da seção no estádio II e $M_{r} \circ$ momento de fissuração.

$$
A_{s, \min }=\frac{M_{r}}{f_{y k} z_{I I}}
$$

Para seções retangulares, admite-se que o braço de alavanca dos esforços internos de flexão vale $\mathrm{z}=0,85 \mathrm{~h}$.

Segundo o Anexo da NBR 7197 (1989), para seção retangular sem armadura, o momento de fissuração calculado no estádio I resulta:

$$
M_{r}=\frac{b h^{2}}{4} f_{t k}
$$

Pela igualdade dos momentos resistentes antes e depois da fissuração, tem-se:

$$
\begin{gathered}
A_{s, \min } f_{y k} 0,85 h=\frac{b h^{2}}{4} f_{t k} \\
A_{s, \min }=\frac{b h}{3,4} \frac{f_{t k}}{f_{y k}}
\end{gathered}
$$

Como consequência,

$$
\rho_{s, \min }=\frac{A_{s, \min }}{b h}=0,30 \frac{f_{t k}}{f_{y k}}
$$

As posições da linha neutra nos estádios I e II não são muito diferentes entre si, para as seções $\mathrm{T}$ com mesa comprimida e pouca espessa. As posições estão próximas à face voltada para a alma da seção. 
Obtém-se, aproximadamente, a mesma condição, válida para seções retangulares, expressa na eq. (5.31), quando se igualam os momentos correspondentes aos estádios I e II.

A determinação da taxa mínima de armadura longitudinal das vigas de concreto de alta resistência foi um aspecto, da pesquisa experimental de PINTO JR (1992), que causou as maiores surpresas, já que as previsões teóricas efetuadas não se confirmaram nos ensaios realizados.

\subsection{APLICAÇÕES}

Com o objetivo de comparar o momento de cálculo no estado limite último, assumindo uma distribuição retangular de tensões de compressão, e o momento último experimental, são feitas as seguintes aplicações.

São utilizados os trabalhos experimentais de PINTO JR (1992), BERNHARDT \& FYNBOE (1986), MARRO (1987) e LAMBOTTE \& TAERWE (1990).

As características das vigas, como resistência à compressão do concreto, taxas de armaduras longitudinal e transversal, traço, tipo de cura, dimensões, etc. são distintas. Portanto, as conclusões aqui encontradas não podem ser consideradas definitivas.

a) PINTO JR (1992)

Antes de fazer a análise comparativa dos seus resultados, é importante destacar as observações citadas em seu trabalho. As vigas ensaiadas apresentaram comportamento instável após a formação de fissuras, devido às baixas taxas de armadura, fator causador do esgotamento prematuro de suas capacidades resistentes e que é justificado pela Mecânica da Fratura. 

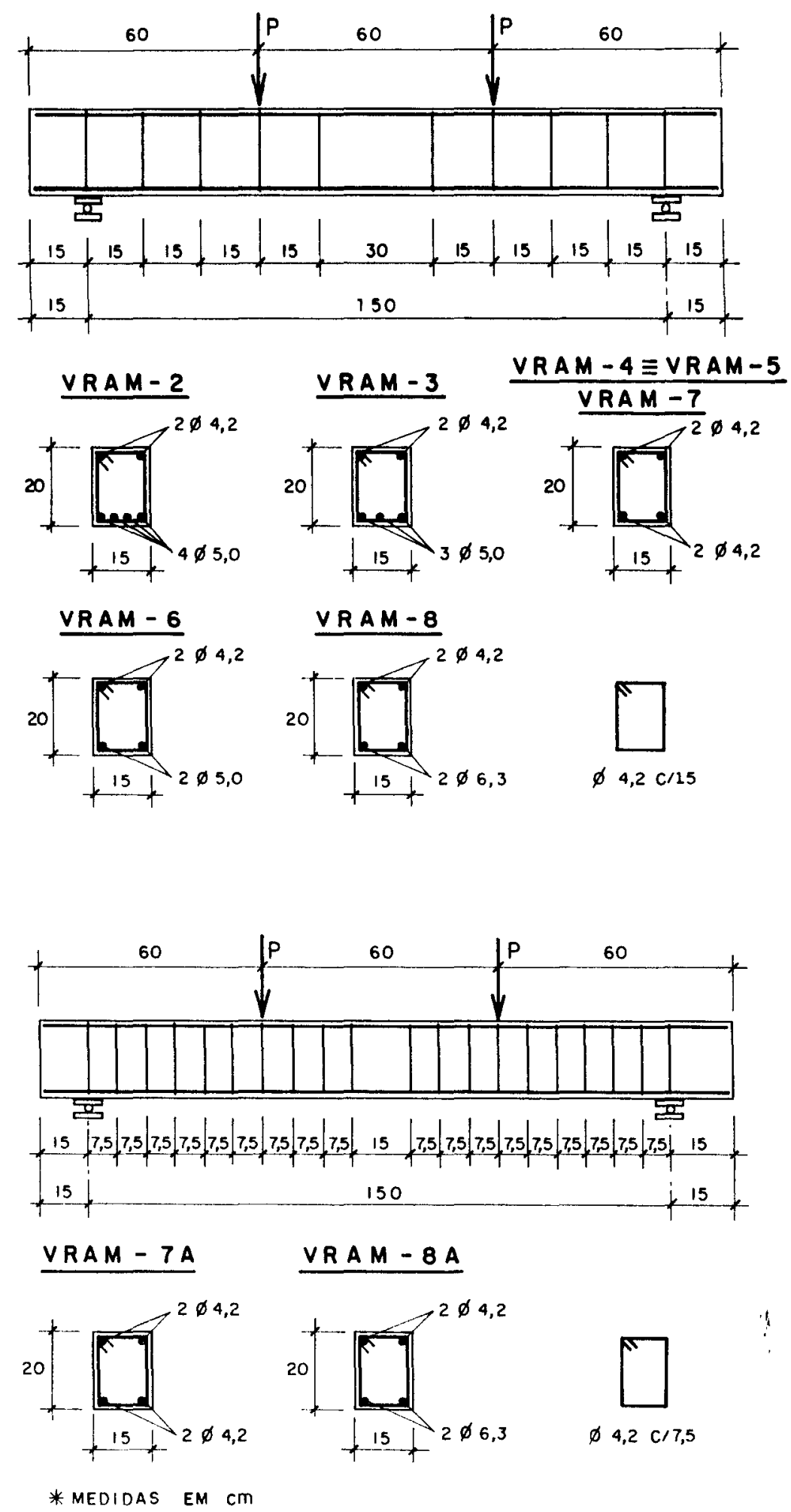

FIGURA 5.6 - Características e esquemas de carregamento das vigas ensaiadas por PINTO JR (1992). 
$B O S C O$ et al (1990) realizaram pesquisa experimental, visando quantificar a taxa de armadura minima longitudinal para as vigas de concreto de alta resistência, que foi desenvolvida à luz dos conceitos da Mecânica da Fratura. Porém, PINTO JR (1992) teve acesso aos resultados de BOSCO et al somente após a realização dos seus próprios ensaios.

As características geométricas e os esquemas de carregamento das vigas ensaiadas estão representados na figura 5.6. Na tabela 5.3, são apresentados os valores últimos teóricos e experimentais para os momentos das vigas.

TABELA 5.3 - Valores de momentos últimos teóricos e experimentais - PINTO JR (1992)

\begin{tabular}{|c|c|c|c|c|c|c|}
\hline VIGA & $\begin{array}{c}\mathbf{f}_{\mathbf{c}} \\
\mathbf{M P a}\end{array}$ & $\begin{array}{c}\mathbf{f}_{\mathbf{y}} \\
\mathbf{M P a}\end{array}$ & $\begin{array}{c}\mathbf{A}_{\mathbf{s}} \\
\mathbf{c m}^{2}\end{array}$ & $\begin{array}{c}\mathbf{M}_{\mathbf{u}} \\
\mathbf{k N m}\end{array}$ & $\begin{array}{c}\mathbf{M}_{\mathbf{u}, \mathbf{e x p}} \\
\mathbf{k N m}\end{array}$ & $\mathbf{M}_{\mathbf{u}, \mathbf{e x p}} / \mathbf{M}_{\mathbf{u}}$ \\
\hline VRAM-2 & 61,7 & 850 & 0,920 & 13,75 & 9,00 & 0,65 \\
\hline VRAM-3 & 79,3 & 850 & 0,690 & 10,41 & 7,88 & 0,76 \\
\hline VRAM-4 & 70,5 & 800 & 0,286 & 4,09 & $*$ & - \\
\hline VRAM-5 & 80,4 & 800 & 0,286 & 4,10 & $*$ & - \\
\hline VRAM-6 & 66,3 & 850 & 0,460 & 6,96 & 5,63 & 0,81 \\
\hline VRAM-7 & 65,5 & 800 & 0,286 & 4,09 & 5,63 & 1,38 \\
\hline VRAM-7A & 74,3 & 800 & 0,286 & 4,09 & $*$ & - \\
\hline VRAM-8 & 75,0 & 595 & 0,706 & 7,48 & 7,61 & 1,02 \\
\hline VRAM-8A & 70,2 & 595 & 0,706 & 7,48 & 3,58 & 0,48 \\
\hline
\end{tabular}

$\left(^{*}\right)$ Na viga VRAM-4, ocorreu ruptura repentina da armadura na seção fissurada, o que configurou um comportamento frágil da peça. Na viga VRAM-5, foi notada uma grande abertura de fissura, indicativo de escoamento da armadura, não se conhecendo, no entanto, o estágio de carregamento em que esse escoamento ocorreu. $\mathrm{Na}$ viga 
VRAM-7A, imediatamente após o aparecimento da fissura, que surgiu com grande profundidade, ocorreram duas reduções sucessivas do nível de carga aplicada.

b) BERNHARDT \& FYNBOE (1986)

BERNHARDT \& FYNBOE (1986) ensaiaram 19 vigas à flexão, com idades que variaram de 28 a aproximadamente 570 dias. As dimensões das vigas eram $15 \times 20 \times 285 \mathrm{~cm}$. Os arranjos da armadura e as posições das ações durante os ensaios são mostrados na figura 5.7 .

A tabela 5.4 resume os dados importantes e os resultados de ensaios para vigas com ruptura por flexão.
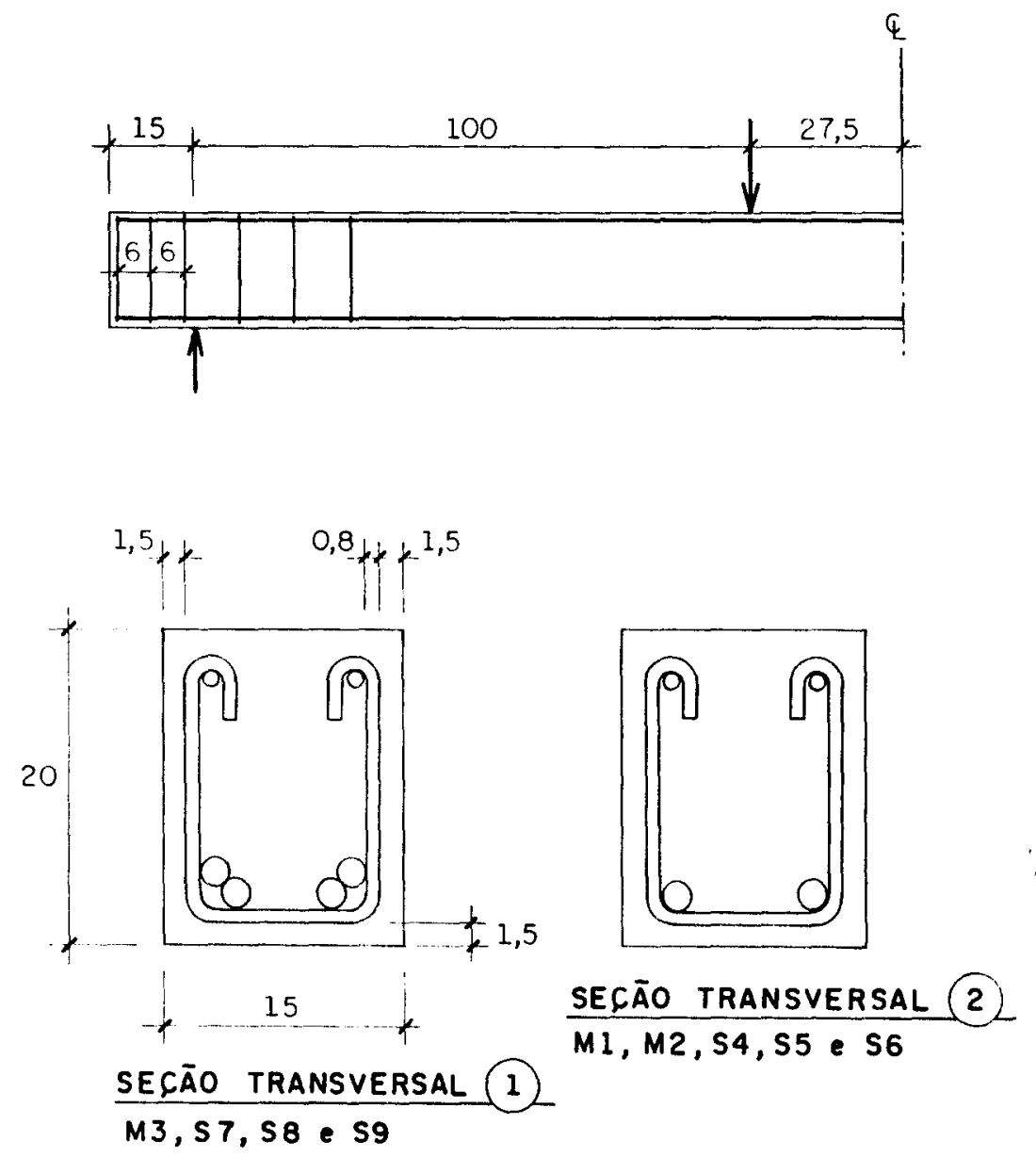

FIGURA 5.7 - Caracteristicas e esquemas de carregamento das vigas ensaiadas por BERNHARDT \& FYNBOE (1992). 
TABELA 5.4 - Valores de momentos últimos teóricos e experimentais BERNHARDT \& FYNBOE (1986).

\begin{tabular}{|c|c|c|c|c|c|c|}
\hline VIGA & $\begin{array}{c}\mathbf{f}_{\mathbf{c}} \\
\mathbf{M P a}\end{array}$ & $\begin{array}{c}\mathbf{f}_{\mathbf{y}} \\
\mathbf{M P a}\end{array}$ & $\begin{array}{c}\mathbf{A}_{\mathbf{s}} \\
\mathbf{c m}^{\mathbf{2}}\end{array}$ & $\begin{array}{c}\mathbf{M}_{\mathbf{u}} \\
\mathbf{k N m}\end{array}$ & $\begin{array}{c}\mathbf{M}_{\mathbf{u}, \mathbf{e s p}} \\
\mathbf{k N m}\end{array}$ & $\mathbf{M}_{\mathbf{u}, \mathbf{e x p}} \mathbf{M}_{\mathbf{u}}$ \\
\hline $\mathbf{M 1 A}$ & 81,3 & 511 & 4,02 & 32,5 & 33,1 & 1,02 \\
\hline M1B & 81,3 & 511 & 4,02 & 32,5 & 31,9 & 0,98 \\
\hline M1C & 102,9 & 511 & 4,02 & 33,0 & 34,4 & 1,04 \\
\hline M2A & 81,3 & 510 & 6,28 & 48,0 & 49,4 & 1,03 \\
\hline M2B & 81,3 & 510 & 6,28 & 48,0 & 50,7 & 1,06 \\
\hline M2C & 105,4 & 510 & 6,28 & 49,4 & 55,4 & 1,12 \\
\hline M3A & 81,3 & 510 & 12,56 & 78,6 & 81,9 & 1,04 \\
\hline M3B & 81,3 & 510 & 12,56 & 78,6 & 79,9 & 1,02 \\
\hline M3C & 102,9 & 510 & 12,56 & 83,6 & 88,4 & 1,06 \\
\hline S4A & 86,3 & 510 & 6,28 & 48,3 & 57,1 & 1,18 \\
\hline S4B & 86,3 & 510 & 6,28 & 48,3 & 51,7 & 1,07 \\
\hline S4C & 104,6 & 510 & 6,28 & 49,3 & 50,9 & 1,03 \\
\hline S5B & 86,3 & 510 & 6,28 & 48,3 & 50,5 & 1,05 \\
\hline S5C & 104,6 & 510 & 6,28 & 49,3 & 53,1 & 1,08 \\
\hline S7C & 102,1 & 510 & 12,56 & 83,5 & 85,9 & 1,03 \\
\hline S8C & 102,1 & 510 & 12,56 & 83,5 & 85,8 & 1,03 \\
\hline
\end{tabular}

c) MARRO (1987)

$M A R R O$ (1987) realizou ensaios à flexão em 8 vigas de concretos de alta e baixa resistências. Os ensaios foram desenvolvidos essencialmente para explorar o campo de altas taxas de armadura. 
A figura 5.8 apresenta as características geométricas das vigas ensaiadas. E a tabela 5.5 apresenta o resumo para análise.
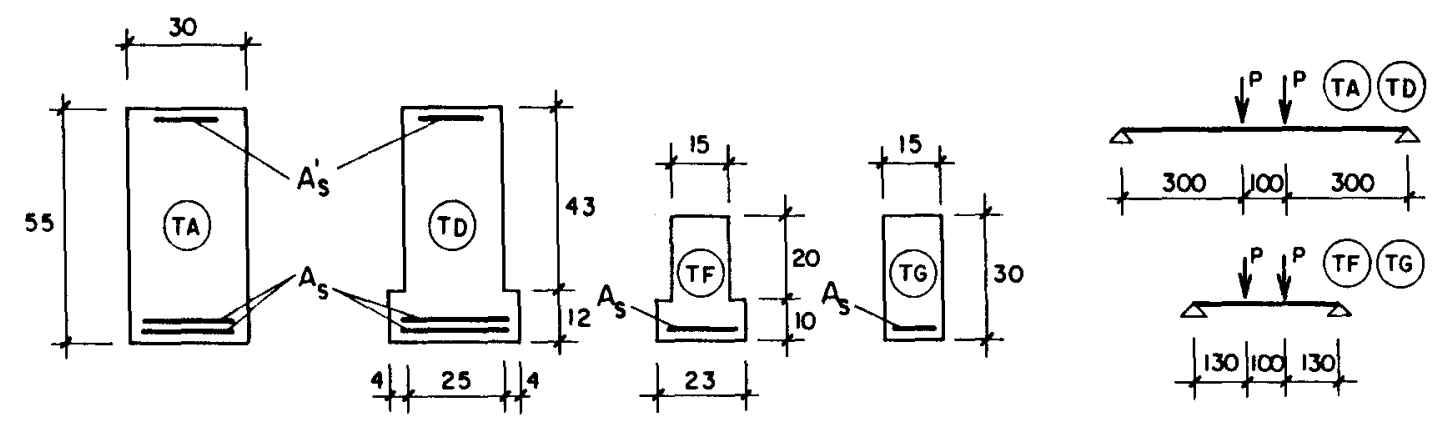

FIGURA 5.8 - Caracteristicas e esquemas de carregamento das vigas ensaiadas por MARRO (1987).

TABELA 5.5 - Valores de momentos últimos teóricos e experimentais - MARRO (1987).

\begin{tabular}{|c|c|c|c|c|c|c|}
\hline VIGA & $\begin{array}{c}\mathbf{f}_{\mathbf{c}} \\
\mathbf{M P a}\end{array}$ & $\begin{array}{c}\mathbf{f}_{\mathbf{y}} \\
\mathbf{M P a}\end{array}$ & $\begin{array}{c}\mathbf{A}_{\mathbf{s}} \\
\mathbf{c m}^{2}\end{array}$ & $\begin{array}{c}\mathbf{M}_{\mathbf{u}} \\
\mathbf{k N m}\end{array}$ & $\begin{array}{c}\mathbf{M}_{\mathbf{u}, \mathbf{e x p}} \\
\mathbf{k N m}\end{array}$ & $\mathbf{M}_{\mathbf{u}, \mathbf{e x p}} / \mathbf{M}_{\mathbf{u}}$ \\
\hline TA35/1 & 35 & 460 & 32,50 & 642,0 & 650 & 1,01 \\
\hline TA35/2 & 31 & 460 & 32,50 & 633,0 & 650 & 1,03 \\
\hline TA70/1 & 49 & 460 & 63,50 & 1185,0 & 1140 & 0,96 \\
\hline TA70/2 & 53 & 460 & 63,50 & 1208,0 & 1170 & 0,96 \\
\hline TA70/3 & 66 & 490 & 63,50 & 1319,0 & 1310 & 0,99 \\
\hline TD90/1 & 73 & 470 & 70,00 & 1368,0 & 1392 & 1,01 \\
\hline TF90/1 & 76 & 450 & 21,00 & 206,0 & 206 & 1,00 \\
\hline TG90/1 & 76 & 450 & 14,00 & 146,0 & 145 & 0,99 \\
\hline
\end{tabular}


d) LAMBOTTE \& TAERWE (1990)

O programa de ensaios consistiu de uma série de 6 vigas, que tinham $20 \times 45 \mathrm{~cm}$ de seção transversal e possuíam vão de $5 \mathrm{~m}$ (figura 5.9 ). Foram usadas três taxas de armadura, isto é, $0,48 \%, 0,97 \%$ e $1,45 \%$ e a armadura era formada de barras de $\phi 16 \mathrm{~mm}$. A tabela 5.6 apresenta o resumo dos valores de cálculo e os obtidos experimentalmente.

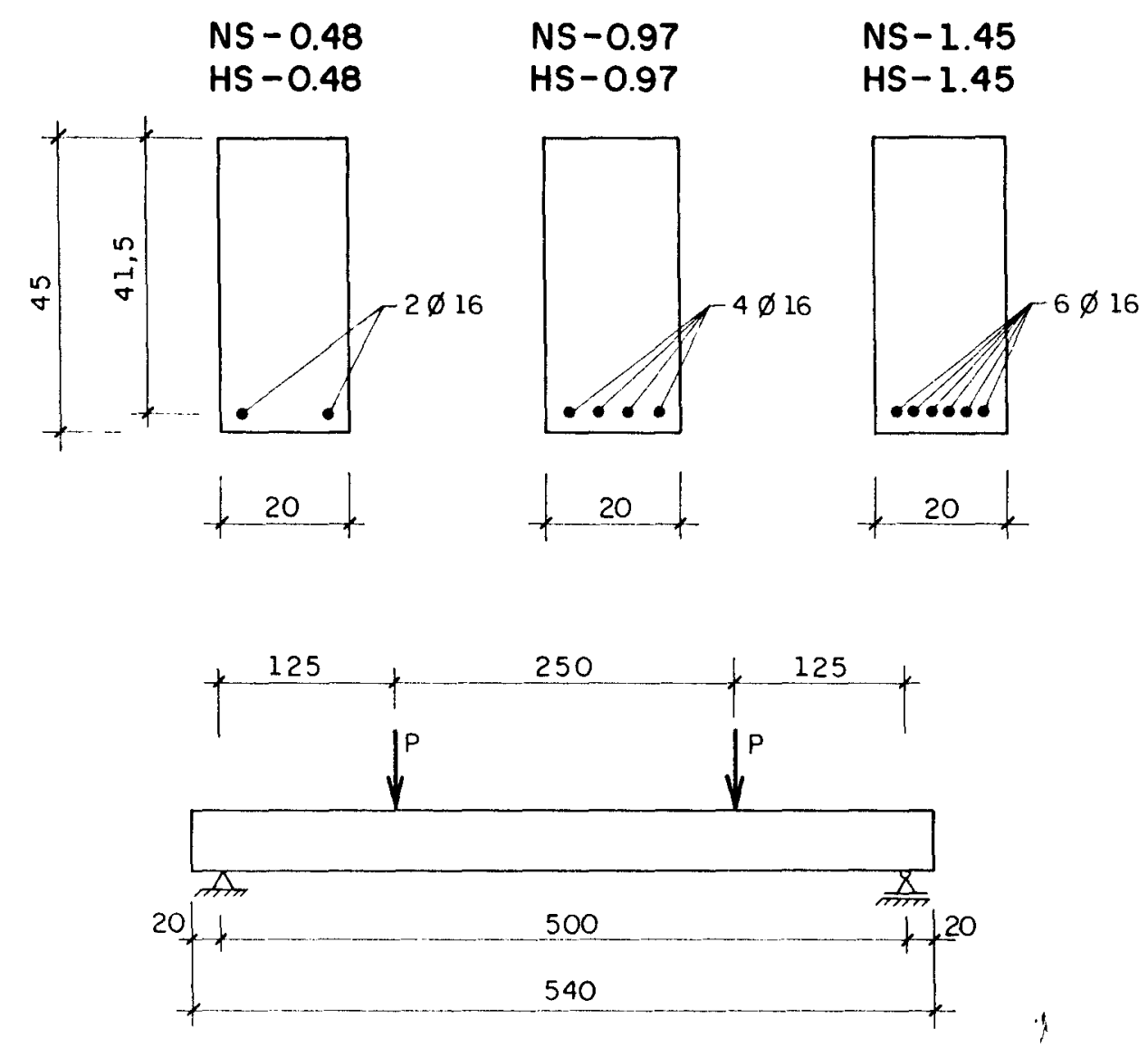

FIGURA 5.9 - Características e esquemas de carregamento das vigas ensaiadas por LAMBOTTE \& TAERWE (1990). 
TABELA 5.6 - Valores de momentos últimos teóricos e experimentais - LAMBOTTE \& TAERWE (1990).

\begin{tabular}{|c|c|c|c|c|c|c|}
\hline VIGA & $\begin{array}{c}\mathbf{f}_{\mathbf{c}} \\
\mathbf{M P a}\end{array}$ & $\begin{array}{c}\mathbf{f}_{\mathbf{y}} \\
\mathbf{M P a}\end{array}$ & $\begin{array}{c}\mathbf{A}_{\mathbf{s}} \\
\mathbf{c m}^{2}\end{array}$ & $\begin{array}{c}\mathbf{M}_{\mathbf{u}} \\
\mathbf{k N m}\end{array}$ & $\begin{array}{c}\mathbf{M}_{\mathrm{u}, \mathrm{exp}} \\
\mathbf{k N m}\end{array}$ & $\mathbf{M}_{\mathrm{u}, \mathrm{exp}} / \mathbf{M}_{\mathbf{u}}$ \\
\hline $\mathbf{N S - \mathbf { 0 . 4 8 }}$ & 36,3 & 545 & 4,32 & 92,0 & 94,5 & 1,03 \\
\hline $\mathbf{H S - 0 . 4 8}$ & 80,9 & 545 & 4,32 & 95,5 & 102,0 & 1,07 \\
\hline NS-0.97 & 37,2 & 545 & $\mathbf{8 , 7 3}$ & 174,7 & 165,7 & 0,95 \\
\hline HS-0.97 & 81,1 & 545 & $\mathbf{8 , 7 3}$ & 188,3 & 180,7 & 0,96 \\
\hline NS-1.45 & 34,0 & 545 & 13,05 & 237,9 & 232,0 & 0,98 \\
\hline HS-1.45 & 81,6 & 545 & 13,05 & 274,9 & 270,7 & 0,98 \\
\hline
\end{tabular}

e) Análise dos resultados

Analisando os resultados vistos nas tabelas 5.4 a 5.6, pôde-se observar que, na sua maioria, os valores últimos experimentais foram coerentes com os valores calculados de acordo com a Teoria do Concreto Armado. Os resultados divergentes obtidos por PINTO JR (1992), resumidos na tabela 5.3, mostram que, para baixas taxas de armadura longitudinal (próximas ao valor mínimo sugerido pelas normas atuais), ocorrem alterações no comportamento. Então deve ser determinado um novo valor para a percentagem mínima de armadura longitudinal das vigas de concreto de alta resistência, com o objetivo de garantir a validade da Teoria.

Conclui-se então que as regras da Teoria do Concreto Armado para a determinação da resistência última à flexão podem ser estendidas a concreto de alta resistência. Alguns pesquisadores alertam que existe perigo de colapso prematuro devido à ruptura brusca do cobrimento e a ruptura pode ser dúctil ou explosiva; e a flecha e a fissuração podem provocar problemas de utilização sob tensões elevadas. 


\section{CISALHAMENTO EM VIGAS}

\subsection{GENERALIDADES}

A fissuração, a resistência ao cisalhamento, o modo de ruptura ao cisalhamento e a ductilidade das vigas são, usualmente, assumidos como dependentes da relação entre a distância de aplicação da carga e a altura útil, a/d, da taxa de armadura de cisalhamento, da resistência à compressão axial, da taxa de armadura longitudinal e de outras variáveis.

A resistência total ao cisalhamento de uma viga é expressa como a soma das contribuições do concreto e da armadura transversal. A contribuição do concreto é dependente do concreto ainda não fissurado, da resistência fornecida pelo engrenamento dos agregados ao longo da face da fissura diagonal e do efeito de pino, fornecido pela armadura longitudinal.

Uma caracteristica da ruptura do concreto de alta resistência solicitado à compressão axial é que ocorre bruscamente; sendo assim, forma-se uma superficie de ruptura lisa e quase plana. Isso contrasta com a superficie de ruptura rugosa, característica do concreto de baixa resistência, com a fissuração interna acompanhando a interface entre o agregado e a pasta, depois se ramificando através da argamassa. Os planos de fissuras lisos ocorrem por causa das diferenças entre resistência e rigidez da pasta em relação ao agregado, valores que são relativamente menores. Além disso, a rigidez da interface é significativamente maior. 
Sabe-se que, na região da fissuração diagonal de vigas que são controladas pela força cortante, o estado de tensão é biaxial, combinando a compressão diagonal, na direção que vai do ponto de aplicação da carga até o apoio, com tração diagonal na direção perpendicular. Era, portanto, de se esperar que a superfície da fissura diagonal de tração na viga de concreto de alta resistência fosse lisa, como na compressão axial.

No $A C I 363$ (1992), comenta-se que alguns ensaios confirmam que a interligação dos agregados decresce com o aumento da resistência do concreto. Desta forma, uma deficiência na resistência ao cisalhamento pode ser produzida, que não é levada em conta pelas equações de cálculo.

A ruptura por cisalhamento em estruturas de concreto armado é, geralmente, brusca e frágil por causa da falta de ductilidade, que pode ser definida como a habilidade de experimentar grandes deformações. Com o desenvolvimento do concreto com resistências maiores, as questões relativas ao cisalhamento e associadas à ruptura estão se tornando cada vez mais importantes. Apesar dos vários estudos realizados no exterior, não há ainda uma teoria aceitável para prever com confiança o comportamento e a ruptura associada a peças de concreto armado ao cisalhamento.

Com respeito à fragilidade do material, MPHONDE \& FRANTZ (1985) comentam que, geralmente, com o crescimento da taxa de armadura transversal, as vigas se tornaram mais dúcteis e as rupturas foram menos bruscas. E todas as vigas que não tinham estribos romperam bruscamente.

De acordo com THORENFELDT \& DRANGSHOLT (1990), a resistência última ao cisalhamento aumenta com a diminuição da relação entre a distância de aplicação da carga e a altura útil e com o aumento da taxa de armadura longitudinal. Concluíram também que o uso de concreto com resistência acima de $80 \mathrm{MPa}$ pode resultar num decréscimo da resistência última ao cisalhamento. Uma razão provável para este comportamento é o decréscimo da ductilidade do concreto com o aumento da resistência.

De acordo com o anexo da NBR 7197 (1989), que altera os dispositivos da NBR 6118 (1978), o valor de cálculo da tensão convencional de cisalhamento no concreto, na alma das peças (tensão de referência) é determinado por: 


$$
\tau_{w d}=\frac{V_{d}}{b_{w} d}
$$

A armadura transversal das peças lineares, para resistir aos esforços oriundos da força cortante, deve ser calculada pela teoria clássica de $M O ̈ R S C H$, com base na seguinte tensão (em MPa):

$$
\tau_{d}=1,15 \tau_{w d}-\tau_{c}>0
$$

com

$$
\tau_{c}=\Psi_{1} \sqrt{t_{c k}}
$$

sendo, nos casos apresentados neste trabalho, $\psi_{1}=0,15$, válido na flexão simples e na flexo-tração com a linha neutra cortando a seção.

O cálculo da força cortante resistente, através do EC-2 (1989), considera uma soma da contribuição do concreto $\left(\mathrm{V}_{\mathrm{cd}}\right)$ com a contribuição da armadura de cisalhamento $\left(\mathrm{V}_{\mathrm{wd}}\right)$. Essa soma, aqui, chama-se $\mathrm{V}_{\mathrm{d}, \mathrm{EC}}$.

A contribuição do concreto, $V_{c d}$, é igual a $V_{R d l}$, obtida através de:

$$
V_{R d 1}=\left[\tau_{R d} k\left(1,2+40 \rho_{1}\right)+0,15 \sigma_{c p}\right] b_{w} d
$$

A parcela $0,15 \sigma_{\mathrm{cp}}$ é igual a zero, uma vez que, neste trabalho, nenhuma das vigas a serem analisadas possuem protensão. $\mathrm{E}$ :

$\tau_{\mathrm{Rd}}=\left(0,25 \mathrm{f}_{\mathrm{ctk} 0,05}\right) / \gamma_{\mathrm{c}} \quad$ é a resistência básica de cisalhamento; por se trạtar de valores experimentais, considera-se $\gamma_{\mathrm{c}}=1,0$

$f_{\text {ctk } 0,05}=0,7 f_{\text {ctm }}$, com: $f_{c t m}=0,30 f_{c k}^{2 / 3}$

$\mathrm{k}=1$, para peças onde mais de $50 \%$ da armadura inferior é interrompida

$k=1,6-d \geq 1, d$ em metros, nos demais casos

$$
\rho_{1}=\frac{A_{s} \ell}{b_{w} d} \leq 0,2
$$


$\mathrm{A}_{\mathrm{sl}}$ área da armadura de tração que se estende a uma distância mínima de $\mathrm{d}+\mathrm{b}_{\mathrm{b}}$ além da seção considerada

$b_{w} \quad$ largura da alma

A contribuição da armadura, $\mathrm{V}_{\mathrm{wd}}$, é dada pela equação:

$$
V_{w d}=\frac{A_{s w}}{S} 0,9 d f_{y w d}
$$

$\mathrm{A}_{\mathrm{sw}} \quad$ área da armadura de cisalhamento

s espaçamentos entre os estribos

$f_{\text {ywd }}$ tensão de escoamento de cálculo da armadura de cisalhamento

Resumindo:

$$
V_{d, E C}=\tau_{R d} k\left(1,2+40 \rho_{1}\right) b_{w} d+\frac{A_{s w}}{S} 0,9 d f_{y w d}
$$

No CEB-90 (1991), de acordo com a verificação do estado limite último, a resistência máxima ao cisalhamento, para uma dada seção e resistência do concreto, é obtida $\operatorname{com} \theta=45^{\circ}$, onde $\theta$ é o ângulo entre a biela comprimida e a horizontal. $O$ ângulo $\alpha$ é o que fica entre a armadura de cisalhamento e a horizontal.

$$
V_{R d, \max }=\frac{f_{c d 2}}{2} b_{w} z(1+\operatorname{cotg} \alpha)
$$

sendo:

$$
f_{c d z}=0,60\left[1-\frac{f_{c k}}{250}\right] f_{c d}
$$

Para as vigas armadas são feitas quatro verificações: banzo tracionado, banzo comprimido, esmagamento da biela comprimida e tração da armadura transversal. Adota-se o menor valor. 
a) Banzo tracionado

$$
F_{R t}=A_{s} f_{y d}
$$

$\mathrm{A}_{\mathrm{s}} \quad$ área da armadura longitudinal

$f_{y d}$ tensão de escoamento da armadura

b) Banzo comprimido

$$
F_{R c}=f_{c d 1} A_{c}+f_{y c d} A_{s c}
$$

sendo:

$$
f_{c d 1}=0,85\left[1+\frac{f_{c k}}{250}\right] f_{c d}
$$

$\mathrm{A}_{c} \quad$ área da seção de concreto comprimido

$f_{\text {ycd }}$ tensão de escoamento da armadura de compressão

$\mathrm{A}_{\mathrm{sc}}$ área da armadura de compressão

c) Esmagamento da biela comprimida

$$
F_{R C w}=f_{c d 2} b_{w} z \cos \theta
$$

d) Tração da armadura transversal

$$
F_{R t w}=\left[\frac{A_{S w} f_{y d}}{S}\right] z
$$

$\mathrm{A}_{\mathrm{sw}} \quad$ área da armadura transversal

$s \quad$ espaçamento entre os estribos 


\subsection{APLICAÇÕES}

Utilizando algumas das normas correntes para concreto de resistência normal e com o intuito de verificar se o cálculo da força cortante resistente é válido também para as vigas de concreto de alta resistência, foi realizado este estudo comparativo. Compara-se a força cortante resistente de cada viga com a força cortante última obtida em ensaios. As normas utilizadas são: NBR 6118 (1978), EC-2 (1989) e CEB90 (1991). Os valores experimentais utilizados foram encontrados em vários trabalhos: FERNANDES (1992), MPHONDE \& FRANTZ (1985), LEVI \& MARRO (1989), BERNHARDT \& FYNBOE (1986) e THORENFELDT \& DRANGSHOLT (1990).

\subsubsection{Pesquisas experimentais de FERNANDES (1992)}

As vigas tinham seção I com as dimensões indicadas na figura 6.1. Foram executadas com concreto de resistência à compressão em torno de $60 \mathrm{MPa}$. Os detalhes das armaduras e o esquema de carregamento estão apresentados na figura 6.2 . 


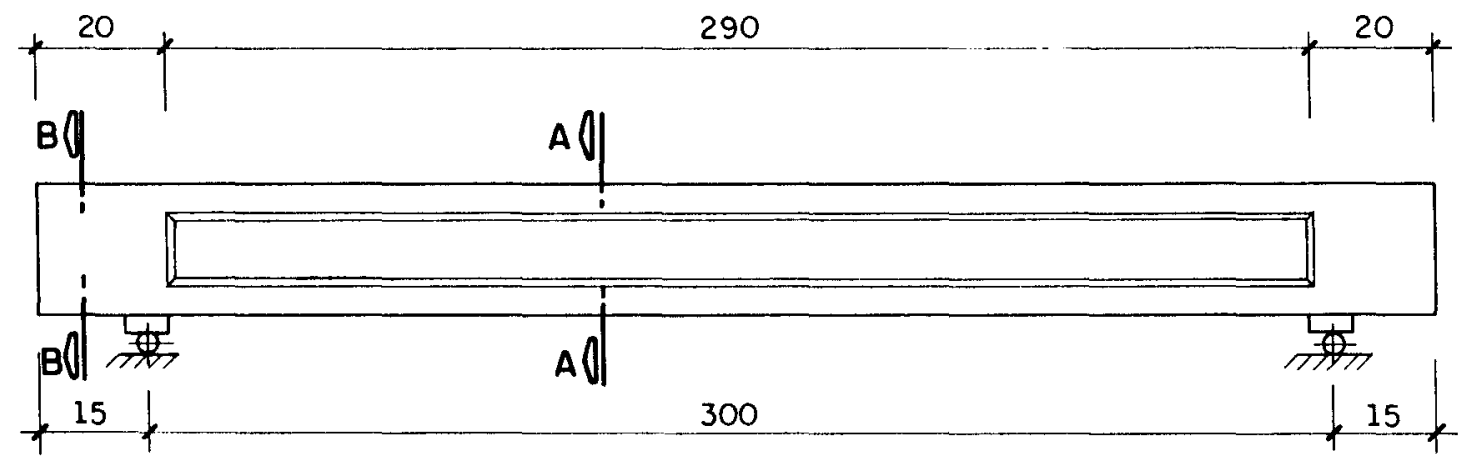

VISTA LATERAL

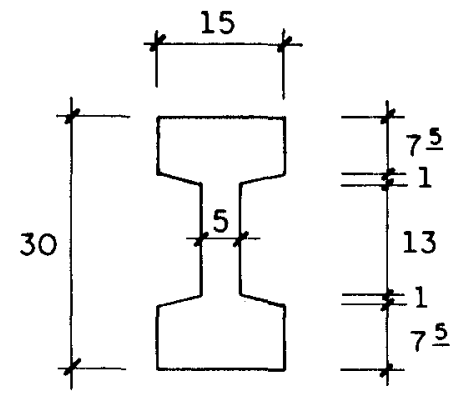

SE CĀO A-A

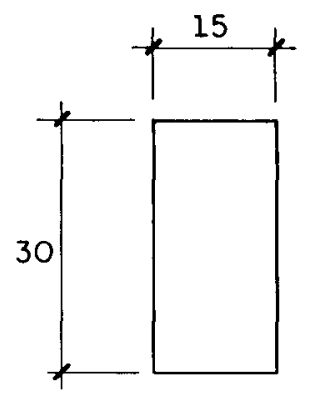

SECĀO B-B

FIGURA 6.1 - Dimensões das vigas ensaiadas por FERNANDES (1992).

Foi usado, como armadura longitudinal, aço CA-50B com $16 \mathrm{~mm}$ de diâmetro, nas vigas cujas denominações terminam em A, e aço CA-50A com $19 \mathrm{~mm}$ de diâmetro, nas vigas cujas denominações terminam em B ou C. A armadura longitudinal era composta de três barras. Para essas armaduras, as taxas longitudinais valem, respectivamente, $4,10 \%$ e $6,18 \%$. 

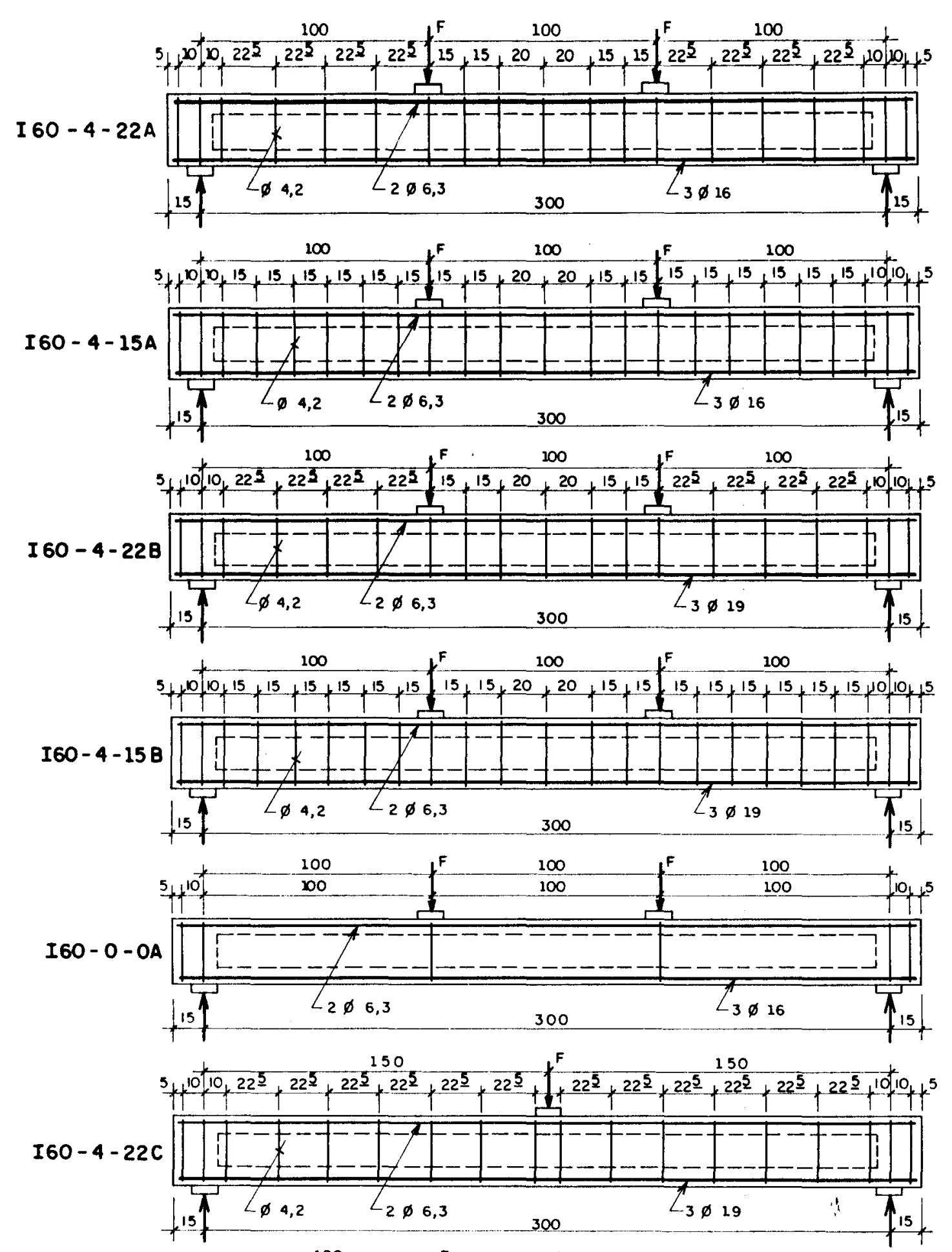

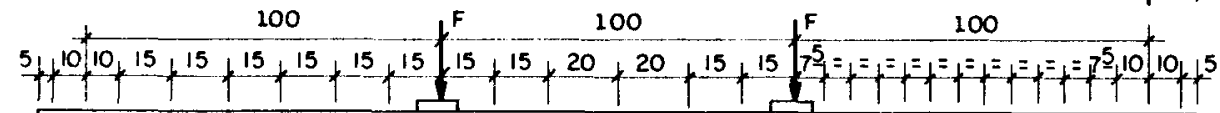

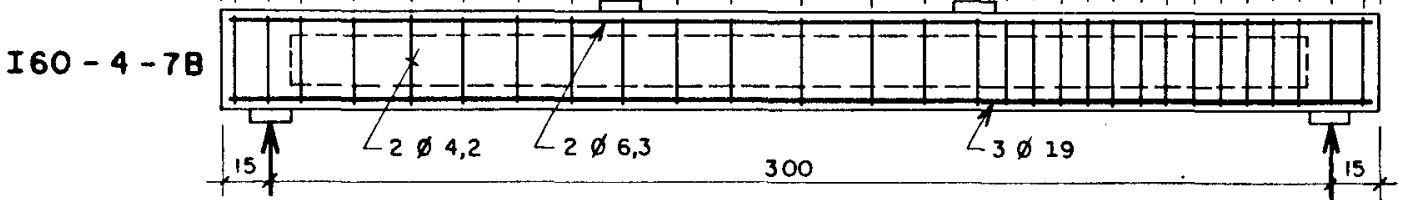

FIGURA 6.2 - Detalhes e esquema de carregamento das vigas ensaiadas por FERNANDES (1992). 
Para a armadura transversal, utilizaram-se estribos com dois ramos de aço CA60B com 4,2 mm de diâmetro, como mostra a figura 6.3. Os espaçamentos adotados, $22,5 \mathrm{~cm}, 15 \mathrm{~cm}$, e $7,5 \mathrm{~cm}$, correspondem às taxas de armadura de $0,252 \%, 0,378 \%$ e $0,756 \%$.

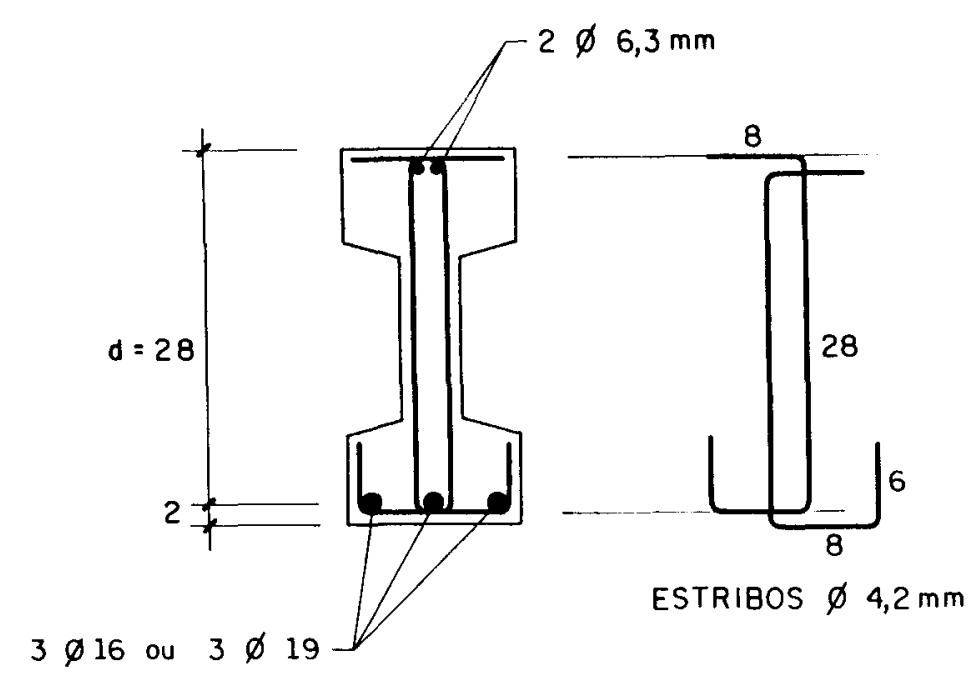

FIGURA 6.3 - Detalhes dos estribos.

$\mathrm{Na}$ evolução dos ensaios, FERNANDES (1992) fez uma previsão analítica da ação que produziria o escoamento da armadura longitudinal das vigas, admitindo-se a validade das hipóteses da NBR 6118 (1978) e o diagrama retangular das tensões no concreto. Utilizou-se a resistência real do concreto de cada viga e os limites de escoamento dos aços foram os obtidos através dos ensaios dos seus corpos-de-prova. A tabela 6.1 apresenta os resultados.

Os valores da força cortante correspondem ao início do escoamento da armadura longitudinal. A partir desses valores, foram calculadas as armaduras transversais necessárias, segundo $M O ̈ R S C H$, admitindo-se o grau total de armação ao cisalhamento. Adotou-se graus parciais de armação ao cisalhamento, para as armaduras transversais, com valores situados entre 0,20 e 0,40 , referentes a $M O ̈ R S C H$, exceto com relação à viga I60-4-7B. As taxas de armadura transversal, $\rho_{\mathrm{w}, \mathrm{M}}$, calculadas para $100 \%$ da força cortante que levaria a armadura longitudinal 
ao cisalhamento e, também, os valores efetivos do grau de armação ao cisalhamento, $\eta$, correspondentes a cada viga, estão apresentados na tabela 6.2 .

TABELA 6.1 - Valores efetivos da força cortante para escoamento da armadura longitudinal.

\begin{tabular}{|c|c|c|c|c|c|c|c|c|c|}
\hline \multirow{2}{*}{ VIGAS } & \multirow{2}{*}{$\begin{array}{c}\mathbf{f}_{\mathrm{c}} \\
\mathbf{M P a}\end{array}$} & \multicolumn{2}{|c|}{$A_{31}$} & \multirow{2}{*}{$\begin{array}{c}f_{y t} \\
M P a\end{array}$} & \multirow{2}{*}{$\begin{array}{c}x \\
\mathbf{c m}\end{array}$} & \multirow{2}{*}{$\mathbf{x} / \mathbf{d}$} & \multirow{2}{*}{$\begin{array}{c}\text { M } \\
\text { kN.cm }\end{array}$} & \multirow{2}{*}{$\begin{array}{c}V \\
k N\end{array}$} & \multirow{2}{*}{ a/d } \\
\hline & & $n-\phi$ & $\mathbf{c m}^{2}$ & & & & & & \\
\hline $160-4-22 A$ & 67,1 & $3 \phi 16$ & 6,15 & 595 & 4,5 & 0,162 & 9580 & 96 & 3,57 \\
\hline $160-4-15 A$ & 78,5 & $3 \phi 16$ & 6,15 & 595 & 3,9 & 0,139 & 9680 & 97 & 3,57 \\
\hline $160-4-22 B$ & 61,1 & $3 \phi 19$ & 9,27 & 530 & 6,7 & 0,239 & 12440 & 124 & 3,57 \\
\hline $160-4-15 B$ & 66,7 & $3 \phi 19$ & 9,27 & 530 & 6,1 & 0,219 & 12550 & 126 & 3,57 \\
\hline I60-0-0A & 61,3 & $3 \phi 16$ & 6,15 & 595 & 5,0 & 0,178 & 9520 & 95 & 3,57 \\
\hline I60-4-22C & 71,4 & $3 \phi 19$ & 9,27 & 530 & 5,7 & 0,205 & 12630 & 84 & 5,36 \\
\hline $160-4-7 B$ & 64,8 & $3 \phi 19$ & 9,27 & 530 & 6,3 & 0,226 & 12510 & 125 & 3,57 \\
\hline
\end{tabular}

TABELA 6.2 - Valores efetivos do grau de armação ao cisalhamento.

\begin{tabular}{|c|c|c|c|c|c|c|c|c|}
\hline \multirow[b]{2}{*}{ VIGAS } & \multirow{2}{*}{$\begin{array}{c}\mathrm{V} \\
\mathrm{kN}\end{array}$} & \multirow{2}{*}{$\begin{array}{c}\tau_{\mathrm{wu}} \\
\mathrm{MPa}\end{array}$} & \multirow{2}{*}{$\begin{array}{c}\mathbf{f}_{\mathrm{yw}} \\
\mathrm{MPa}\end{array}$} & \multirow[b]{2}{*}{$\begin{array}{c}\rho_{w, M} \\
\%\end{array}$} & \multicolumn{2}{|c|}{ EXISTENTE } & \multirow[b]{2}{*}{$\eta=\rho_{w} / \rho_{w, M}$} & \multirow[b]{2}{*}{$\mathbf{a} / \mathbf{d}$} \\
\hline & & & & & $\begin{array}{l}\mathbf{A}_{\mathrm{sw}} / \mathbf{s} \\
\mathbf{c m}^{2} / \mathbf{m}\end{array}$ & $\begin{array}{l}\rho_{w} \\
\%\end{array}$ & & \\
\hline $160-4-22 \mathrm{~A}$ & 96 & 6,86 & 850 & 0,928 & 1,26 & 0,252 & 0,272 & 3,57 \\
\hline I60-4-15A & 97 & 6,93 & 850 & 0,938 & 1,89 & 0,378 & 0,403 & 3,57 \\
\hline $160-4-22 B$ & 124 & 8,86 & 850 & 1,199 & 1,26 & 0,252 & 0,210 & 3,57 \\
\hline I60-4-15B & 126 & 9,00 & 850 & 1,218 & 1,89 & 0,378 & 0,310 & 3,57 \\
\hline I $611-0-1) \mathrm{A}$ & 95 & 6,79 & - & - & - & - & - & 3,57 \\
\hline I60-4-22C & 84 & 6,00 & 850 & 0,812 & 1,26 & 0,252 & 0,310 & 5,36 \\
\hline I60-4-7B & 125 & 8,93 & 850 & 1,208 & 3,98 & 0,756 & 0,626 & 3,57 \\
\hline
\end{tabular}


Para fazer a comparação entre a capacidade resistente da seção da viga ao cisalhamento e os valores experimentais, foi adotado um roteiro de cálculo que segue a NBR 6118 (1978), depois um outro de acordo com o EC-2 (1989) e, por fim, o CEB-90 (1991). Como ilustração, são feitos os cálculos para a viga I60-4-22A e os resultados das restantes vigas, que foram analisados da mesma maneira, estão descritos na tabela 6.3. Segue o cálculo da capacidade resistente ao cisalhamento da viga $160-4-22 \mathrm{~A}$.

a) Utilizando a NBR 6118 (1978)

$$
\begin{aligned}
& \mathrm{b}_{\mathrm{w}}=5 \mathrm{~cm} \\
& \mathrm{~d}=28 \mathrm{~cm} \\
& \rho_{\mathrm{l}}=4,10 \% \\
& \rho_{\mathrm{w}}=0,252 \% \\
& \left.\mathrm{f}_{\mathrm{ck}}=\mathrm{f}_{\mathrm{c}, \mathrm{exp}}-8 \mathrm{MPa}=52,4 \mathrm{MPa} \quad \text { [Expressão do CEB- } 90(1991)\right] \\
& \mathrm{f}_{\mathrm{ywd}}=\mathrm{f}_{\mathrm{y}, \text { exp }}=850 \mathrm{MPa} \\
& \tau_{c}=\Psi_{1} \sqrt{f_{c k}}=1,09 \mathrm{MPa} \\
& \tau_{d}=\rho_{w} f_{y w d}=2,14 \mathrm{MPa} \\
& \tau_{w d}=\frac{\tau_{c}+\tau_{d}}{1,15}=2,81 \mathrm{MPa} \\
& V_{d, N B R}=\tau_{w d} b_{w} d=393,0 \mathrm{MPa} \mathrm{cm}^{2}=39,3 \mathrm{kN}
\end{aligned}
$$

b) Utilizando o EC-2 (1989)

O cálculo da capacidade resistente ao cisalhamento da viga 160-4-22A, utilizando a eq. (6.6), é o seguinte:

$$
\begin{aligned}
& \mathrm{f}_{\mathrm{ctm}}=0,30 \mathrm{f}_{\mathrm{ck}}^{2 / 3}=4,55 \mathrm{MPa} \\
& \mathrm{f}_{\mathrm{ctk} 0.05}=0,7 \mathrm{f}_{\mathrm{ctm}}=3,19 \mathrm{MPa}
\end{aligned}
$$


$\tau_{\mathrm{Rd}}=0,25 \mathrm{f}_{\mathrm{ckk} 0,05}=0,80 \mathrm{MPa}$

$\rho_{1}=\rho_{\ell}=0,041$

$\mathrm{A}_{\mathrm{sw}} / \mathrm{s}=1,26 \mathrm{~cm}^{2} / \mathrm{m}=0,0126 \mathrm{~cm}^{2} / \mathrm{cm}$

$V_{d, E C}=56,2 \mathrm{kN}$

c) Utilizando o CEB-90 (1991)

$\mathrm{f}_{\mathrm{cd} 2}=30,7 \mathrm{MPa}$

$\mathrm{f}_{\mathrm{cd} 1}=43,6 \mathrm{MPa}$

$\mathrm{V}_{\mathrm{Rd, \text {max }}}=193,8 \mathrm{kN}$

$\mathrm{F}_{\mathrm{Rt}}=365,9 \mathrm{kN}$

$\mathrm{F}_{\mathrm{Rc}}=294,0 \mathrm{kN}$

$F_{\text {Rcw }}=273,9 \mathrm{kN}$

$\mathrm{F}_{\mathrm{Rtw}}=27,0 \mathrm{kN}$

$V_{d, C E B}=27,0 \mathrm{kN}$ 
TABELA 6.3 - Valores teóricos e os experimentais obtidos por FERNANDES (1992).

\begin{tabular}{|c|c|c|c|c|c|c|c|c|c|c|c|c|}
\hline VIGA & $\begin{array}{c}\mathbf{f}_{\mathrm{ck}} \\
\mathbf{M P a}\end{array}$ & $\begin{array}{c}\mathbf{f}_{\mathbf{y w}} \\
\mathbf{M P a}\end{array}$ & $\begin{array}{l}\rho_{1} \\
\%\end{array}$ & $\begin{array}{l}\rho_{w} \\
\%\end{array}$ & $\begin{array}{c}\mathbf{A}_{\mathrm{sw}} / \mathrm{s} \\
\mathbf{c m}^{2} / \mathbf{m}\end{array}$ & $\begin{array}{c}\mathbf{V}_{\mathrm{d}, \mathrm{NBR}} \\
\mathbf{k N}\end{array}$ & $\begin{array}{c}\mathbf{V}_{\mathrm{d}, \mathbf{E C}} \\
\mathbf{k N}\end{array}$ & $\begin{array}{c}\mathbf{V}_{\mathrm{d}, \mathrm{CEB}} \\
\mathbf{k N}\end{array}$ & $\begin{array}{c}V_{u, \text { exp }} \\
k N\end{array}$ & $\mathbf{V}_{\mathrm{u}, \mathrm{exp}} / \mathbf{V}_{\mathrm{d}, \mathrm{NBR}}$ & $\mathbf{V}_{\mathrm{u}, \mathrm{exp}} / \mathrm{V}_{\mathrm{d}, \mathrm{EC}}$ & $\mathbf{V}_{\mathrm{u}, \exp } / \mathbf{V}_{\mathrm{d}, \mathrm{CEB}}$ \\
\hline $160-4-22 A$ & 52,4 & 850 & 4,10 & 0,252 & 1,26 & 39,3 & 56,2 & 27,0 & 70 & 1,78 & 1,25 & 2,59 \\
\hline $160-4-15 A$ & 62,7 & 850 & 4,10 & 0,378 & 1,89 & 53,6 & 73,4 & 40,5 & 100 & 1,87 & 1,36 & 2,47 \\
\hline I60-4-22B & 47,0 & 850 & 6,18 & 0,252 & 1,26 & 38,6 & 62,1 & 27,0 & 100 & 2,59 & 1,61 & 3,70 \\
\hline I60-4-15B & 52,0 & 850 & 6,18 & 0,378 & 1,89 & 52,3 & 78,1 & 45,0 & 110 & 2,10 & 1,41 & 2,44 \\
\hline $160-0-0 A$ & 47,2 & - & 4,10 & - & - & 12,5 & 27,3 & - & 40 & 3,20 & 1,47 & - \\
\hline I60-4-22C & 56,3 & 850 & 6,18 & 0,252 & 1,26 & 39,8 & 66,6 & 27,0 & 75 & 1,88 & 1,13 & 2,78 \\
\hline $160-4-7 B$ & 50,3 & 850 & 6,18 & 0,756 & 3,98 & 91,2 & 122,0 & 85,3 & 120 & 1,32 & 0,98 & 1,41 \\
\hline
\end{tabular}




\subsubsection{Pesquisas experimentais de MPHONDE \& FRANTZ (1985)}

MPHONDE \& FRANTZ (1985) ensaiaram doze vigas com estribos, cujas dimensões eram $15,2 \times 33,7 \times 243,8 \mathrm{~cm}$, com altura útil de $29,8 \mathrm{~cm}$ e cobrimento de $2,5 \mathrm{~cm}$.

As vigas tinham armadura simples e foram carregadas no meio do vão para ter uma relação entre a distância de aplicação da carga e a altura útil (a/d) de 0,36.

Para garantir a ruptura por cisalhamento, cada viga teve uma armadura longitudinal de tração com 3 barras de $25 \mathrm{~mm}$, com uma placa metálica soldada na extremidade para fornecer uma boa ancoragem. Os estribos possuíam pequenos espaçamentos e os diâmetros das barras eram $3,2,4,8$ e 3,2+4,8; a tensão de escoamento, $\tau_{\mathrm{d}}$, era de $0,34,0,69$ ou $1,03 \mathrm{MPa}$, respectivamente.

A figura 6.4 mostra alguns detalhes das amostras. Na identificação da amostra, para B50-7-3, 'B50' significa a tensão de escoamento do estribo de 50 psi $(0,34 \mathrm{MPa})$, '7', a resistência do concreto de 7000 psi (48 MPa) e '3', uma relação a/d de 3,6.

A armadura de flexão tinha grau 60 que, de acordo com o $A C I 318$ (1983), significa uma tensão de escoamento de $65 \mathrm{ksi}$ ou $448 \mathrm{MPa}$. Os estribos eram formados por barras lisas recozidas com tensões de escoamento de 303 e $269 \mathrm{MPa}$, para as barras de 3,2 e 4,8 $\mathrm{mm}$ de diâmetro, respectivamente.

$\mathrm{O}$ procedimento usado na tabela 6.4 foi o mesmo do item anterior.

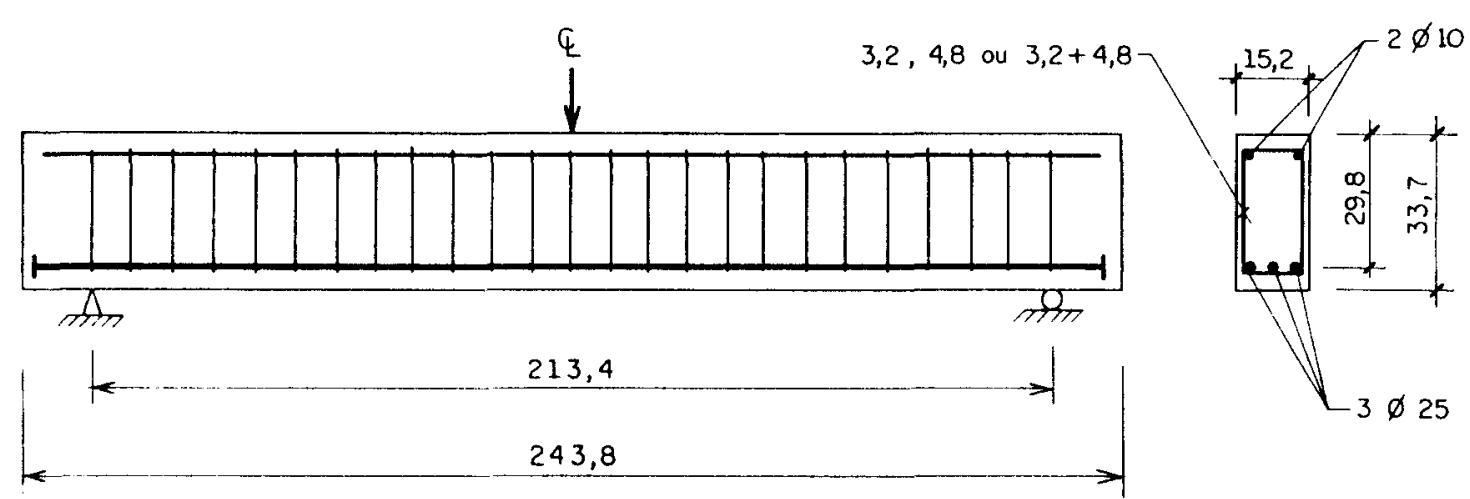

FIGURA 6.4 - Detalhe das vigas ensaiadas por MPHONDE \& FRANTZ (1985). 
TABELA 6.4 - Valores teóricos e os experimentais obtidos por MPHONDE \& FRANTZ (1985).

\begin{tabular}{|c|c|c|c|c|c|c|c|c|c|c|c|c|}
\hline VIGA & $\begin{array}{c}\mathbf{f}_{\mathrm{ck}} \\
\mathbf{M P a}\end{array}$ & $\begin{array}{c}\mathbf{f}_{\mathbf{y w}} \\
\mathbf{M P a}\end{array}$ & $\begin{array}{l}\rho_{1} \\
\%\end{array}$ & $\begin{array}{l}\rho_{w} \\
\%\end{array}$ & $\begin{array}{c}A_{s / \mathrm{d}} / \mathrm{s} \\
\mathrm{cm}^{2} / \mathrm{m}\end{array}$ & $\begin{array}{c}\mathbf{V}_{\mathrm{d}, \mathrm{NBR}} \\
\mathbf{k N}\end{array}$ & $\begin{array}{c}\mathbf{V}_{\mathrm{d}, \mathrm{EC}} \\
\mathbf{k N}\end{array}$ & $\begin{array}{c}\mathbf{V}_{\mathrm{d}, \mathrm{CEB}} \\
\mathbf{k N}\end{array}$ & $\begin{array}{c}\mathbf{V}_{\mathbf{u}, \exp } \\
\mathbf{k N}\end{array}$ & $\mathbf{V}_{\mathrm{n}, \mathrm{exp}} / \mathbf{V}_{\mathrm{d}, \mathrm{NBR}}$ & $\mathbf{V}_{\mathrm{a}, \exp } / \mathbf{V}_{\mathrm{d}, \mathbf{E C}}$ & $V_{a, e x p} / V_{d, C E B}$ \\
\hline B50-3-3 & 14,1 & 303 & 2,87 & 0,112 & 1,71 & 35,6 & 46,5 & 13,9 & 76,1 & 2,14 & 1,64 & 5,47 \\
\hline B50-7-3 & 31,8 & 303 & 2,87 & 0,112 & 1,71 & 46,7 & 69,9 & 13,9 & 93,6 & 2,00 & 1,34 & 6,73 \\
\hline B50-11-3 & 51,7 & 303 & 2,87 & 0,112 & 1,71 & 55,9 & 91,4 & 13,9 & 97,7 & 1,75 & 1,07 & 7,03 \\
\hline B50-15-3 & 75,0 & 303 & 2,87 & 0,112 & 1,71 & 64,6 & 113,2 & 13,9 & 111,2 & 1,72 & 0,98 & 8,00 \\
\hline B100-3-3 & 19,9 & 269 & 2,87 & 0,257 & 3,91 & 53,5 & 69,2 & 28,2 & 95,2 & 1,78 & 1,38 & 3,38 \\
\hline B100-7-3 & 39,1 & 269 & 2,87 & 0,257 & 3,91 & 64,1 & 92,5 & 28,2 & 120,2 & 1,88 & 1,30 & 4,26 \\
\hline B100-11-3 & 60,6 & 269 & 2,87 & 0,257 & 3,91 & 73,2 & 114,4 & 28,2 & 150,9 & 2,06 & 1,32 & 5,35 \\
\hline B100-15-3 & 73,9 & 269 & 2,87 & 0,257 & 3,91 & 78,0 & 126,5 & 28,2 & 115,5 & 1,48 & 0,91 & 4,10 \\
\hline B150-3-3 & 20,7 & 269 & 2,87 & 0,383 & 2,74 & 67,5 & 61,9 & 19,8 & 138,7 & 2,05 & 2,24 & 7,01 \\
\hline B150-7-3 & 38,6 & 269 & 2,87 & 0,383 & 2,74 & 77,3 & 83,5 & 19,8 & 133,1 & 1,72 & 1,59 & 6,72 \\
\hline B150-11-3 & 61,5 & 269 & 2,87 & 0,383 & 2,74 & 86,9 & 106,8 & 19,8 & 161,3 & 1,86 & 1,51 & 8,15 \\
\hline B150-15-3 & 74,7 & 269 & 2,87 & 0,383 & 2,74 & 91,6 & 118,8 & 19,8 & 149,7 & 1,63 & 1,26 & 7,56 \\
\hline
\end{tabular}




\subsubsection{Pesquisas experimentais de LEVI \& MARRO (1989)}

LEV \& MARRO (1989) ensaiaram sete vigas geometricamente idênticas, de acordo com o esquema da figura 6.5. Em todos os casos, a armadura transversal era composta de estribos com diâmetro de $\phi 12 \mathrm{~mm}$ com espaçamentos diferentes em cada caso. As vigas tinham $10,10 \mathrm{~m}$ de comprimento. Foram ensaiadas sobre dois apoios e carregadas com duas cargas concentradas iguais, distantes $2,00 \mathrm{~m}$ entre si e aplicadas, cada uma, a $3,80 \mathrm{~m}$ do apoio mais próximo. A altura útil pode ser estimada em $94 \mathrm{~cm}$, do que resulta uma relação $a / d=4$.

As notações RC $30 \mathrm{Al}, \ldots, \mathrm{RC} 70 \mathrm{Bl}$, significam:

RC concreto armado

$30,60,70$ resistências cúbicas do concreto simples em MPa

A, B espaçamentos dos estribos. $A=22,5 \mathrm{~cm} \mathrm{e} B=15,0 \mathrm{~cm}$

1,2 número da viga

O procedimento utilizado para a elaboração da tabela 6.5 foi o mesmo do item 6.2 .1 . 

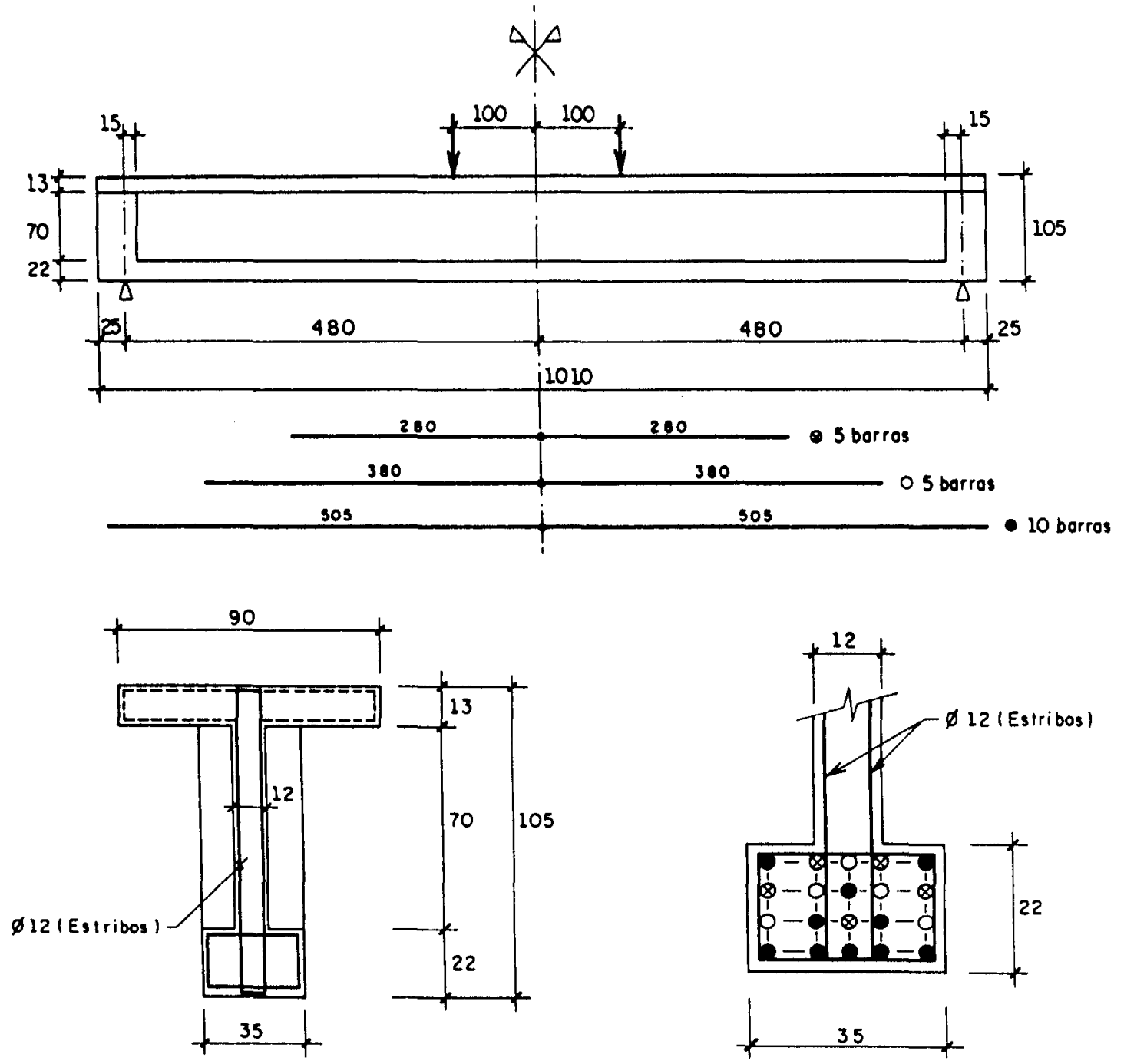

FIGURA 6.5 - Detalhe das vigas ensaiadas por $L E V I$ \& $M A R R O$ (1989). 
TABELA 6.5 - Valores teóricos e os experimentais obtidos por LEVI \& MARRO (1989).

\begin{tabular}{|c|c|c|c|c|c|c|c|c|c|c|c|c|}
\hline VIGA & $\begin{array}{c}\mathbf{f}_{\mathrm{ck}} \\
\mathbf{M P a}\end{array}$ & $\begin{array}{c}\mathbf{f}_{\mathrm{ym}} \\
\mathrm{MPa}\end{array}$ & $\begin{array}{l}\rho_{1} \\
\%\end{array}$ & $\begin{array}{l}\rho_{w} \\
\%\end{array}$ & $\begin{array}{c}A_{s w} / \mathbf{s} \\
\mathbf{c m}^{2} / \mathbf{m}\end{array}$ & $\begin{array}{c}\mathbf{V}_{\mathrm{d}, \mathrm{NBR}} \\
\mathbf{k N}\end{array}$ & $\begin{array}{c}\mathbf{V}_{d, E c} \\
k N\end{array}$ & $\begin{array}{c}\mathbf{V}_{d, \mathbf{C E B}} \\
\mathbf{k N}\end{array}$ & $\begin{array}{c}\mathbf{V}_{\text {s,exp }} \\
\mathbf{k N}\end{array}$ & $\mathbf{V}_{\text {d,exp }} / \mathbf{V}_{\text {d,NBR }}$ & $\mathbf{V}_{\mathrm{u}, \text { exp }} / \mathbf{V}_{\mathrm{d}, \mathrm{EC}}$ & $\mathbf{V}_{\mathrm{u}, \mathrm{exp}} / \mathbf{V}_{\mathrm{d}, \mathrm{CEB}}$ \\
\hline RC $30 \mathrm{Al}$ & 17,0 & 480 & 3,25 & 0,84 & 10,05 & 456,2 & 506,1 & 408,1 & 676 & 1,48 & 1,34 & 1,66 \\
\hline RC 30 A2 & 17,0 & 480 & 3,25 & 0,84 & 10,05 & 456,2 & 506,1 & 408,1 & 688 & 1,51 & 1,36 & 1,69 \\
\hline RC $60 \mathrm{Al}$ & 39,0 & 480 & 3,82 & 0,84 & 10,05 & 487,4 & 594,0 & 408,1 & 990 & 2,03 & 1,67 & 2,43 \\
\hline RC $60 \mathrm{A2}$ & 39,0 & 480 & 3,82 & 0,84 & 10,05 & 487,4 & 594,0 & 408,1 & 938 & 1,92 & 1,58 & 2,30 \\
\hline RC $60 \mathrm{~B} 1$ & 42,0 & 480 & 5,09 & 1,25 & 15,08 & 683,9 & 843,9 & 612,4 & 1181 & 1,73 & 1,40 & 1,93 \\
\hline RC $60 \mathrm{B2}$ & 42,0 & 480 & 5,09 & 1,25 & 15,08 & 683,9 & 843,9 & 612,4 & 1239 & 1,81 & 1,47 & 2,02 \\
\hline RC 70 B1 & 52,0 & 480 & 5,09 & 1,25 & 15,08 & 694,6 & 879,3 & 612,4 & 1330 & 1,91 & 1,51 & 2,17 \\
\hline
\end{tabular}




\subsubsection{Pesquisas experimentais de BERNHARDT \& FYNBOE (1986)}

BERNHARDT \& FYNBOE (1986) ensaiaram onze vigas de concreto armado, confeccionadas com concreto de alta resistência, com ruptura por cisalhamento.

As dimensões das vigas são $15 \times 20 \times 285 \mathrm{~cm}$. Os arranjos das armaduras e as posições das cargas estão mostrados na figura 5.7.

O diâmetro da armadura longitudinal é $\$ 16 \mathrm{~mm}$, com uma tensão de escoamento da $511 \mathrm{MPa}$. 0 diâmetro da armadura de cisalhamento é $\phi 8 \mathrm{~mm}$ e sua tensão de escoamento é $427 \mathrm{MPa}$.

Para a seção transversal 1 e 2, adotou-se uma altura útil de $15,7 \mathrm{~cm}$ e 16,7 $\mathrm{cm}$, respectivamente.

O procedimento utilizado para a elaboração da tabela 6.6 foi o mesmo do item 6.2 .1 . 
TABELA 6.6 - Valores teóricos e os experimentais obtidos por BERNHARDT \& FYNBOE (1986).

\begin{tabular}{|c|c|c|c|c|c|c|c|c|c|c|c|c|}
\hline VIGA & $\begin{array}{c}\mathbf{f}_{\mathrm{ck}} \\
\mathbf{M P a}\end{array}$ & $\begin{array}{c}\mathbf{f}_{\mathbf{y w}} \\
\mathbf{M P a}\end{array}$ & $\begin{array}{l}\rho_{1} \\
\%\end{array}$ & $\begin{array}{l}\rho_{w} \\
\%\end{array}$ & $\begin{array}{c}A_{1} / \mathbf{s} \\
\mathbf{c m}^{2} / \mathbf{m}\end{array}$ & $\begin{array}{c}\mathbf{V}_{\mathrm{d}, \mathrm{NBR}} \\
\mathbf{k N}\end{array}$ & $\begin{array}{c}\mathbf{V}_{\mathrm{d}, \mathbf{E C}} \\
\mathbf{k N}\end{array}$ & $\begin{array}{c}\mathbf{V}_{\mathrm{d}, \mathrm{CEB}} \\
\mathbf{k N}\end{array}$ & $\begin{array}{c}V_{n, \exp } \\
k N\end{array}$ & $\mathbf{V}_{\mathrm{u}, \mathrm{exp}} / \mathbf{V}_{\mathrm{d}, \mathrm{NBR}}$ & $\mathbf{V}_{\mathrm{u}, \mathrm{exp}} / \mathbf{V}_{\mathrm{d}, \mathbf{E C}}$ & $\mathbf{V}_{\text {a,exp }} / \mathbf{V}_{\mathrm{d}, \mathrm{CEB}}$ \\
\hline S5A & 78,3 & 427 & 2,09 & 0,447 & 6,70 & 70,4 & 91,9 & 43,0 & 109,4 & 1,55 & 1,19 & 2,54 \\
\hline S6A & 78,3 & - & 2,09 & - & - & 28,9 & 48,9 & - & 94,4 & 3,27 & 1,93 & - \\
\hline S6B & 78,3 & - & 2,09 & - & - & 28,9 & 48,9 & - & 122,4 & 4,24 & 2,50 & - \\
\hline S6C & 78,3 & - & 2,09 & - & - & 28,9 & 48,9 & - & 114,4 & 3,96 & 2,34 & - \\
\hline S7A & 78,3 & 427 & 4,19 & 0,673 & 10,10 & 86,0 & 125,9 & 60,9 & 139,5 & 1,62 & 1,11 & 2,29 \\
\hline S7B & 78,3 & 427 & 4,19 & 0,673 & 10,10 & 86,0 & 125,9 & 60,9 & 149,5 & 1,74 & 1,19 & 2,45 \\
\hline S8A & 78,3 & 427 & 4,19 & 0,447 & 6,70 & 66,2 & 105,3 & 40,4 & 124,5 & 1,88 & 1,18 & 3,08 \\
\hline S8B & 78,3 & 427 & 4,19 & 0,447 & 6,70 & 66,2 & 105,3 & 40,4 & 134,5 & 2,03 & 1,28 & 3,33 \\
\hline S9A & 78,3 & - & 4,19 & - & - & 27,1 & 64,9 & - & 79,5 & 2,93 & 1,23 & - \\
\hline S9B & 78,3 & - & 4,19 & - & - & 27,1 & 64,9 & - & 63,5 & 2,34 & 0,98 & - \\
\hline S9C & 94,1 & - & 4,19 & - & - & 29,8 & 73,5 & - & 67,5 & 2,27 & 0,92 & - \\
\hline
\end{tabular}




\subsubsection{Pesquisas experimentais de THORENFELDT \& DRANGSHOLT (1990)}

THORENFELDT \& DRANGSHOLT (1990) ensaiaram vigas de concreto armado à ruptura por cisalhamento, com concreto de alta resistência e sem armadura transversal.

As seções transversais das vigas das séries $1,2,4$ e 5 têm altura de $25 \mathrm{~cm}$ e largura de $15 \mathrm{~cm}$. A seção transversal das vigas da série 6 têm o dobro das dimensões das séries anteriores.

Dentro de cada série, o tipo de concreto, o tipo de cura e a resistência à compressão foram constantes, enquanto a relação a/d e a taxa de armadura longitudinal foram variadas.

A notação da viga B21 significa: série 2, cálculo da viga do tipo 1 .

A geometria e o detalhamento da armadura das vigas das séries $1,2,4$ e 5 são mostradas na figura 6.7. As vigas das séries 1 e 2 são armadas longitudinalmente por 3 barras de $16 \mathrm{~mm}$ de diâmetro. As vigas das séries 4 e 5 têm 5 barras de $16 \mathrm{~mm}$. A geometria das vigas da série 6 é a mesma, com todas as dimensões lineares dobradas.

A tensão de escoamento das armaduras era $500 \mathrm{MPa}$. 

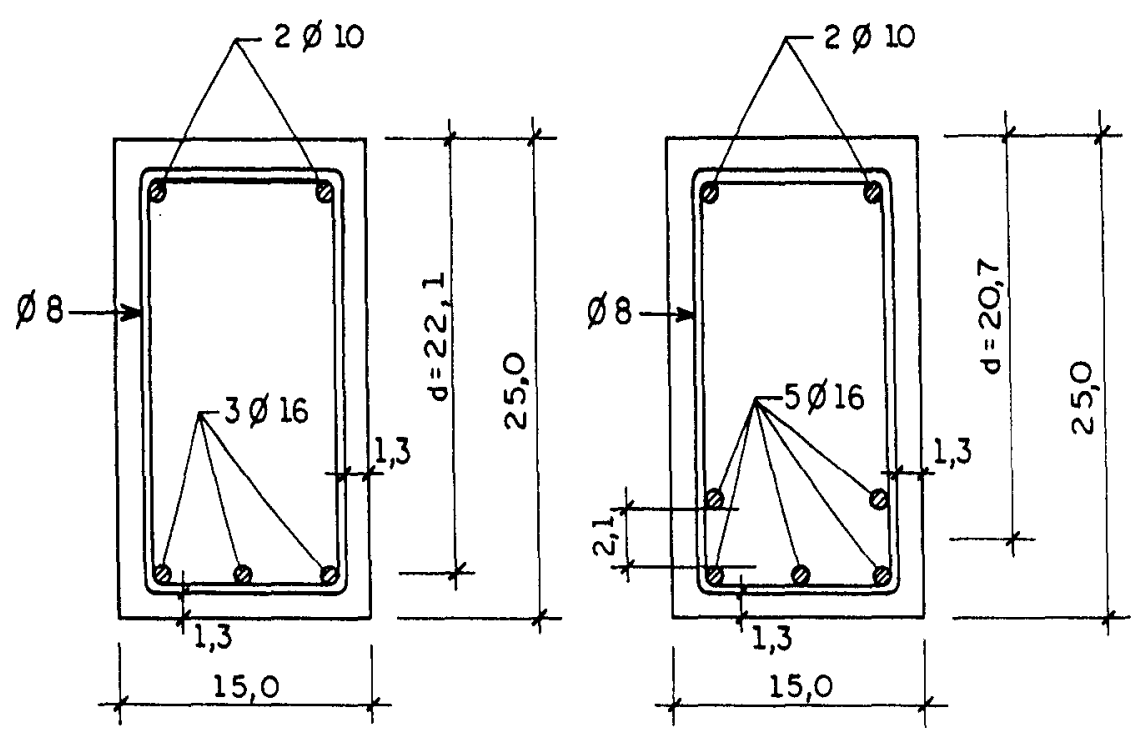

a) SECĀO TRANSVERSAL

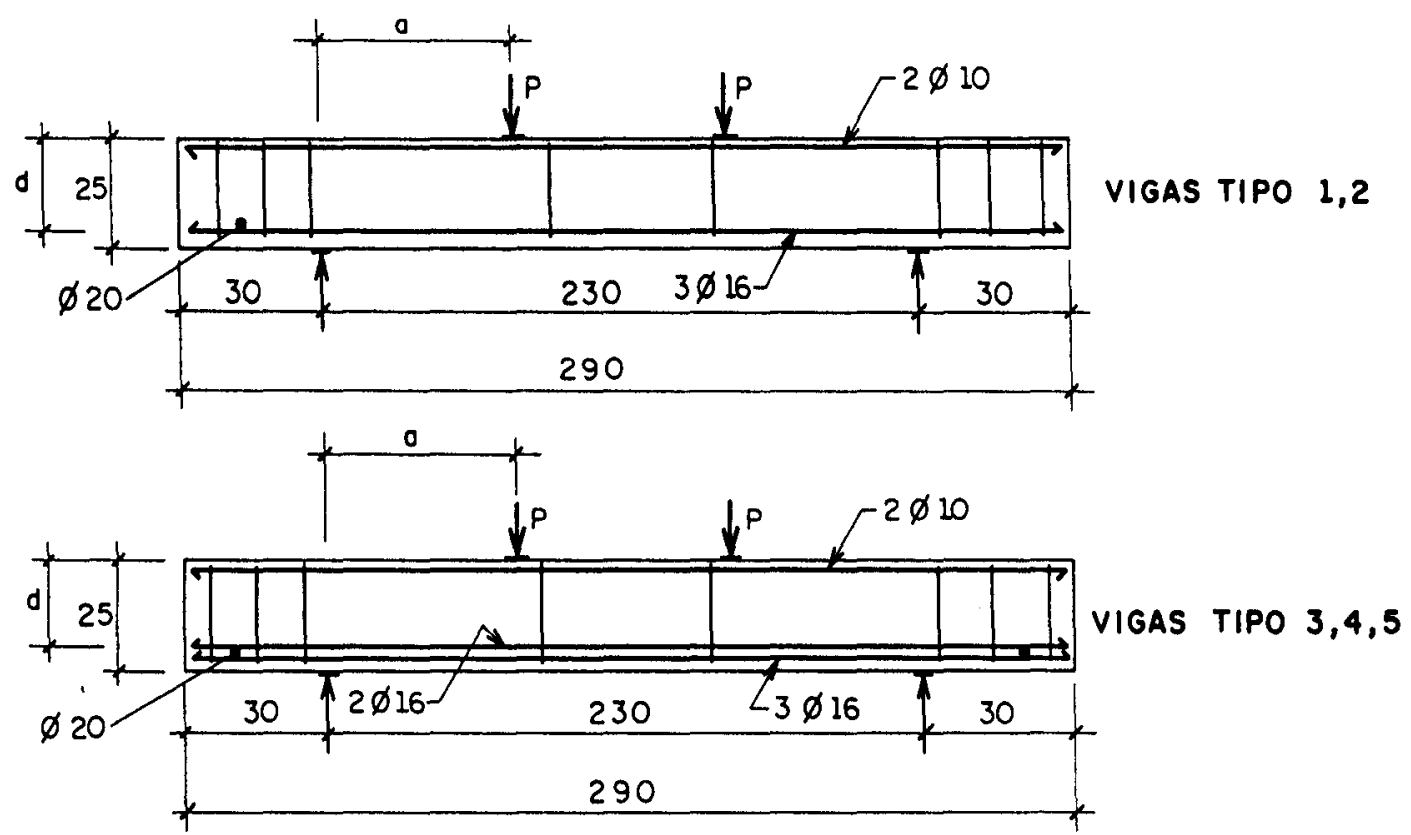

b) VISTA LATERAL

FIGURA 6.6 - Detalhes das vigas ensaiadas por THORENFELDT \& DRANGSHOLT (1990).

O procedimento utilizado para a elaboração da tabela 6.7 foi o mesmo do item 6.2 .1 . 
TABELA 6.7 - Valores tedricos e os experimentais obtidos por THORENFELDT \& DRANGSHOLT (1990).

\begin{tabular}{|c|c|c|c|c|c|c|c|}
\hline VIGA & $\begin{array}{c}\mathbf{f}_{\mathbf{c t}} \\
\mathbf{M P a}\end{array}$ & $\begin{array}{l}p_{1} \\
x_{0}\end{array}$ & $\begin{array}{c}\mathbf{V}_{\mathrm{d}, \mathrm{NBX}} \\
\mathbf{k N}\end{array}$ & $\begin{array}{c}\mathbf{V}_{\mathrm{d}, \mathrm{EC}} \\
\mathrm{kN}\end{array}$ & $\begin{array}{c}\mathbf{V}_{\text {watp }} \\
\mathbf{k N}\end{array}$ & $V_{\text {undeq }} / V_{\text {dNBRR }}$ & $\mathbf{V}_{\text {upexp }} / V_{\mathrm{d}, \mathrm{BC}}$ \\
\hline B11 & 46,0 & 1,82 & 29,3 & 43,1 & 58,1 & 1,98 & 1,35 \\
\hline B12 & 46,0 & 1,82 & 29,3 & 43,1 & 70,8 & 2,42 & 1,64 \\
\hline B13 & 46,0 & 3,23 & 27,5 & 52,2 & 70,5 & 2,56 & 1,35 \\
\hline B14 & 46,0 & 3,23 & 27,5 & 52,2 & 82,6 & 3,00 & 1,58 \\
\hline B15 & 46,0 & 3,23 & 27,5 & 52,2 & 107,1 & 3,89 & 2,05 \\
\hline B21 & 69,8 & 1,82 & 36,1 & 56,9 & 67,9 & 1,88 & 1,19 \\
\hline B22 & 69,8 & 1,82 & 36,1 & 56,9 & 102,7 & 2,84 & 1,80 \\
\hline B23 & 69,8 & 3,23 & 33,8 & 68,9 & 77,8 & 2,30 & 1,13 \\
\hline B24 & 69,8 & 3,23 & 33,8 & 68,9 & 82,6 & 2,44 & 1,20 \\
\hline B25 & 69,8 & 3,23 & 33,8 & 68,9 & 175,8 & 5,20 & 2,55 \\
\hline $\mathbf{B 4 3}$ & 78,4 & 3,23 & 35,9 & 74,4 & 86,2 & 2,40 & 1,16 \\
\hline B44 & 78,4 & 3,23 & 35,9 & 74,4 & 107,2 & 2,99 & 1,44 \\
\hline B45 & 78,4 & 3,23 & 35,9 & 74,4 & 148,3 & 4,13 & 1,99 \\
\hline B51 & 89,7 & 1,82 & 41,0 & 67,2 & 56,2 & 1,37 & 0,84 \\
\hline B52 & 89,7 & 1,82 & 41,0 & 67,2 & 77,7 & 1,90 & 1,16 \\
\hline B53 & 89,7 & 3,23 & 38,4 & 81,4 & 76,8 & 2,00 & 0,94 \\
\hline B54 & 89,7 & 3,23 & 38,4 & 81,4 & 77,7 & 2,02 & 0,95 \\
\hline B61 & 69,8 & 1,82 & 144,5 & 227,5 & 179,8 & 1,24 & 0,79 \\
\hline B62 & 69,8 & 1,82 & 144,5 & 227,5 & 438,7 & 3,04 & 1,93 \\
\hline B63 & 69,8 & 3,23 & 135,3 & 275,5 & 222,5 & 1,64 & 0,81 \\
\hline B64 & 69,8 & 3,23 & 135,3 & 275,5 & 280,7 & 2,07 & 1,02 \\
\hline B65 & 69,8 & 3,23 & 135,3 & 275,5 & 576,3 & 4,26 & 2,09 \\
\hline
\end{tabular}




\subsubsection{Conclusões}

Deve-se observar que todas as vigas analisadas apresentam características distintas; portanto as conclusões, aqui mostradas, não são definitivas. As características que mais variaram entre as amostras foram: forma da seção transversal, características geométricas, traço, resistência à compressão do concreto, tensão de escoamento das armaduras longitudinal e de cisalhamento, relação entre a distância do ponto de aplicação da carga e a altura útil (a/d), tipo de cura, taxa de armadura longitudinal, taxa de armadura transversal.

Não levando em conta essas variáveis, pode-se constatar que os valores das forças cortantes obtidas experimentalmente são, geralmente, superiores aos valores encontrados para força cortante resistente da seção de cada viga, ou seja, as normas analisadas subestimam a capacidade resistente da seção ao cisalhamento.

Os valores experimentais mais discrepantes correspondem, em média, a 3,9 vezes o valor calculado usando o CEB-90 (1991). Utilizando a NBR 6118 (1978), encontra-se diferença média de 2,3 vezes. Por fim, as forças cortantes calculadas que mais se aproximam das forças cortantes últimas são as encontradas a partir do $E C-2$ (1989) que, em média, valem 1,4 vezes os valores de ruína. 


\section{CONCLUSÕES}

Ao final deste trabalho de pesquisa, pode-se destacar algumas conclusões sobre composição, produção, propriedades mecânicas e projeto de pilares e de vigas de concreto de alta resistência.

\subsection{COMPOSIÇÃO E PRODUÇÃO}

Sobre os materiais utilizados na sua composição, sabe-se que:

a) cimento - pode ser utilizado o cimento portland comum (CP 32).

b) agregado miúdo - deve possuir partículas de forma arredondada e textura lisa e o módulo de finura deve estar em torno de 3,0.

c) agregado graúdo - deve ser limpo, cúbico, anguloso, 100\% de agregado britado, com um mínimo de partículas lamelares e alongadas e com diâmetro máximo entre 9,5 e $12,5 \mathrm{~mm}$.

d) aditivo incorporador de ar - seu uso é recomendado em casos que o principal interesse seja melhor durabilidade e resistência às intempéries, pois provoca queda de resistência mecânica.

e) aditivo retardador de pega - aplicado para controlar a taxa de endurecimento e para controlar a pega.

f) aditivo redutor de água (plastificante) - melhora a consistência e aumenta a resistência do concreto sem aumentar o consumo de cimento e água. 
g) aditivo superplastificante - empregado com o objetivo de produzir concreto com reduzido conteúdo de cimento, mantendo a relação água/cimento.

h) aditivo acelerador de pega - usado em concreto de alta resistência se for imprescindível uma desforma antecipada.

i) escória de alto forno - atua no concreto como substituição parcial do cimento.

j) cinza volante - substitui em torno de $8 \%$ a $10 \%$ da massa do cimento Portland.

k) microssflica - o uso criterioso ajuda a economizar cimento; reduz as reações álcali-agregados.

l) água - deve ser de qualidade potável, isenta de matérias orgânicas e de substâncias estranhas e nocivas.

Maiores teores de cimento e menores teores de água produzem maiores resistências. $\mathrm{O}$ uso de superplastificantes fornece menores fatores água/material cimentante e maiores abatimentos. E fatores água/material cimentante variam de 0,27 a 0,50 para concretos de alta resistência.

\subsection{PROPRIEDADES MECÂNICAS}

PINTO JR (1992) sugere, no caso do cimento ARI, utilizar o valor 0,70 para determinar a tensão de cálculo $\left(\sigma_{\mathrm{cd}}\right)$ no dimensionamento de estruturas, substituindo o valor 0,85 usado no concreto de resistência normal. O valor sugerido por PINTO $J R(1992)$ assume uma perda de resistência menor $(0,8 \mathrm{em}$ vez de 0,75$)$ que para o concreto usual, considera o crescimento da resistência, após 28 dias, pouco significativo e leva em conta a tendência em adotar o cilindro de $100 \times 200 \mathrm{~mm}$ em lugar do cilindro padrão. Ressalta-se, então, que para a adoção deste coeficiente, devem ser feitas novas pesquisas para que o mesmo seja confirmado.

A progressão da microfissuração interna durante a aplicação do carregamento determina a forma do diagrama tensão-deformação do concreto. Comparando com o 
diagrama tensão-deformação do concreto de resistência normal, a forma do diagrama para o concreto de alta resistência é mais linear, com deformação para a tensão máxima ligeiramente maior e mais íngreme na parte descendente da curva, caracterizando a ruptura de maneira frágil, após ser alcançada a tensão máxima.

Para o concreto de alta resistência, o módulo de deformação longitudinal é maior que os apresentados pelos concretos usuais, sendo que o crescimento não ocorre de maneira proporcional. Ensaios realizados no Brasil obtiveram melhores estimativas com o uso da equação do CEB-90 (1991).

No limite elástico, o intervalo de variação do coeficiente de Poisson, de acordo com a literatura adotada para o concreto de alta resistência, é comparável ao de baixa resistência, variando entre 0,18 e 0,24 .

De acordo com ensaios realizados por FERNANDES (1992) e PINTO JR (1992) para resistências à compressão acima de $50 \mathrm{MPa}$, as resistências à tração na compressão diametral ficam bem representadas pela equação proposta por CARRASQUILLO et al (eq. 3.11).

\subsection{PROJETO DE PILARES}

Analisando apenas a compressão axial de pilares e baseando-se nas comparações feitas entre o valor estimado e o obtido em ensaios por AGOSTINI (1992) e CUSSON \& PAULTRE (1994), pode-se constatar que, para baixas taxas de armadura transversal, o valor da carga de ruptura experimental não chegou a alcançar o valor previsto, sendo importante definir a seção resistente de concreto. Para os pilares que possuíam distribuição de armadura transversal mais densa, a carga que provocou a ruína, geralmente, alcançou valores próximos ou superiores aos previstos, chegando a ser $37 \%$ maior. Este comportamento comprova que a capacidade resistente do pilar solicitado a compressão axial cresce com o aumento do confinamento do núcleo de concreto pela armadura transversal. 
Pode-se concluir que pilares de concreto de alta resistência exigem uma quantidade consideravelmente maior de armadura de confinamento, para se obter o mesmo comportamento dúctil verificado em concretos de baixa resistência.

\subsection{FLEXÃO EM VIGAS}

Analisando a flexão em vigas de concreto de alta resistência, pode-se observar que, na sua maioria, os valores últimos experimentais foram próximos dos valores calculados de acordo com a Teoria do Concreto Armado. Foram exceções os resultados obtidos experimentalmente por PINTO JR (1992) e mostram que, para baixas taxas de armadura longitudinal (próximas ao valor mínimo sugerido pelas normas atuais), ocorrem alterações no comportamento. Deve ser determinado um novo valor para a percentagem mínima de armadura longitudinal das vigas de concreto de alta resistência, com o objetıvo de garantir a validade da Teoria.

Para a determinação da resistência última de peças fletidas, conclui-se que as regras da Teoria do Concreto Armado podem ser estendidas, em se tratando de concreto de alta resistência. E, alguns pesquisadores alertam para o perigo de colapso prematuro devido à ruptura brusca do cobrimento e a ruptura pode ser dúctil ou explosiva; e a flecha e a fissuração podem provocar problemas de utilização sob tensões elevadas.

\subsection{CISALHAMENTO EM VIGAS}

Observando o cisalhamento nas vigas e comparando valores experimentais com os de cálculo, por meio do CEB-90 (1991), NBR 6118 (1978) e EC-2 (1989), vêse que os valores encontrados para força cortante resistente da seção de cada viga são, geralmente, inferiores aos valores últimos encontrados experimentalmente, ou 
seja, as normas analisadas subestimam a capacidade resistente da seção ao cisalhamento, sendo muito a favor da segurança.

Os valores experimentais correspondem, em média, a 3,9 vezes o valor calculado usando o CEB-90 (1991), 2,3 vezes utilizando a NBR 6118 (1978) e 1,4 vezes utilizando o $E C-2$ (1989).

Deve-se observar que todas as peças analisadas apresentam características distintas; portanto as conclusões, aqui mostradas, não são definitivas. As características que mais variaram entre as amostras foram: forma da seção transversal, dimensão, traço, resistência à compressão do concreto, tensão de escoamento das armaduras, tipo de cura, taxa de armadura longitudinal, taxa de armadura transversal.

Pode-se portanto concluir, no final deste trabalho, que o concreto de alta resistência constitui vasto campo para novas pesquisas experimentais. 


\section{REFERÊNCIAS BIBLIOGRÁFICAS}

ABDEL-FATTAH, H.; AHMAD, S.H. (1989). Behavior of hoop-confined high strength concrete under axial e shear loads. ACI Structural Journal, v.86, n.6, p.652-659, Nov-Dec.

AGOSTINI, L.R.S. (1992). Pilares de concreto de alta resistência. São Paulo. Iv. Tese (doutorado) - Escola Politécnica da Universidade de São Paulo. (Exemplar de defesa).

AHMAD, S.H.; SHAH, S.P. (1982). Stress-strain curves of concrete confined by spiral reinforcement. ACI Journal, v.79, n.6, p.484-490, Nov-Dec.

AHMAD, S.H.; SHAH, S.P. (1987). High strength concrete: a review. In: SYMPOSIUM ON UTILIZATION OF HIGH STRENGTH CONCRETE, 1. Stavenger, Norway, June. Proc.

AMERICAN CONCRETE INSTITUTE. Committee 212. (1981). Admixtures for concrete. Concrete International: Design \& Construction, v.3, n.5, p.24-52, May.

AMERICAN CONCRETE INSTITUTE. Committee 318. (1989). Building code requirements of reinforced concrete. Detroit, $\mathrm{ACI}$. 
AMERICAN CONCRETE INSTITUTE. Committee 363. (1984). State-of-the-art report on high strength concrete. Detroit, ACI.

AMERICAN CONCRETE INSTITUTE. Committee 363. (1992). State-of-the-art report on high strength concrete. Detroit, ACI.

ASHOUR, S.A.; WAFA, F.F. (1993). Flexural behavior of high-strength concrete fiber reinforced concrete beams. ACI Structural Journal, v.90, n.3, p.273-287, May-June.

ASSOCIAÇÃO BRASILEIRA DE NORMAS TÉCNICAS. (1978). NBR 6118-Projeto $e$ execução de obras de concreto armado. Rio de Janeiro, 76 p.

ASSOCIAÇÃO BRASILEIRA DE NORMAS TÉCNICAS. (1989). NBR 7197-Projeto de estruturas de concreto protendido. Rio de Janeiro.

ASSOCIAÇÃO BRASILEIRA DE NORMAS TÉCNICAS. (1994). NB1/94 - Texto base para a revisão.

BERNHARDT, C.J.; FYNBOE, C.C. (1986). High strength concrete beams. Nordic Concrete Research. Oslo, n.5, p.19-26.

BERNHARDT, C.J.; FYNBOE, C.C.; JENSEN, A.P. Bjelker med langtidslast. Hфyfast betong, Delrapport 7. SINTEF report STF65 A 85062

BERNHARDT, C.J.; HOFF. Fors $\varnothing$ k med bjelder i høyfast betong 'HSC. Hфyfast betong, Delrapport 0. ', SINTEF report STF65 A 85021.

BJERKELI, L.; TOMASZEWICZ, A.; JENSEN, J.J. (1990). Deformation properties and ductility of high strength concrete. In: HESTER, W.T. High-strength concrete. Detroit, ACI, p.215-238. (SP-121). 
BLICK, R.L. (1973). Some factors influencing high-strength concrete. Modern Concrete, v.36, n.12, p.38-41, Apr.

BosCO, C.; CARPINTERI, A.; DEBERNARDI, P.G. (1990). Minimum reinforcement in high strength concrete. Journal of Structural Engineering, ASCE, v.116, n.2, p.427-437, Feb.

CARRASQUILLO, P.M.; CARRASQUILLO, R.L. (1988). Evaluation of the use of current concrete practice in the production of high-strength concrete. $\boldsymbol{A C I}$ Materials Journal, v.85, p.49-54.

CARRASQUILLO, R.L.; NILSON, A.H.; SLATE, F.O. (1982). Properties of high strength concrete subject to short-term loads. ACI Journal, v.79, n.2, p.162-163, Mar-Apr.

CARRASQUILLO, R.L.; SLATE, F.O.; NILSON, A.H. (1981). Microcraking and behavior of HSC subject to short-term loading. ACIJournal, v.78, n.3, p.171-178, May-June.

CEB-FIP Model Code 1990, Final draft. (1991). Bulletin d'Information, n.203, July.

CORDON, W.A.; GILLESPIE, H.A. (1963). Variables in concrete aggregates and portland cemente paste which influence the strength of concrete. ACI Journal, v.60, n.8, p.1029-1052, Aug.

CUSSON, D.; PAULTRE, P. (1994). High-strength concrete columns confined by retangular ties. Journal of Structural Engineering, ASCE, v.120, n.3, p.783-804, Mar.

DAL BUSCO, S. (1988). Déformabilité et capacité portante dos colonnes en béton armé. Thèse $\mathrm{N}^{\circ} 734$. Ecole Polytechinique Fédérale de Lausanne. 
EUROCODE No. 2. (1989). Design of concrete structures. Part 1: general rules and rules for buildings.

FAFITIS, A.; SHAH, S.P. (1985). Lateral reinforcement for high strength concrete columns. In: RUSSEL, H.G. High-strength concrete. Detroit, ACI, p.213-232. (SP-87).

FERNANDES, G.B. (1992). Cisalhamento de vigas de concreto de alta resistência. São Paulo. 2v. Tese (doutorado) - Escola Politécnica da Universidade de São Paulo. (Exemplar de defesa).

FERRARI, P. (1994). Armadura reduzida para cisalhamento em vigas de concreto de alta resistência. Campinas. 1v. Dissertação (mestrado) - Universidade Estadual de Campinas - UNICAMP. (Exemplar de defesa).

FIP/CEB Working Group on High Strength Concrete. (1990). High strength concrete: state of the art report. Bulletin d'Information, n.197, Aug.

FUSCO, P.B. (1984). Estruturas de concreto: solicitações tangenciais; problemas básicos de cisalhamento no concreto estrutural; problemas gerais de dimensionamento. São Paulo, Universidade de São Paulo.

FUSCO, P.B. (1986). Estruturas de concreto: solicitaçōes normais; estados limites últimos; teoria e aplicações. Rio de Janeiro, Guanabara Dois.

GAYNOR, R.D.; MEININGER, R.C. (1983). Evaluating concrete sands: five tests to estimate quality. Concrete International: Design \& Construction, v.5, n. 12, p.5360, Dec

HIGH strength concrete does have its problems. (1978). ACI Journal, v.75, n.8-9. 
HØISETH; HOFF; JENSEN. Søyler under sentrisk last. Hoyfast betong, Delrapport 2.. SINTEF report STF65 A 83049.

JENSEN, A.P. (1983). Beams and shell in high-strength concrete. Nordic Concrete Research, Oslo, n.2, p.114-124.

KAPLAN, M.F. (1959). Ultrasonic pulse velocity, dynamic modulus of elasticity, Poisson's ratio and strength of concrete made with thirteen different coarse aggregates. RILEM Bulletin, Paris, n.1, p.58-73, mar.

KERBER, J.A.; ROMAN, H.R. (1994). O encontro dos concretos. Concretos de alta resistência x Concretos de baixa resistência. Materiais diferentes? Revista do IBRACON, v.4, n.9, p.28-34, ago-set.

KONG, F.K. et al. (1983). Failure criteria for concrete. In: HANDBOOK of structural concrete. Pitman Books. Chapter 10.

LAMBOTTE, H.; TAERWE, L.R. (1990). Deflection and cracking of high-strength concrete beams and slabs. In: HESTER, W.T. High strength concrete. Detroit, ACI, p.109-128. (SP-121).

LEVI, F.; MARRO, P. (1989). Shear tests up to failure of beams made with normal and high strength concrete. In: COMITE EURO-INTERNATIONAL DU BETON. Design aspects of high strength concrete. Lausanne, p.13-23.

MACGREGOR, J.G. (1992). Reinforced concrete mechanics and design. Englewood Cliffs, NJ, Prentice Hall.

MACININIS, C.; THOMPSON, D.V. (1970). Special techniques for producing highstrength concrete. ACI Journal, v.67, p.996-1002. 
MARRO, P. (1987). Bending and shear tests up to failure of beams made with highstrength concrete. In: HOLAND, I. et al. Utilization of high-strength concrete. Trondheim, Tapir, p.183-193.

MARTINEZ, S.; NILSON, A.H.; SLATE, F.O. (1984). Spirally-reinforced highstrength concrete columns. ACI Journal, v.81, n.5, p.431-442, Sept-Oct.

MEHTA, P.K.; GJØRV, O.E. (1982). Properties of portland cement concrete containing fly-ash and condensed silica-fume. Cement and Concrete Research, v.12, n.5, p.587-595, Sept.

MONTOYA, P.J.; MESEGUER, A.G.; CABRE, F.M. (1981). Hormigon armado. Barcelona, Gustavo Gili. 2v.

MPHONDE, A.G.; FRANTZ, G.C. (1985). Shear test of high and low-strength concrete beams with stirrups. In: RUSSEL, H.G. High-strength concrete. Detroit, ACI, p.179-196. (SP-87).

NAM, C.H. et al. (1994). Microlevel study of integration in high-strength concrete innovation. Journal of Construction Engineering and Management, ASCE, v.117, n.2, p.294-309, June.

NILSON, A.H. (1985). Design implications of current research on high strength concrete. In: RUSSEL, H.G. High-strength concrete. Detroit, ACI, p.85-118. (SP87).

NILSON, A.H. (1987). High strength concrete - an overview - of Cornell research. In: SYMPOSIUM ON UTILIZATION OF HIGH-STRENGTH CONCRETE, 1. Stavenger, Norway, June. Proc, p.27-38. 
PERENCHIO, W.F.; KLIEGER, P. (1978). Some physical properties of high strength concrete. Research and Development Bulletin, Portland Cement Association. Skokie, $7 \mathrm{p}$.

PINTO JR., N.O. (1992). Flexão de vigas de concreto de alta resistência. São Paulo. 2v. Tese (doutorado) - Escola Politécnica da Universidade de São Paulo. (Exemplar de defesa).

POITEVIN. (1986). Structural lightweight concrete in France. FIP notes 1.

REINECK, K.H. (1989). Theoretical considerations and experimental evidence on web compression failures of high strength concrete beams. In: COMITE EUROINTERNATIONAL DU BETON. Design aspects of high strength concrete. Lausanne, p.61-73.

RÜSCH, H. (1960). Research toward a general flexural theory for structural concrete. ACI Journal, v.57, n.1, p.1-28, July.

RÜSCH, H. (1975). Hormigon armado y hormigon pretensado: propiedades de los materiales y procedimientos de cálculo. Barcelona, Compañia Editorial Continental. (Original alemán).

SAKAGUCHI, N. et al. (1990). Shear strength of high-strength concrete members. In: HESTER, W. T. High strength concrete. Detroit, ACI, p.155-178. (SP-121).

SCHIMIDT, W.; HOFFMAN, E.S. (1975). 9000 psi concrete - why? Why not? Civ. Engrg. ASCE, v.45, p.52-55.

SHAH, S.P.; AHMAD, S.H. (1994). High performance concrete: properties and applications. Great Britain. McGraw-Hill. 
SHEEHAN, T. (1991). High strength concrete: a review of U.S. expertise. Concrete, p.35-37, Nov-Dec.

SHEIKH, S.A.; SHAH, D.V.; KHOURY, S.S. (1994). Confinement of high strength concrete columns. ACI Structural Journal, v.91, n.1, p.100-111, Jan-Feb.

SHIDELER, J.J. (1957). Lightweight-aggregate concrete for structural use. $\boldsymbol{A C I}$ Journal, v.54, n.4, p.299-328, Oct.

SMADI, M.M.; SLATE, F.O; NILSON, A.H. (1985). High, medium and low strength concretes subjected to sustained loads - strains, strength and failure. $\boldsymbol{A C I}$ Journal, v.82, n.5, Sept-Oct.

SMITH, G.J.; RAD, F.N. (1989). Economic advantages of high-strength concretes in columns. Concrete International, p.37-43, Apr.

SWAMY, R.N. (1985). High-strength concrete: material properties and structural behavior. In: RUSSEL, H.G. High-strength concrete. Detroit, ACI, p.119-146. (SP-87).

SWARTZ, S.E. et al. (1985). Structural bending properties of higher strength concrete. In: RUSSEL, H.G. High-st-rength concrete. Detroit, ACI, p.147-178. (SP-87).

THORENFELDT, E.; DRANGSHOLT, G. (1990). Shear capacity of reinforced highstrength concrete beams. In: HESTER, W.T. High strength concrete. Detroit, ACI, p.129-154. (SP-121).

TOMASZEWICZ, A.; JENSEN, J.J. (1986). Høyfast betong, Delrapport 11. SINTEF, FCB - raport, dec. 
UNIVERSIDADE DE SÃO PAULO. Escola de Engenharia de São Carlos. Serviço de Biblioteca. (1993). Diretrizes para elaboração de dissertaçōes e teses na EESC - USP. São Carlos. 56p.

WILLS JR, M.H. (1967). How aggregate particle shape influences concrete mixing water requirement and strength. Journal of Materials, v.2, n.4, p.843-865, Dec.

WOLSIEFER, J. (1984). Ultra high-strength field placeable concrete with silica fume admixture. Concrete International, v.6, p.25-31. Apr.

YONG, Y.K.; NOUR, M.G.; NAWY, E.G. (1988). Behavior of laterally confined high-strength concrete under axial loads. Journal of Structural Engineering, ASCE, v.114, n. 2, p.332-351, Feb. 